\title{
1 Gene age shapes the transcriptional landscape of sexual 2 morphogenesis in mushroom forming fungi 3 (Agaricomycetes)
}

4 Zsolt Merényi ${ }^{1}$, Máté Virágh ${ }^{1}$, Emile Gluck-Thaler ${ }^{2}$, Jason C. Slot ${ }^{3}$, Brigitta Kiss ${ }^{1}$, Torda

5 Varga ${ }^{1}$, András Geösel ${ }^{4}$, Botond Hegedüs ${ }^{1}$, Balázs Bálint ${ }^{1}$, László G. Nagy ${ }^{1,5, *}$

$6{ }^{1}$ Synthetic and Systems Biology Unit, Biological Research Center, Szeged, 6726, Hungary

$7 \quad{ }^{2}$ Department of Biology, University of Pennsylvania, 433 S University Ave, Philadelphia, PA

8 19104-4544, USA

$9{ }^{3}$ College of Food, Agricultural, and Environmental Sciences, Department of Plant 10 Pathology, The Ohio State University, Columbus, USA

${ }^{4}$ Institute of Horticultural Science, Department of Vegetable and Mushroom Growing, Hungarian University of Agriculture and Life Sciences, Budapest, 1118, Hungary

${ }^{5}$ Department of Plant Anatomy, Institute of Biology, Eötvös Loránd University, Budapest, 1117, Hungary

*Author for correspondence: lnagy@fungenomelab.com

Key words: developmental hourglass, oyster mushroom, allelic imbalance, mushroom development, Agaricomycetes, Cryptococcus neoformans

\section{Abstract}

Multicellularity has been one of the most important innovations in the history of life. The role of gene regulatory changes in driving transitions to multicellularity is being increasingly recognized; however, factors influencing gene expression patterns are poorly known in many clades. Here we compared the developmental transcriptomes of complex multicellular fruiting bodies of eight Agaricomycetes and Cryptococcus neoformans, a closely related human pathogen with a simple morphology. In-depth analysis in Pleurotus ostreatus revealed that allele-specific expression, natural antisense transcripts and developmental gene expression, but not RNA editing or a "developmental hourglass" act in concert to shape its transcriptome during fruiting body development. We found that transcriptional patterns of genes strongly depend on their evolutionary ages. Young genes showed more developmental and allele-specific expression variation, possibly because of weaker evolutionary constraint, suggestive of non-adaptive expression variance in fruiting bodies. These results prompted us to define a set of conserved genes specifically regulated only during complex morphogenesis by excluding young genes and accounting for deeply conserved ones shared with species showing simple sexual development. Analysis of the resulting gene set revealed evolutionary and functional associations with complex multicellularity, which allowed us to speculate they are involved in complex multicellular morphogenesis of mushroom fruiting bodies. 


\section{Introduction}

37 The emergence of multicellularity has been one of the most influential transitions in evolution (Knoll, 2011; Smith and Szathmary, 1995). However, while simple multicellular aggregations evolved several times and evidence is accumulating that these transitions may not have had as many genetic obstacles as originally thought (Abedin and King, 2008; Kiss et al., 2019; Nagy et al., 2018; Sebé-Pedrós et al., 2017), origins of complex multicellularity (CM) seem to be rare evolutionary events. Simple multicellularity refers to cell aggregations, colonies or filaments, whereas CM comprises 3-dimensional organisms in which not all cells are in direct contact with the environment. CM probably required the evolution of mechanisms for transport, cell adhesion and complex developmental programs (Knoll, 2011). Diverse studies suggest that besides changes in gene content or protein sequence, the evolution of gene expression and genome regulation are also important in the transition to CM (King et al., 2003; Merényi et al., 2020; Sebé-Pedrós et al., 2018).

Uniquely across life on Earth, fungi show evidence for multiple evolutionary origins of CM (Nagy, 2018; Nguyen et al., 2017). Complex multicellularity in fungi, as defined by Knoll (2011) refers to fruiting bodies and some other 3-dimensional structures (e.g. sclerotia, ectomycorrhizae, see Nagy et al., 2018). CM in fungi is restricted to certain stages of the life cycle and starts by the transition from simple hyphal growth to 3-dimensional organization e.g. during the development of sexual fruiting bodies. This allows real-time transcriptomic readouts of changes associated with transitions in complexity level, which make fungi an ideal model system to investigate CM. Fungi reach the highest level of multicellular complexity in fruiting bodies of Agaricomycetes (Kües \& Navarro-González, 2015; Nagy, 2018), which includes most industrially cultivated edible and medicinal mushrooms. CM fruiting bodies in the Agaricomycetes have been widely studied by transcriptomic approaches, however, the interpretation of transcriptomes has been complicated by the lack of an understanding of the general principles of transcriptome evolution. This has, among other factors, impeded the definition of core CM- and development-related genes and pathways and thus reaching a general synthesis on the genetics of CM in the Agaricomycetes. Recent studies of fruiting body development reported species-specific and conserved genes (Krizsán et al., 2019; Nguyen et al., 2017), natural antisense transcripts (Muraguchi et al., 2015; Ohm et al., 2010; Shao et al., 2017), allele specific expression (Gehrmann et al., 2018), RNAediting (Zhu et al., 2014), small RNA (Lau et al., 2018), alternative splicing (Krizsán et al., 2019), chromatin remodelling (Vonk and Ohm, 2021) as well as developmental hourglass (Cheng et al., 2015), however, how widespread these are during and how significant their contributions to fruiting body development are not known.

Similarly, several genes and cellular processes have been identified in agaricomycete fruiting bodies. Fruiting bodies are composite structures in which structural cell types enclose reproductive ones (basidia, meiospores) into a protective environment. Basidium and spore development are evolutionarily significantly older than CM fruiting bodies (Viragh et al, 2021). The genes underlying basidium and spore development show up in developmental transcriptomes, and, if not properly accounted for, can blur signals for real CM-related genes. Accordingly, while some hitherto identified genes can be linked to CM functions (e.g. defense of fruiting bodies, see Künzler, 2018), most fruiting body-expressed genes, including those related to cell wall remodeling (Liu et al., 2021), transcriptional regulation, selective 
protein degradation (Krizsán et al., 2019) or complex secretomes (Almási et al., 2019) could relate either to $\mathrm{CM}$ or more general functions.

One of the main goals of this study was to systematically tease apart the components and driving forces of transcriptome evolution in a CM fungus. To this end, we examined natural antisense transcripts, allele-specific expression, and RNA-editing in a well-resolved developmental transcriptome of Pleurotus ostreatus (oyster mushroom). We found that developmental and allele-specific expression of a gene strongly correlate with the gene's evolutionary age. Building on this observation, the second aim of this study was to identify conserved gene families whose expression patterns associate with CM in the Agaricomycetes. For this, we compared the transcriptomes of eight CM fungi and that of a species with simple sexual development (Cryptococcus neoformans). The gene-age related stratification of developmental transcriptomes was prevalent across all examined species, however, these were not compatible with developmental hourglass concept as postulated for animals. Nevertheless, the evolutionary conservation of gene expression allowed the separation of genes related to general sexual processes from ones restricted to $\mathrm{CM}$ species, providing functional hypotheses for genes potentially linked to sculpting CM fruiting bodies. These data will help to understand both complex multicellular and simple sexual morphogenesis in Basidiomycete fungi.

\section{Results and Discussion}

\section{Overview of new RNA-Seq data}

We present highly resolved developmental transcriptome data for Pleurotus ostreatus (oyster mushroom), one of the three most widely cultured species worldwide (Zhu et al., 2019), as well as for Pterula gracilis, a closely related species with a simple fruiting body morphology (Figure 1). In P. ostreatus we sampled six developmental stages and up to four tissue types within a stage, whereas in Pt. gracilis, tissues could not be separated, therefore we sampled four developmental stages (Figure 1-figure supplement 1 and 2). Strand-specific RNA-Seq yielded 15.9-34.0 million reads per sample (Dryad: Table D1). Multidimensional scaling of the normalized transcriptome data accurately identified sample groups with biological replicates being tightly positioned together (Figure 1-figure supplement 3 ). Fruiting body samples grouped in two main groups, the early (primordia and young fruiting bodies) and mature fruiting bodies, irrespective of the tissue types. For uniformity in downstream analyses, we reanalysed data from former studies (Almási et al., 2019; Gehrmann et al., 2018; Ke et al., 2020; Krizsán et al., 2019; Liu et al., 2018; Sipos et al., 2017), yielding data for eight species in the order Agaricales (Figure 1), which comprises a single origin of complex fruiting body morphologies (Marisol et al., 2020; Varga et al., 2019). P. ostreatus and Pt. gracilis had 4,294 and 474 developmentally expressed genes ( $\geq 4 \mathrm{FC})$, respectively. Pleurotus has a similar number of developmentally expressed genes to those reported earlier for other mushroom-forming fungi, while Pt. gracilis has fewer, possibly due to its simple morphology (Almási et al., 2019; Krizsán et al., 2019; Sipos et al., 2017) (Figure 1-figure supplement 4). To validate the relevance of developmentally expressed genes, we collected experimentally validated, fruiting related genes from $P$. ostreatus and the model species Coprinopsis cinerea. For these genes, $92.3 \%$ of the P. ostreatus orthologs showed developmental expression (at 
fold change $>2$ ) in our dataset (Supplementary File 1), indicating that our approach captures CM-related genes with high sensitivity.

\section{Developmentally expressed genes, natural antisense transcripts and gene age distribution}

Developmentally expressed genes displayed limited physical clustering in the genomes (Appendix 1, Dryad: Table D2), which is different from some key genes involved in animal and plant pattern formation (Meyerowitz, 2002). Notably, some of the developmental gene 'hotspots' overlapped with putative natural product biosynthetic gene clusters, a wellknown group of clustered genes in fungal genomes (Keller 2018).

In addition to protein coding genes, strand-specific RNA-Seq data allowed us to annotate natural antisense transcripts (NATs) in the transcriptomes of $P$. ostreatus and $P t$. gracilis (Appendix 2). NATs were abundant in both species (2,043 and 763 in $P$. ostreatus and $P t$. gracilis, respectively), consistent with a previous report (Ohm et al., 2010) and showed dynamic developmental expression. However, they showed very little conservation across species, which potentially stems from fast evolution and/or recent origins. It has been proposed that NATs can arise from random promoters as transcriptional noise (Lloréns-Rico et al, 2016), a possibility that may be true for several or most, but probably not for all NATs in P. ostreatus and Pt. gracilis. The cryptic nature of NATs hardly allows functional inferences to be made (e.g. based on correlated expression with sense genes, see Appendix 2), yet their recent origins and expression patterns suggest they may be a source of developmental innovation at small time scales (Appendix 2).

To understand the composition of developmental transcriptomes, we sorted all protein coding genes (including developmentally expressed ones) using a phylostratigraphic approach, in which gene ages are assigned based on the set of species that possess clear orthologs (see Methods). We found that developmental transcriptomes showed a clear gene age patterns: they are dominated by old and young genes in all species, creating ' $U$ ' shaped distributions (Figure 2). This shape simply mirrors the genome-wide gene age distribution, indicating that the genomes of the examined species are dominated by conserved and young genes. If we statistically corrected for these U-shaped gene age distributions, we found that genes displayed an enrichment of developmental expression (at fold change $>4$ ) among young genes in most species (Fisher's exact test, FDR corrected $\mathrm{P}<0.05$, Figure 2), indicating that young genes have a disproportionately high share among developmentally expressed ones in fruiting bodies. This could be either because these young genes are needed for sculpting fruiting body morphologies, or because in young genes neutrally arising expression variation (i.e. transcriptional noise) is better tolerated than in conserved ones and leads to patterns we recognize as developmental expression. 


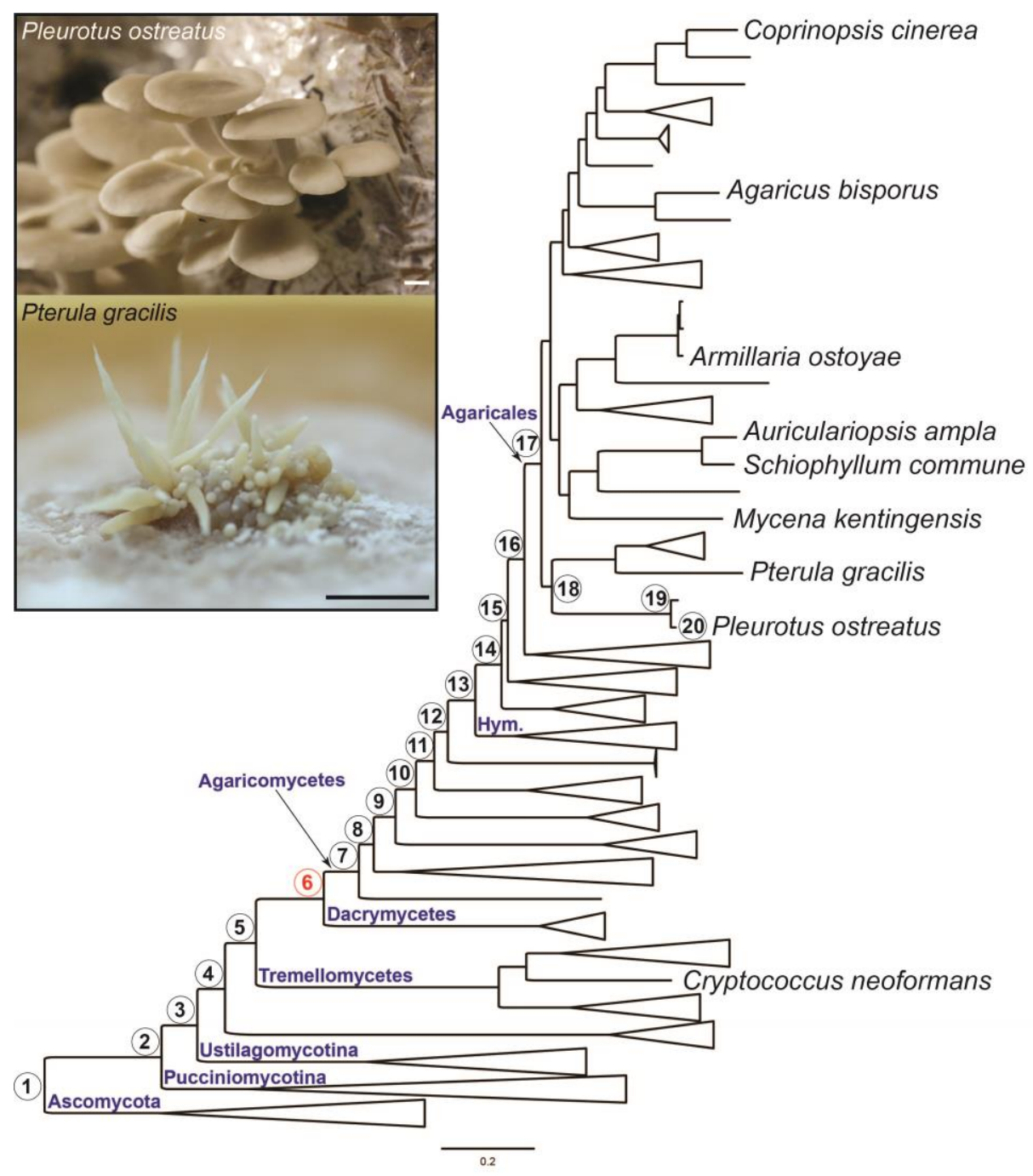

159 Figure 1 Pylostratigraphic gene ages and phylogenetic relationships among nine species

160 analysed in this study. Numbers in circles next to nodes represent gene ages used in phylostratigraphic analyses of $P$. ostreatus. Nodes are numbered from 1-20 from the root of the tree to the tip harbouring $P$. ostreatus. The first emergence of complex multicellularity in this lineage is shown with red, according to Merényi et al (2020). The scale bar represents 0.2 expected change per site. Fruiting bodies of Pleurotus ostreatus (upper) and Pterula gracilis (lower) are shown in the box. Abbreviations as follows: 'Hym' Hymenochetales 

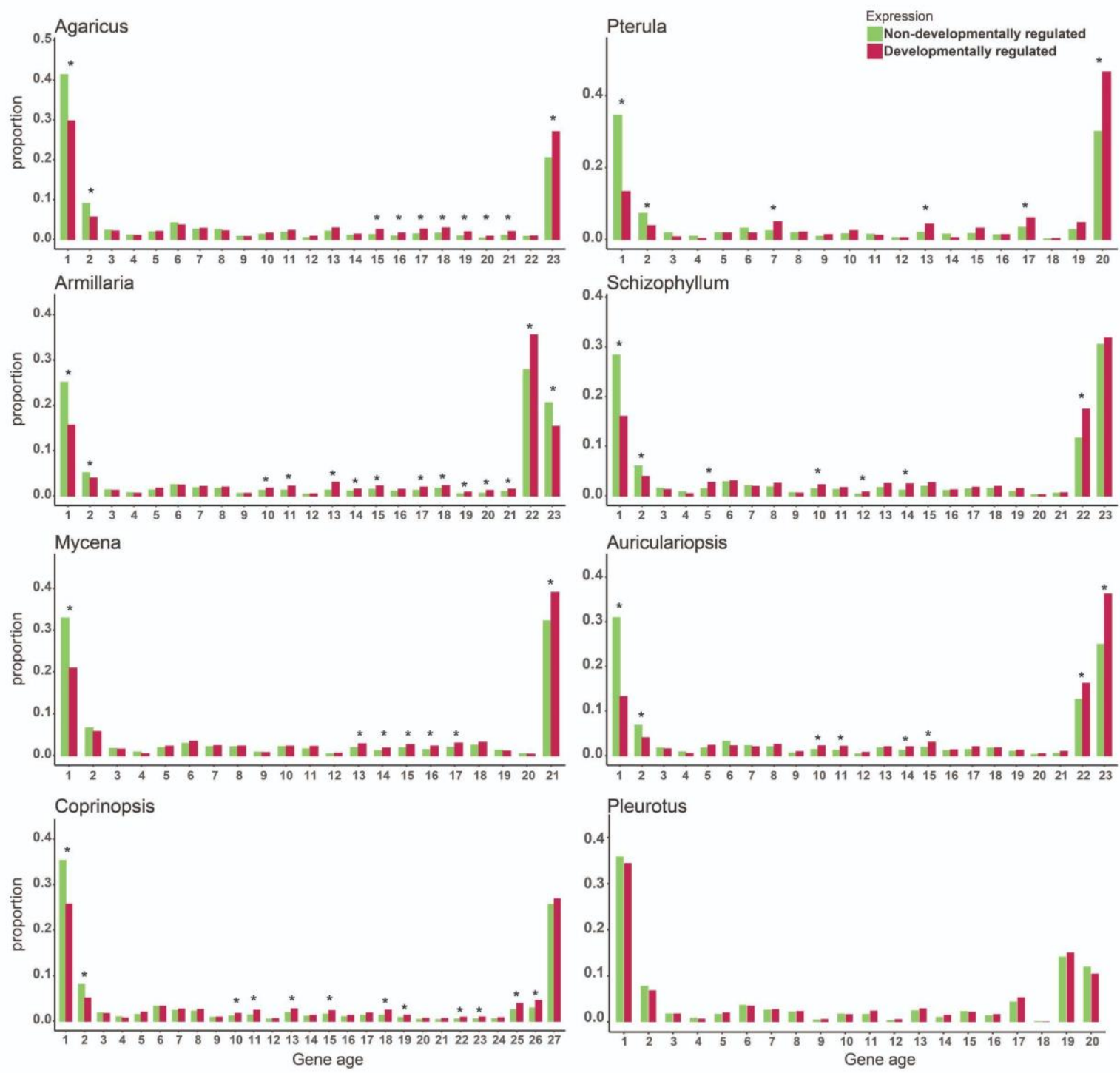

Figure 2 Proportion of Developmentally expressed (DR > 4 FC) genes in different gene ages. Asterisk $(*)$ represents significant differences p-value $<0.05$ (Fisher's exact test with BenjaminiHochberg correction). Gene age was calculated based on orthogroup membership (the presence of clear orthologs across species). For each species, nodes along the node path were numbered in ascending order on the species tree from root to tip starting with the value 1. (See Figure 1 for an example); node numbers were then used as the gene age values.

\section{Developmental hourglass}

To examine how young genes contribute to the CM transcriptome, we calculated transcriptome age indices (TAI) for each developmental stage in each species. TAI calculations weigh phylostratigraphic patterns by expression level, thus provide a weighted view of the contribution of young and old genes to the transcriptome. This way, TAIs link gene ages to the developmental hourglass concept, which has been proposed to explain the incorporation of genetic novelty into the developmental programs of CM eukaryotes (Domazet-Lošo and Tautz, 2010; Drost et al., 2017), including fungi (Cheng et al., 2015). The hourglass concept posits that evolutionarily older genes are expressed at middevelopment (Domazet-Lošo and Tautz, 2010) while the alternative 'early conservation' model implies that old genes are expressed early in development (Piasecka et al., 2013). 
Fungi do not display developmental transitions (e.g. phylotypic stage, mid-developmental transition) similar to those of metazoans, but they have a complex developmental program, and it has been proposed that the hourglass phenomenon would arise in any species with a sufficiently complex development (Domazet-Lošo et al., 2017). In fungi, the emergence of fruiting body primordia on vegetative mycelia comprises the largest developmental transition; dimensions change from fractal-like in mycelia to 3D in fruiting bodies, which necessitates turning on several traits for complex multicellularity (Nagy et al., 2018). Accordingly, the largest transcriptomic reprogramming (e.g. in terms of differentially or developmentally expressed genes) was reported for this transition (Krizsan et al., 2019, Sipos et al., 2017, Muraguchi et al 2015).

To test if a developmental hourglass can be found in fungi, we analysed the transcriptomes of the nine species based on TAIs (see Methods). For the examined species, we did not obtain uniform signal for either the hourglass or the early-conservation model (Figure 3). In other words, based on the TAI profiles, it appears that young genes (which drive TAI to higher values) do not have a uniform contribution to fruiting body transcriptomes across the examined species. In A. ampla, $C$. neoformans and S. commune TAI values were lowest early in development, compatible with the early conservation model, whereas in A. ostoyae, A. bisporus, C. cinerea, M. kentingensis and Pt. gracilis the opposite pattern (TAIs highest in early development) was observed. Typical hourglass-like patterns were seen only in $P$. ostreatus, which seems to be an exception among the examined species (Figure 3).

Overall, we interpret these results as evidence for neither the hourglass nor the early conservation models being applicable to mushroom development. Complex multicellular fruiting bodies of fungi, to our best knowledge, do not undergo the key developmental transitions (e.g. phylotypic stage, mid-developmental transition) like animal embryos do (Viragh et al., 2021). Rather, they follow unique developmental programs, that are discussed in the second half of the paper. 

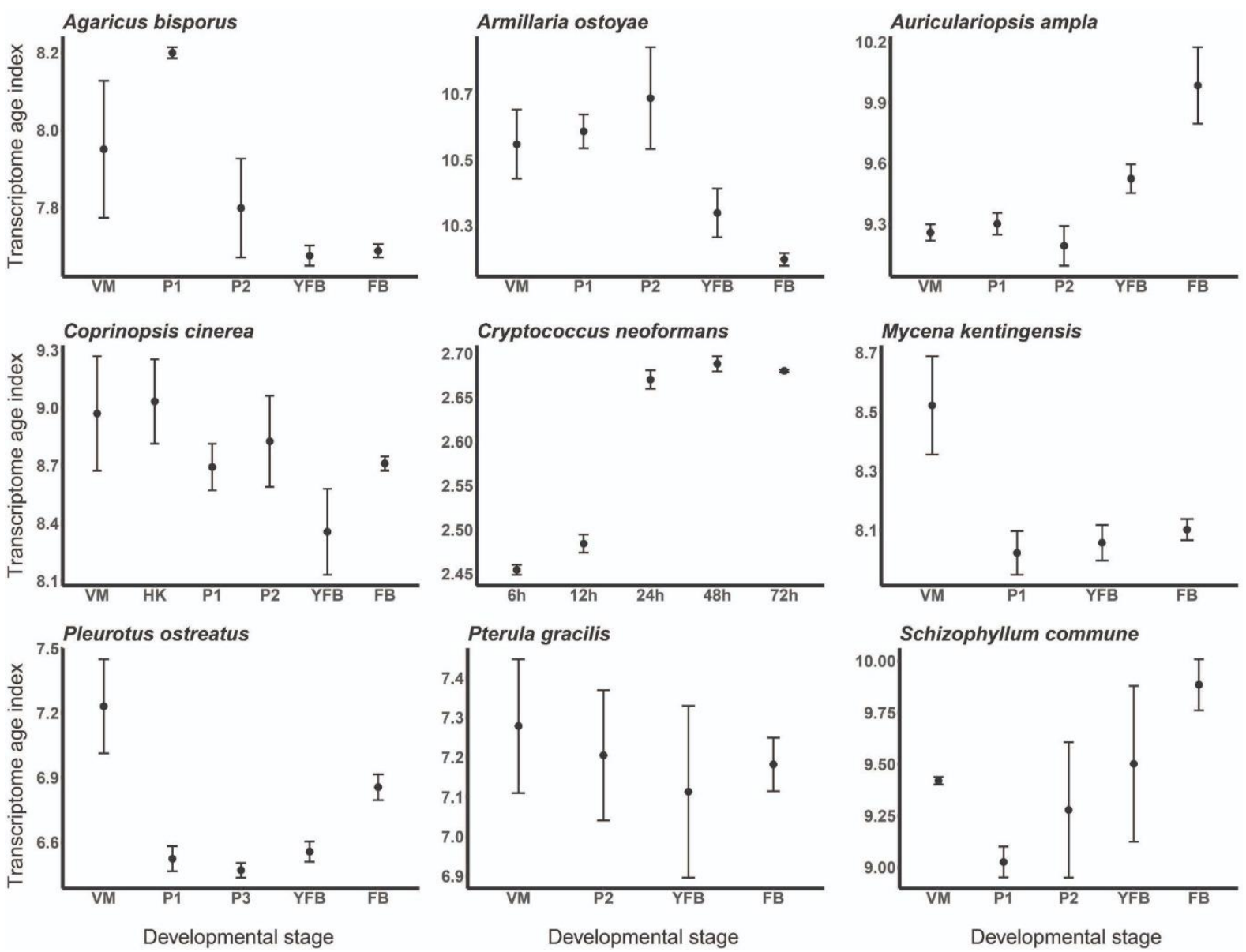

Figure 3 Transcriptome conservation in the nine species based on transcriptome age index (TAI). Abbreviations as follows: 'VM' vegetative mycelium; 'P1' stage 1 primordium; 'P3' stage3 primordium; 'YFB' young fruiting body, 'FB' fruiting body.

\section{Allele-specific expression but not RNA editing is abundant in fruiting bodies of $P$. ostreatus}

Allele specific expression (ASE) and RNA-editing are two processes that can shape the transcriptome by altering abundances and sequences of transcripts, respectively. Both have recently been reported in CM fungi (Gehrmann et al., 2018, Zhu et al., 2014), but how widespread they are and how they contribute to fruiting body development is poorly known. We chose $P$. ostreatus to analyse the contributions of ASE and RNA editing, because both parental genomes have been sequenced (Alfaro et al., 2016; Riley et al., 2014), and sufficiently differ from each other to classify single nucleotide variants either as ASE (variants differing from one parental genome) or RNA editing (variants differing from both parental genomes).

Overall, 2,244,348 variants served as input to the ASE analysis and were used to decide which haploid nucleus the reads originated from (Dryad: Table D3). We inferred that $31.2 \%$ and $32.2 \%$ of the reads derive from one (PC15) and the other (PC9) haploid parental nucleus, respectively, while $36.5 \%$ of reads were not assigned to either parental genome (Dryad: Table D3). This allowed us to characterize 10,419 PC15 genes (84.5\% of all genes and $96.8 \%$ of expressed genes) for ASE. Similar to gene expression, allele specific 
expression levels showed clear stage- and tissue-specific patterns (Figure 4-figure supplement 1).

At the scale of the entire genome or scaffolds, the two parental genomes expressed the 10,419 expressed genes were assigned as Equally Expressed genes (EE genes, hereafter) in all stages and tissue types and 2,626 genes $(25.2 \%)$ were biased towards the same nucleus in all biological replicates of at least one stage or tissue (referred to as ASE genes, Figure 4). Of these, 1,560 genes showed $2<\mathrm{FC}<4$-fold expression imbalance (hereafter referred to as S2 genes; $15 \%$ ) and 1,066 showed over four-fold difference (S4 genes; 10.2\%) between the two nuclei in at least one stage (averaged across replicates, Dryad: Table D4). In comparison, in A. bisporus ASE was reported for 411 genes ( $4 \%$ of the genome), perhaps due to fewer SNPs between parental nuclei (Gehrmann et al., 2018).

Enrichment analysis based on InterPro domains and GO terms of ASE genes highlighted a significant overrepresentation of 83 IPR and 45 GO terms, respectively (Supplementary File 2/a-d), several of which are associated with genes known to be involved in fruiting body formation (Krizsán et al., 2019), such as hydrophobins, glycoside hydrolase families, aquaporins and fungal type protein kinases (Supplementary File 2/a-d). For example, we detected ASE in hydrophobin genes (Figure 5/a) which are one of the most studied fruiting body-related gene families (Bayry et al., 2012). Both the fungal type cell wall GO term (GO:0009277) and the hydrophobin-related (IPR001338) terms were significantly overrepresented among genes with ASE. Of the 27 hydrophobins of $P$. ostreatus 21 showed developmental regulation (FC>2), of which 14 showed ASE (FC>2). Mycotoxin biosynthetic process (GO:0043386) was also enriched in both the GO and IPR analyses (Figure 5/b). Pleurotus has 16 genes in the UstYa-like mycotoxin biosynthesis protein family (probably involved in dikaritin production Vogt \& Künzler 2019), of which six were developmentally expressed (FC>4), and all of these showed ASE, while only one of the remaining ten genes showed ASE. These examples highlighted how allele specific expression can generate expression variance in developmentally expressed genes and thus potentially influence fruiting-related gene expression.

Adenosine-to-inosine (A-to-I) RNA editing is another source of single nucleotide variants in the transcriptome that was recently described in CM fungi (Zhu et al., 2014, Liu et al., 2017, Bian et al., 2019, Teichert, 2020). In contrast to ASE, however, our analyses did not yield considerable signal for A-to-I editing in P. ostreatus (Appendix 3, Dryad: Table D5). In fact, most candidate sites turned out to be likely sequencing errors or hallmarks of polyadenylation sites (See Appendix 3 for details), indicating that RNA editing is probably not associated with fruiting body development in this species. 

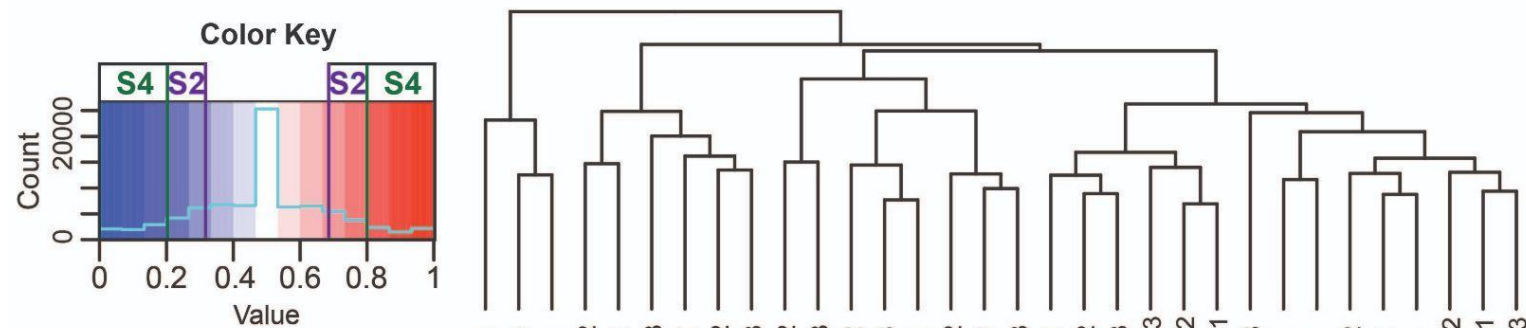

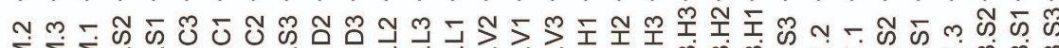

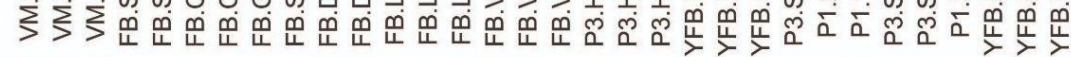
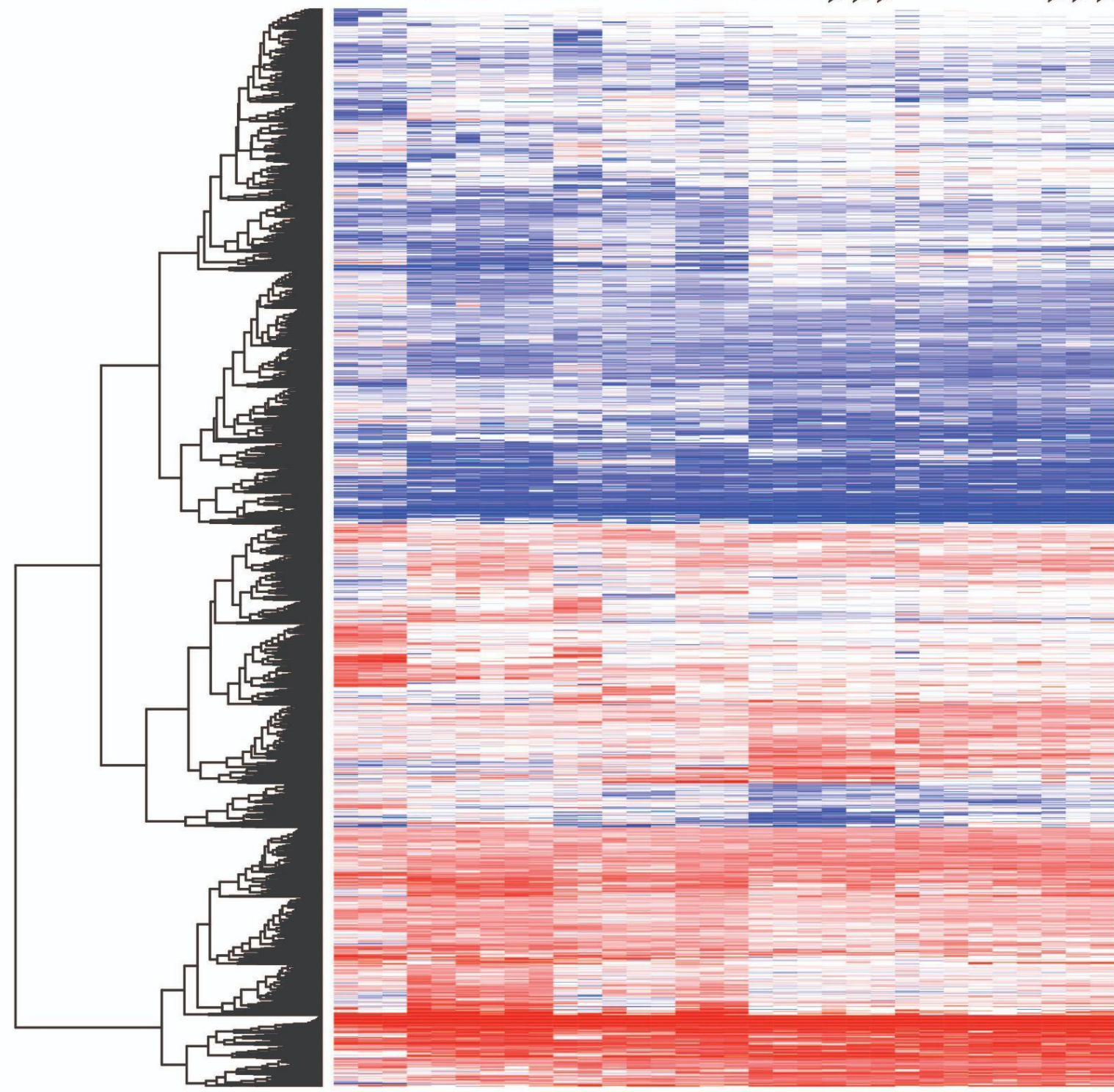

Figure 4 Contribution of two haploid nuclei of P.ostreatus to total gene expression. Expression of PC15 relative to the sum of PC15 and PC9 (AS ratio) was visualised in a heatmap for genes that showed at least two-fold ASE in at least one stage. Thresholds that we used to define S2 and S4 gene sets are marked in the colour key. Abbreviations are as follows: 'VM' vegetative mycelium; 'P1' stage 1 primordium; 'P3' stage3 primordium; 'YFB' young fruiting body, 'FB' fruiting body; ' $\mathrm{H}$ ' cap (entire); 'C' cap trama; 'L' lamellae; 'S' stipe; 'V' cuticle; 'D' dedifferentiated tissue of cap. 
a

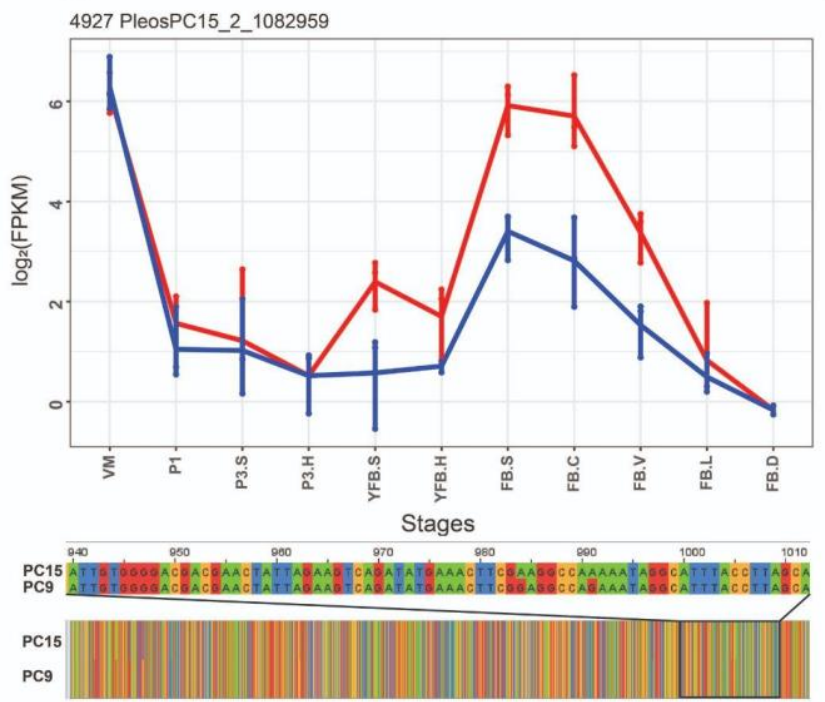

b

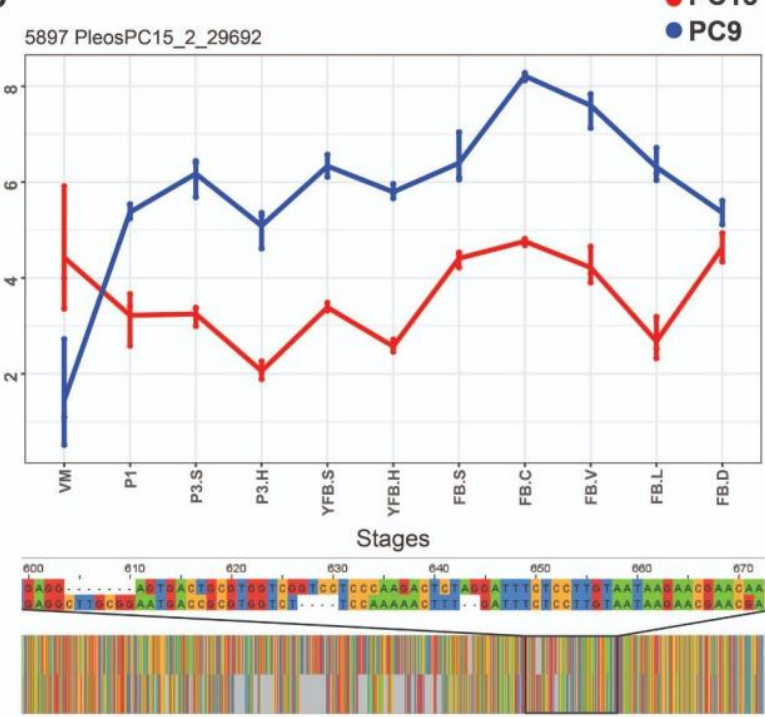

Figure 5 Examples for allele specific expression (ASE) during fruiting body formation of Pleurotus ostreatus. Expression level ( $\log _{2}$ transformed FPKM) from the two nuclei are coloured with blue (PC9) and red (PC15). P. ostreatus gene- and protein-IDs (PleosPC15_2) are displayed in each plot as a title. a) Hydrophobin, b) UstYa-like mycotoxin biosynthesis protein genes. Differences in the upstream gene regions are shown under the plots. Abbreviations are as follows: 'VM' vegetative mycelium; 'P1' stage 1 primordium; 'P3' stage3 primordium; 'YFB' young fruiting body, 'FB' fruiting body; 'H' cap (entire); 'C' cap trama; 'L' lamellae; 'S' stipe; 'V' cuticle; 'D' dedifferentiated tissue of cap.

\section{Allele-specific expression is enriched in young genes}

We next asked what mechanisms could give rise to ASE. Gehrmann et al. (2018) found that DNA methylation can explain at most $10 \%$ of ASE, which is consistent with the negligible role of gene body methylation in fungi (Montanini et al., 2014), suggesting other mechanisms. Following reports of divergent cis-regulatory alleles causing allelic gene expression imbalance (Gaur et al., 2013; Chen et al., 2016; Cowles et al., 2002; McManus et al., 2010; M. Wang et al., 2017), we hypothesised that ASE may arise from cis-regulatory divergence between nuclei of $P$. ostreatus. The dikaryotic stage of fungi, in which two haploid nuclei coexist in the same cellular compartment, represents a compatible environment for ASE to arise. Indeed, upstream $1 \mathrm{~kb}$ regions, that presumably contain cis-regulatory elements, of S2 and S4 genes are significantly more different (Kruskal-Wallis with Nemenyi post hoc test $P<2 \mathrm{e}^{-16}$ ) between the two parents than upstream regions of EE genes (Figure 6/a). This raises the possibility that divergent cis-regulatory elements in the same transregulatory cellular environment cause differential binding of transcription factors, resulting in biased transcript accumulation from the two nuclei. Amino acid sequences of S4 and S2 genes are also significantly more different between the two parents (Kruskal-Wallis test with Nemenyi post hoc test $P<2.2 \mathrm{e}^{-16}$ Figure 6-figure supplement 1/a) than those of EE genes. Together, these observations indicate that ASE in P. ostreatus may arise from the divergence of cis-regulatory alleles, possibly in fast-evolving genes. Analysis of selection strength based on $\mathrm{dN} / \mathrm{dS}$ ratios indicated higher $\mathrm{dN} / \mathrm{dS}$ and thus weaker selection among ASE than among EE genes (Kruskal-Wallis test with Nemenyi post hoc test $\mathrm{P}=2.0 \mathrm{e}^{-10}$ and $1.6 \mathrm{e}^{-5}$ Figure $6 / \mathrm{b}$, 
Figure 6-figure supplement $1 / \mathrm{b}$ ), suggesting that ASE is enriched in genes that are released from selection constraints.

A well-known group of genes under relaxed selection are evolutionarily young genes; i.e. those that duplicated or arose via de novo gene birth recently. Therefore, we tested whether ASE is correlated with relative gene age in our dataset. ASE genes were strongly and significantly overrepresented in the youngest gene ages (Fisher's exact test $\mathrm{P}=1.1 \mathrm{e}^{-12}-2.4 \mathrm{e}^{-}$ ${ }^{68}$ ), with a clear trend (Figure 7/a, Mann-Kendall test $\mathrm{P}=2.5 \mathrm{e}^{-6}$ ) of increasing ASE incidence towards young genes. At the same time, ASE is significantly underrepresented in the oldest age categories (gene age 1-4: $P=1.2 \mathrm{e}^{-2}$ to $7.8 \mathrm{e}^{-103}$, Fisher's exact test, Figure 7/a). These observations are consistent with young genes tolerating allelic expression imbalance better than conserved ones, possibly due to relaxed constraint (Dong et al., 2011; Gu et al., 2005; Kondrashov et al., 2002).

If genes under weak selection can tolerate expression variation, and developmental expression is considered an adaptively or neutrally arising expression variation, then ASE genes and developmentally expressed genes should overlap to some extent. Indeed, half of the ASE genes (S4: $52.7 \%$ and S2: 49.1\%) were also developmentally expressed (FC>4), significantly more than in EE genes $\left(31.8 \%\right.$, Fisher's Exact Test $\left.\mathrm{p}=8.2 \mathrm{e}^{-58}\right)$. We observed that as we move towards younger genes, the proportion of developmentally expressed ASE genes increases, as compared to non-ASE genes (Figure 7/b, Figure 7-figure supplement 1). The strongest overrepresentation of ASE genes can be observed among developmentally expressed genes that arose in the genus Pleurotus (gene age 19-20, $\mathrm{P}_{\mathrm{S} 4 / \mathrm{EE}}=3.0 \mathrm{e}^{-20}-9.52 \mathrm{e}^{-14}$, Fisher's Exact Test).

Taken together, the above observations allow us to speculate that ASE is, to a large extent, likely arising as a neutral phenomenon. Accordingly, we see two implications on the interpretation of fruiting body transcriptome data. First, it is possible that some of the developmental variation generated by ASE can prove adaptive at small evolutionary scales, which may manifest as between-strain differences within a species. Alternatively, ASE may be tolerated in genes with limited or species-specific functions, in which case it may have no or weak phenotypic impact on CM fruiting bodies. The overlap of ASE and developmentally expressed genes further suggest that developmentally expression in young genes can partially be neutrally arising expression variance as well. 
a

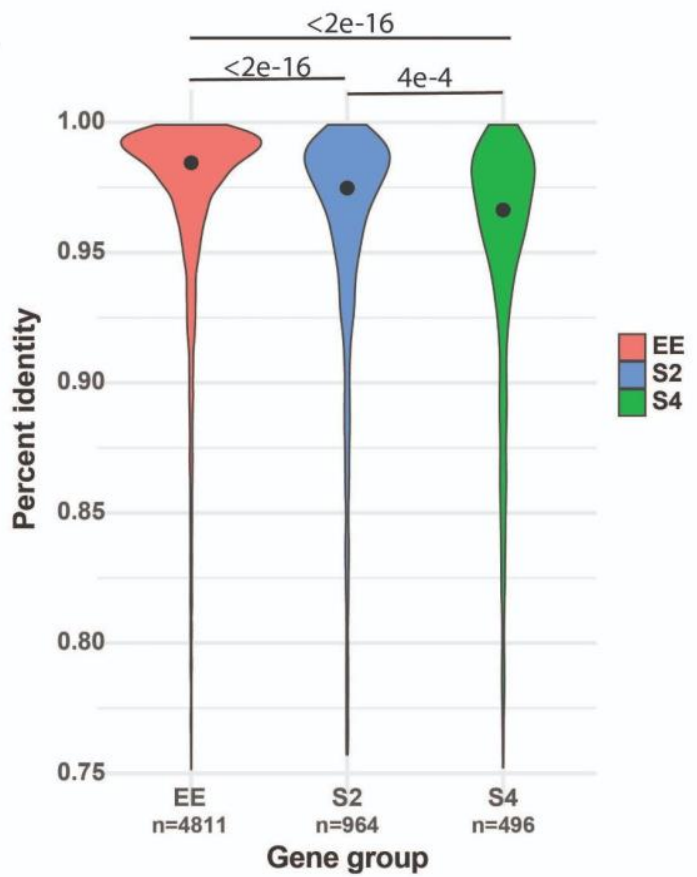

b

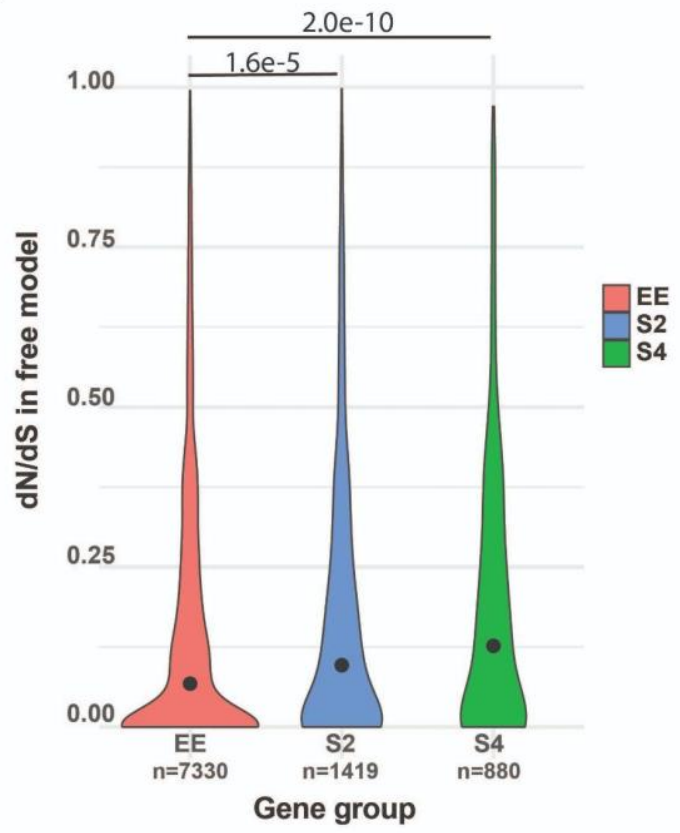

Figure 6 Allele-specific expression may arise from cis-regulatory divergence. a) percent sequence identity between the $1 \mathrm{~kb}$ upstream regions of PC15 and PC9 genes b) dN/dS distribution for ASE (S2 and S4) and equally expressed genes under the free model in CODEML. Abbreviations are as follows: 'EE' equally expressed; 'S2' Allele Specific Expression with 2 fold change; 'S4' Allele Specific Expression with 4 fold change.

a

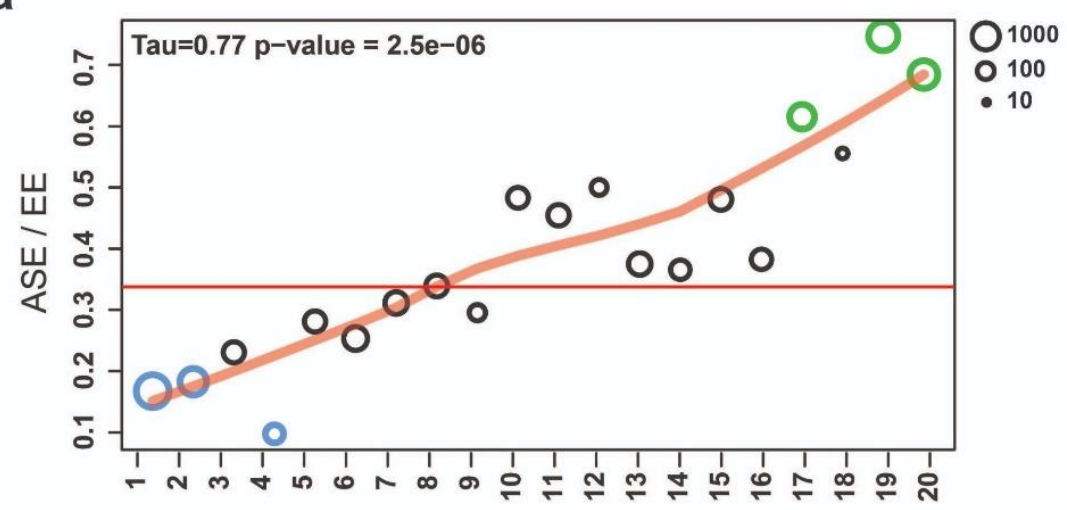

b

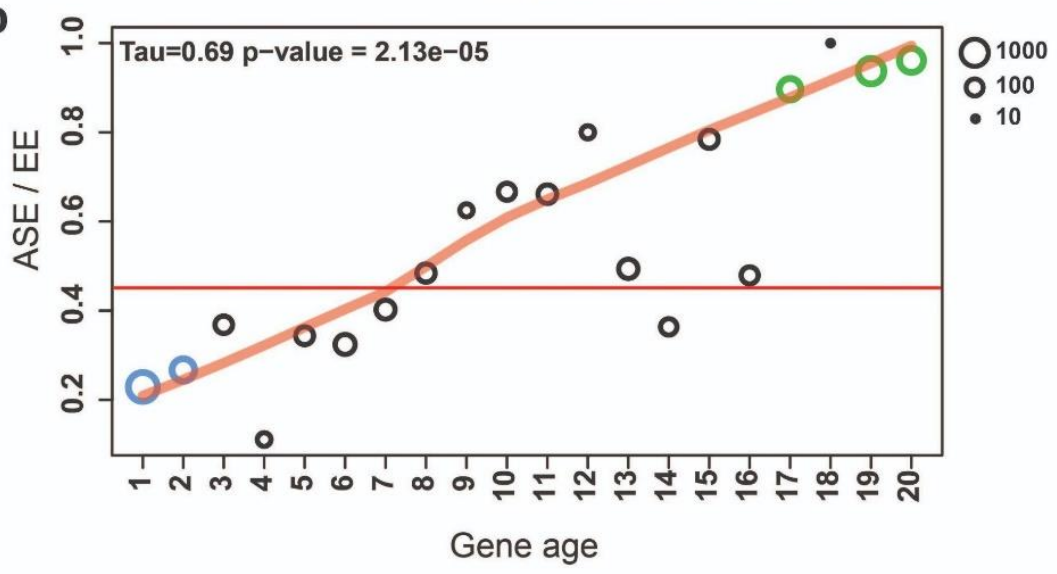


Figure 7 ASE genes are enriched among young genes. The proportion of ASE shows a significant tendency towards higher values (Mann-Kendall statistics) across gene ages, in the case of a) all genes b) developmentally expressed genes (FC $>4)$. Horizontal red line represents the ratio of all ASE/EE genes, while significant differences from the background (Fisher's exact test p-value $<0.001$ ) are shown with green (overrepresentation) and blue (underrepresentation). Size of circles represents the number of proteins ( $\log _{10}$ transformed). Abbreviations are as follows: 'EE' equally expressed; 'ASE' Allele Specific Expression with at least two-fold change.

\section{Comparative transcriptomics defines core developmentally expressed genes in the Basidiomycota}

We have above shown that the high number of young developmentally expressed genes could be either the result of neutral transcriptional variation and/or might be responsible for species specific functions. Therefore, we hereafter focus on conserved developmentally expressed genes to characterize core functions and gene families associated with the development of CM fruiting bodies.

Fruiting bodies encompass multiple processes, including sexual spore formation, defense and tissue differentiation, among others, but only some of these are relevant from the perspective of the origin of CM. To identify core fruiting-related genes which participate in the sculpting of fruiting bodies in Agaricomycetes in general, young and/or species-specific genes and genes with species-specific developmental expression need to be eliminated from the transcriptomes. To remove young genes, we first looked for sets of 1-to-1 orthologs across the examined species, hereafter called 'orthogroups' (1 gene per species), which show developmentally dynamic expression in most species (FC>2/4, see Methods). This yielded 1,781 orthogroups, considered hereafter as conserved developmental orthogroups.

To distinguish genes related to basic sexual processes (sporulation, meiosis) from those restricted to $\mathrm{CM}$ fruiting bodies, we reanalysed transcriptome data for sexual sporulation and basidium development of Cryptococcus neoformans (Liu et al., 2018). This species is closely related to the Agaricomycetes, has a simple, non-CM development so we used it here as a minimal model of sexual development (Figure 8/a). Of the 1,781 conserved orthogroups, 913 and 868 were developmentally expressed both in C. neoformans and CM species and only in CM species (Figure 8/b, Supplementary File 3/a-b-c), and are referred to as Shared and CM-specific orthogroups, respectively. Of the $868 \mathrm{CM}$-specific orthogroups, 754 were completely missing in $C$. neoformans whereas 114 were present but not developmentally expressed (Figure 8/b, Supplementary File 3/c). The 754 orthogroups might be missing from $C$. neoformans because they evolved later (in Agaricomycetes) or because they were lost during the reductive evolution of this species. Shared orthogroups included highly conserved gene functions, such as mitosis/meiosis, general transcription factors or ribosomal proteins, whereas CM-specific orthogroups contained more genes encoding sequence-specific transcription factors, cell wall remodelling, oxylipin biosynthesis, protein ubiquitination (F-box, BTB/POZ and RING zinc finger domain proteins) as well as functionally unclassified proteins (Figure 8/c Figure 8-figure supplement 1 Supplementary File 3/b).

Cell division-related (DNA replication, meiosis, mitosis, DNA repair, etc.) and ribosomal protein encoding genes comprised the most frequent annotations in shared orthogroups (Figure 8/d, Figure 8-figure supplement 1). Meiosis happens in basidia in both C. neoformans and fruiting body forming fungi and associated genes showed clear peaks in their expression (Figure 8 -figure supplement 2). C. neoformans showed a single peak in 
402

403

404

405

406

407

408

409

410

411

412

meiotic/mitotic gene expression, whereas CM fungi showed two peaks, one corresponding to meiosis in gills and another to intense cell division (mitosis) in primordia. Ribosomal protein gene expression, as a proxy for the activity of protein synthesis, has been widely associated with cell growth and proliferation (Jorgensen et al., 2002; Kraakman et al., 1993). Ribosomal proteins showed an early peak in all species, while in CM species a second peak was also observed, coincident with meiosis and spore production in gills, suggesting increased protein synthesis (Figure 8-figure supplement 3). We infer that in CM species the first ribosomal gene expression peak corresponds to an early, proliferative phase of development followed by the transition to growth by cell expansion (Krizsán et al., 2019), which gives the final shape and size of fruiting bodies before spore release.

a

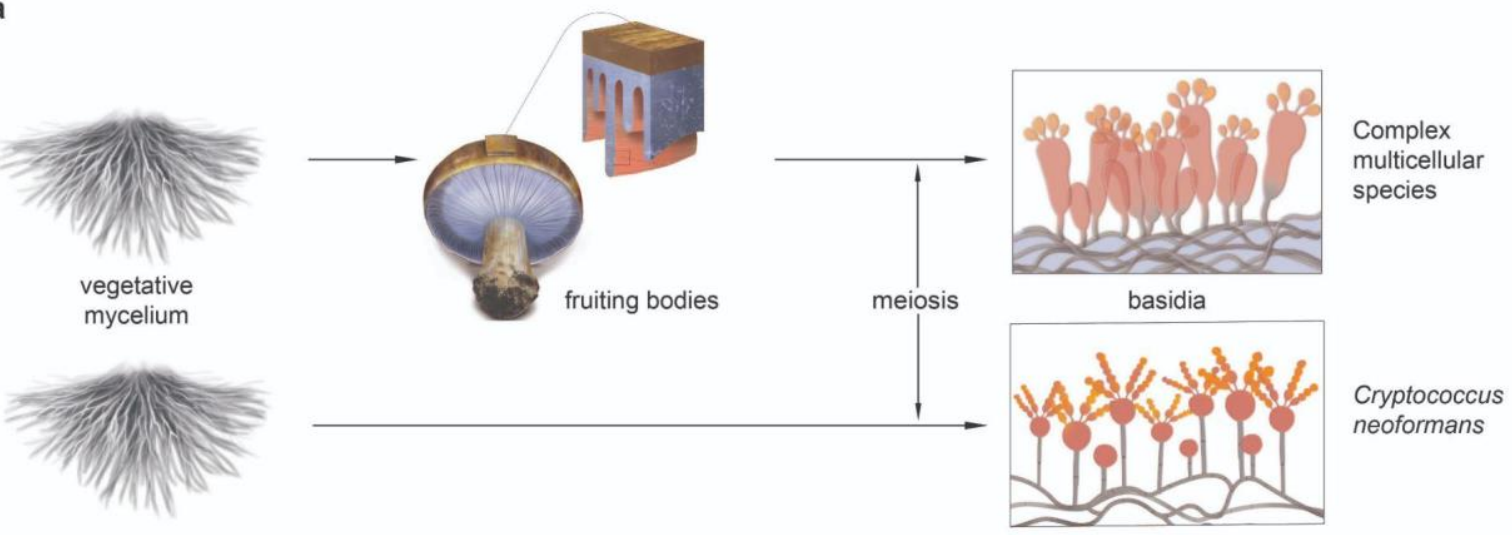

b
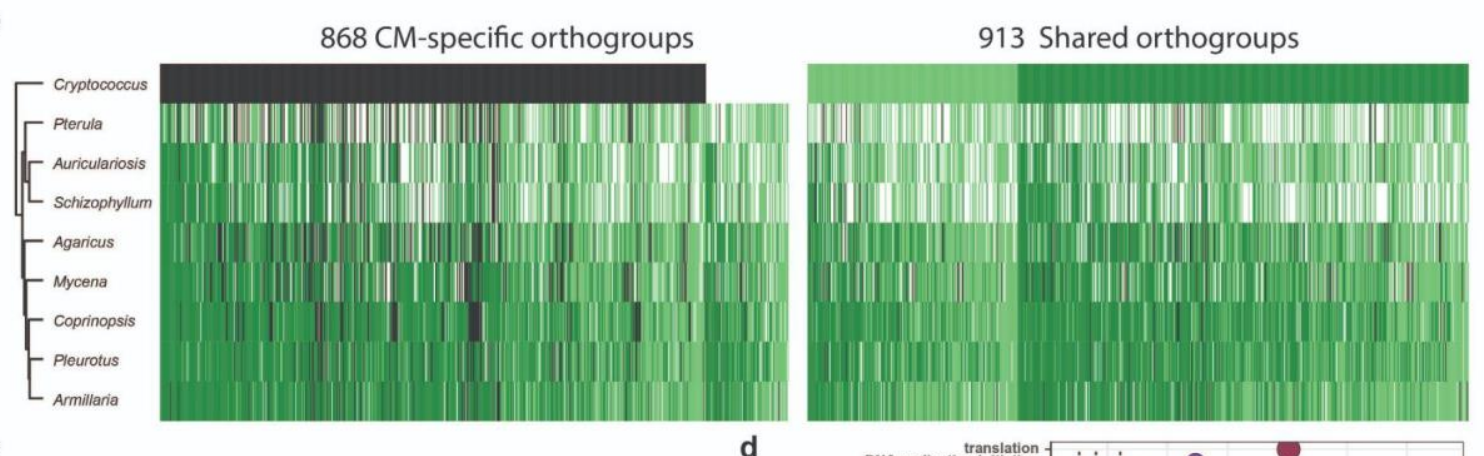

C
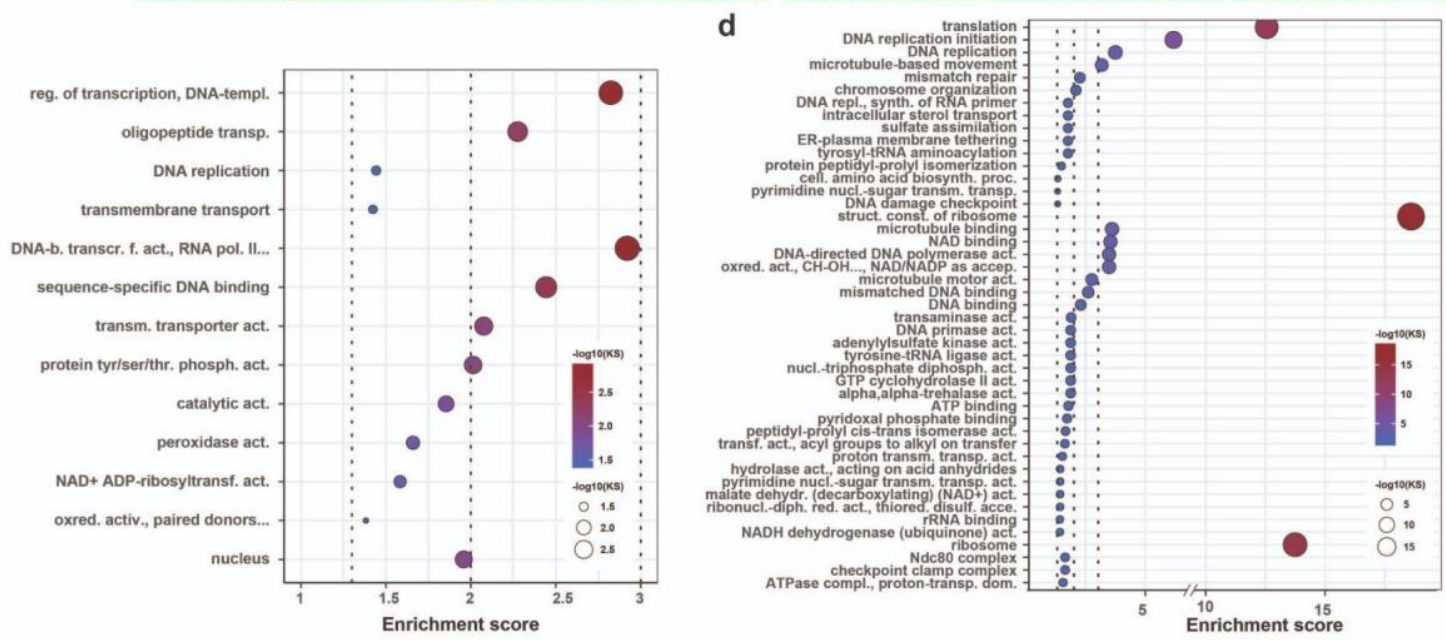

Figure 8 Conserved developmental expression in CM fungi. a) Schematic representation of 
across the nine species. Dark and light green refers to genes with developmental regulation at fold change $>4$ and 2, respectively, whereas white and black denote non-developmentally expressed and missing genes, respectively. Dendrogram was inferred in a hierarchical clustering based on expression categories. Gene Ontology (GO) enrichment for c) CM-specific and d) Shared orthogroups. KS means the p-value of Kolmogorov-Smirnov test implemented in the R package 'topGO'. On panels $\mathrm{c}$ and d, cutoff lines (dashed line) are drawn at enrichment scores corresponding to $p=0.05, p=0.01$ and $\mathrm{p}=0.001$ (from left to right). GO terms are ordered by Kolmogorov-Smirnov p-values. See also Supplementary File 5/a-b for GO enrichment details.

Several cell surface proteins (fasciclins, ricin-B lectins and the PriA family) and putative cell wall remodelling enzymes (e.g. chitin- and glucan- active glycoside hydrolases, expansins, CE4 chitooligosaccharide deacetylases, laccases) previously linked to fruiting body morphogenesis (Pezzella et al., 2013; Xie et al., 2018) were shared between $C$. neoformans and fruiting body forming species (Supplementary File 3/d), suggesting that these families are important for sexual morphogenesis in general, not restricted to fruiting bodies, as thought previously. Cell wall remodelling enzymes have been hypothesised to produce fruiting body-specific cell wall architectures (Buser et al., 2010; Krizsán et al., 2019; Liu et al., 2021; Ohga, 2000); the upregulation of these in C. neoformans suggests a role during non-CM sexual processes as well, possibly in generating aerial hypha- or basidiumspecific cell walls. Most genes related to glycogen metabolism also showed shared expression (Supplementary File 3/f). Glycogen has been known as a storage material in fruiting bodies, but our observations indicate that it may serve that role in $C$. neoformans too and possibly as an energy source for sexual development or as storage carbohydrate in spores, in general. Notable transcription factors in shared orthogroups included the light sensing white collar complex member WC-1, orthologs of $S$. cerevisiae sexual reproductionrelated Ste12, a Basidiomycota-specific velvet factor as well as orthologs of the carbon catabolite repressor CreA of A. nidulans.

In comparison to shared orthogroups, $\mathrm{CM}$-specific orthogroups contained more transcription factors, genes related to cell wall biosynthesis/modification and defense (Figure 8 - figure supplement 1, Supplementary File 3/d-e-g). 33 CM-specific orthogroups of transcription factors were detected, including those containing the hom 1 , fst 3 and fst 4 genes of $S$. commune, which were reported to influence the formation of fruiting bodies (Ohm et al 2011; Figure 8-figure supplement 1). Based on our 109-species dataset, these three genes evolved after $C$. neoformans (Tremellomycetes) split off from CM fungi: Fst4 and Hom1 emerged in the MRCA of Agaricales and Gomphales (node 11 in Figure 1) while Fst3 appeared in the MRCA of Agaricales and Auriculariales (node 10 in Figure 1). Hydrophobins and cerato-platanins, as well as fatty acid desaturases and linoleate-diol synthases were exclusively found in CM-specific orthogroups (Figure 8-figure supplement 1). Hydrophobins and cerato-platanins are cell surface proteins that confer hydrophobicity to hyphae and are completely missing from the genome of $C$. neoformans, probably as a consequence of the adaptation to a primarily yeast-like lifestyle (Nagy et al., 2014). Fatty acid desaturases and linoleate-diol synthases are putatively related to the biosynthesis of signaling-related oxylipins (Orban et al., 2021) and linoleic acid (a fruiting body-enriched membrane constituent (Sakai and Kajiwara, 2003; Song et al., 2018)), respectively. We also detected a large number of conserved unannotated genes (172 orthogroups) among CMspecific orthogroups. Unannotated genes include, for example, S. commune Spc14 and Spc33, 
which were shown to participate in septal pore cap formation in Agaricomycetes (van Peer et al., 2010), and Cc.ctg1 of $C$. cinerea, which was suggested to be required for stipe elongation (Nakazawa et al., 2008). These genes are conserved across Agaricomycetes, but do not contain any known conserved protein motifs. Functional speculations are hardly possible for the vast majority of unannotated orthogroups, yet their propensity among CM-specific genes underscores the still cryptic nature of CM development in fungi. The complete list of Shared and CM-specific orthogroups is given in Supplementary File 3/b-c, however, their comprehensive discussion is beyond the scope of the current paper.

CM-specific orthogroups showed a phylostratigraphic enrichment in early mushroomforming fungi (FDR $<0.01$, Fisher's exact test, Figure 9). We detected a preponderance of $\mathrm{CM}$-specific orthogroup origins from the most recent common ancestor of Dacrymycetes and Agaricomycetes (node 6 on Figure 1) to that of Hymenochaetales and Agaricales (node 13 on Figure 1). These may correspond to innovations related to CM fruiting bodies, which is consistent with the origins of jelly-like fruiting bodies in the Dacrymycetes+Agaricomycetes ancestor (Viragh et al., 2021). This observation complements our previous analysis (Krizsán et al., 2019) that could not resolve a clear signal of genetic innovation correlated with CM, possibly because of confounding effects of shared orthogroups.

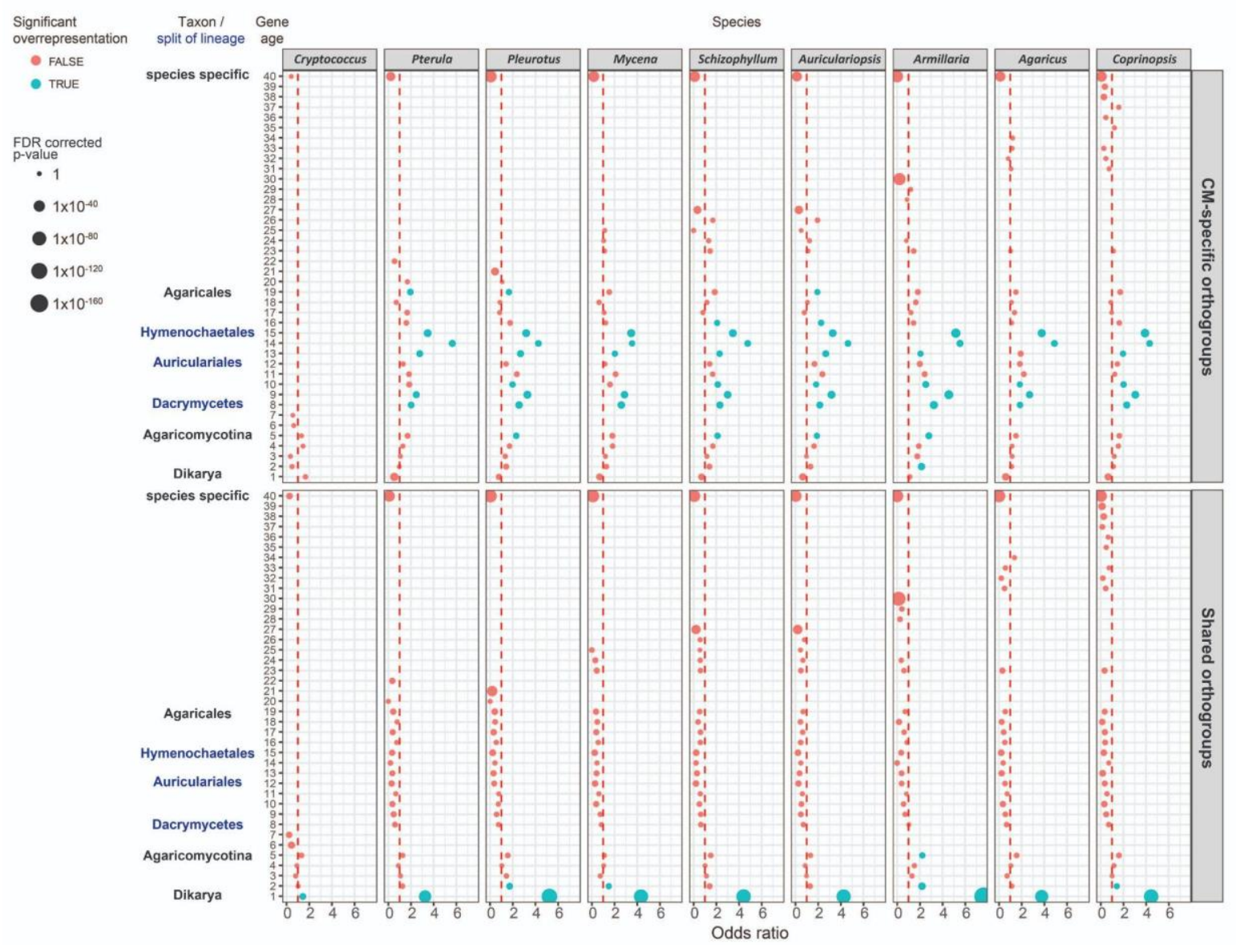
orthogroups. CM-specific orthogroups are significantly enriched in the most recent common ancestors of lineages in which the first complex structures emerged (see also Figure 1). Y-axis represents relative gene age (for definition of gene ages see Dryad: Figure D1). X-axis displays the 
odds ratio of the enrichment of developmentally expressed orthogroups relative to all orthogroups in a given age category based on Fisher's exact test. If the odds ratio exceeds 1 (red dotted line) developmentally expressed orthogroups are overrepresented in that gene age. Significant (FDR p< 0.05 ) overrepresentation is indicated by blue. The size of circles corresponds to the FDR corrected pvalue of Fisher's exact test.

\section{Conclusions}

In this study, we analyzed developmental transcriptomes of complex multicellular fungi in the Agaricomycetes, using a comparative dataset that included the first well-resolved developmental gene expression profiling data for Pleurotus ostreatus (oyster mushroom), the second most widely cultured mushroom species worldwide (Grimm and Wösten, 2018; Royse et al., 2017). We detected evidence for widespread developmental expression of genes, allele-specific expression imbalance between parental monokaryons, natural antisense transcripts, but not for RNA editing or the developmental hourglass. We found that the detected phenomena affect genes of various evolutionary ages and speeds to different extents. For example, developmental and allele-specific expression was most pronounced among evolutionarily young genes. On the other hand, natural antisense transcripts showed no conservation across species, suggesting that they evolve at a high rate. These observations allow us to speculate that the complex interplay of these processes in the transcriptome may provide multiple gears for transcriptome evolution that probably facilitates the incorporation of evolutionary innovations into fruiting body development of Agaricomycetes.

The availability of the genomes of both parental monokaryons (Alfaro et al., 2016; Riley et al., 2014) as well as new strand-specific RNA-Seq data allowed bioinformatic deconvolution of RNA editing, allele-specific expression and antisense transcription in the $P$. ostreatus transcriptome. We found virtually no evidence for RNA editing, whereas allele specific expression was abundant, which supports a previous report of ASE in CM fungi (Gehrmann et al., 2018). RNA editing has been recently reported in the Agaricomycetes (Zhu et al., 2014), however, in contrast to the Ascomycota (Lau et al., 2020; Liu et al., 2016; Teichert et al., 2017), it displayed no clear-cut enrichment of A-to-I compatible variants in three previous studies (Bian et al., 2019; Teichert, 2020; Zhu et al., 2014) or in this study. Rather, our final candidate RNA-editing sites merely alluded to potential polyA site- and/or read alignment inaccuracies leading us to conclude that RNA editing is not abundant in $P$. ostreatus.

On the other hand, ASE was detected in thousands of genes in P. ostreatus. In a previous study on A. bisporus, ASE was interpreted as a regulated and adaptive mechanism that could, for example, aid the division of labour between nuclei in a dikaryotic hyphal cell (Gehrmann et al., 2018). We found that in P. ostreatus ASE is characteristic of young genes and likely arises from promoter divergence, which creates a cellular environment with divergent cis-regulatory alleles but identical trans-regulatory elements. At the same time, young genes are known to be under weaker evolutionary constraint than conserved ones, raising the possibility that ASE might arise neutrally in the transcriptome. This would be consistent with the neutral model of expression evolution (Fay and Wittkopp, 2008) and nonadaptive explanations, such as leaky regulation or transcriptional noise (Cheng et al., 2017; Khan et al., 2012; Shih and Fay, 2021; Wainer-Katsir and Linial, 2019). Under this interpretation, ASE may be a tolerated, rather than an adaptive phenomenon in agaricomycete fungi. However, even if neutral at the level of the individual, ASE may generate useful gene 
expression variation that can serve as substrate for adaptive evolution (even for developmental functions), similar to how transcription from random promoters can facilitate de novo gene birth (Van Oss and Carvunis, 2019). Indeed, we detected ASE for several fastevolving development-related genes, such as hydrophobins or the putatively defense-related dikaritin-synthesis family. ASE may have important implications in mushroom breeding, where intraspecific hybrids (e.g. Gaitán-Hernández and Salmones, 2008) harbouring cisregulatory alleles with various levels of divergence may show differences in industrially relevant traits (Gehrmann et al., 2018).

As in the case of ASE, young genes might display more expression variance and noise across development, whereas genes with conserved developmental expression more likely provide clues about key CM functions. Fruiting bodies integrate several ancient processes, such as mitosis/meiosis and sporulation, which are conserved across all organisms and fungi, respectively, but distinct from $\mathrm{CM}$ morphogenesis. These considerations led us to design analyses, that remove both young and very ancient genes. These helped us distinguish conserved genes related to simple sexual development from those characteristic of only CM species. This may also help establishing a minimal model of sexual development (e.g. for pathogens like $C$. neoformans) in the Basidiomycota, that include several genes previously considered specifically expressed in fruiting bodies. Notable examples include fasciclins, which have been implicated in cell adhesion (Nagy et al., 2018), and the PriA family of secreted cell surface proteins (including $C$. neoformans cfl1 and dha1 Gyawali et al., 2017) with unknown function. On the other hand, this strategy yielded a focused set of 868 orthogroups that comprised genes developmentally expressed only in CM species not in $C$. neoformans. We speculate that these genes contain those related to CM morphogenesis, although this will need to be verified by functional studies in the future. Indeed, CM-specific orthogroups identified regulatory genes reported in mushrooms (e.g. hom1, fst 3 , fst 4 , wc1; Hou et al., 2020; Kamada et al., 2010; Ohm et al., 2011) but also novel ones, such as a velvet factor that is widely conserved in Agaricomycetes and showed stipe-specific expression in $\mathrm{CM}$ species. We anticipate that these orthogroups will comprise a valuable resource for functional studies of CM morphogenesis in fungi which, with continuous developments of genetic engineering methods, will make it possible to address the developmental roles of these genes at scale.

\section{Materials \& Methods}

\section{Key Resources Table}

\begin{tabular}{|l|l|l|l|l|}
\hline $\begin{array}{l}\text { Reagent type } \\
\text { (species) or } \\
\text { resource }\end{array}$ & Designation & $\begin{array}{l}\text { Source or } \\
\text { reference }\end{array}$ & Identifiers & $\begin{array}{l}\text { Additional } \\
\text { information }\end{array}$ \\
\hline $\begin{array}{l}\text { strain, strain } \\
\text { background } \\
\text { (Pleurotus } \\
\text { ostreatus) }\end{array}$ & N001 & CETC & CECT-20600 & $\begin{array}{l}\text { Wild-type } \\
\text { Dikaryotic } \\
\text { strain }\end{array}$ \\
\hline
\end{tabular}




\begin{tabular}{|l|l|l|l|l|}
\hline $\begin{array}{l}\text { strain, strain } \\
\text { background } \\
\text { (Pterula gracilis) }\end{array}$ & CBS 309.79 & CBS & CBS 309.79 & $\begin{array}{l}\text { Wild-type } \\
\text { Dikaryotic } \\
\text { strain }\end{array}$ \\
\hline
\end{tabular}

\section{Growth condition, sampling and RNA-Sequencing}

565 For fruiting the dikaryotic strain N001 (CECT-20600) of Pleurotus ostreatus (recently

566 interpreted as $P$. cf. floridanus J. Li et al., 2019) we first prepared spawn by inoculating 567 sterilized rye and incubating for 10 days. Pasteurized straw-based commercial oyster compost 568 (95 vol\%) and the colonized spawn (5 vol\%) were mixed gently and three kilograms were 569 filled into polyethylene bags. Bags were incubated in the dark at $27{ }^{\circ} \mathrm{C}$ and $85-90 \%$ relative 570 humidity for 17 days. Next, bags were transferred to the growing room for fruiting at 18-19 $571{ }^{\circ} \mathrm{C}$, relative humidity 80-85\% and 8/16h light/dark period (with approximately 1200 lux light 572 intensity). We sampled vegetative mycelium (VM), six developmental stages and five tissue 573 types, each in three biological replicates as explained in Figure 1-figure supplement 1. VM 574 was collected from the sawdust culture. We defined stage 1 primordia (P1) as the globose575 triangular hyphae-covered structures without clearly recognizable differentiation; stage 2(P2) 576 primordia were defined as the first time point when caps were recognizable as pointed tips.

577 Stage 3 primordia (P3) had a clearly differentiated and pigmented cap and an appearing 578 fracture below the cap. The young fruiting body (YFB) stage was defined as the time point 579 when the lamellae are clearly recognizable below the cap, and the diameter of the cap is less 580 than $2 \mathrm{~cm}$. Finally, in the mature fruiting body stage (FB) lamellae are fully developed, and 581 meiosis/sporulation have started, and the cap expands $(>5 \mathrm{~cm})$. In the case of stage 1 and 2 582 primordia (P1 and P2) the whole tissue was collected containing both stipe and cap initials. In 583 the stage 3 primordium (P3) and the young fruiting body (YFB) stages, stipes and caps were sampled separately. We divided mature fruiting bodies (FB) into stipe (S), cap trama (C), cap cuticle (V) and gills (L). We defined cap $(\mathrm{H})$ as the whole upper part of the fruiting body (in P3 and YFB) while cap trama (C) refers to just the inner part of cap without lamellae or cuticule (in FB) (see Figure 1-figure supplement 1). The last stage we sampled was the dedifferentiated cap trama (D), a dissection from inner cap tissue which was inoculated for $24 \mathrm{~h}$ on a sterile PDA-agar plate, until the emergence of new hyphae. Tissue from 3-8 individual fruiting bodies was pooled for each replicate of each sample type.

Pterula gracilis CBS 309.79 was inoculated onto Malt Extract Agar plates with cellophane, and incubated at $25^{\circ} \mathrm{C}$ for 25-27 days. For fruiting, plates were moved to a growth chamber at $15{ }^{\circ} \mathrm{C}$ under $10 / 14 \mathrm{~h}$ light/dark period (light intensity: $11 \mu \mathrm{E} \mathrm{m}^{-2} \mathrm{~s}^{-1}$ ). VM samples were scraped off the cellophane after three days. We defined primordia (P) as small $(<1 \mathrm{~mm})$ globose structures, young fruiting bodies as $\sim 5 \mathrm{~mm}$ long awl-shaped structures, while structures longer than $10 \mathrm{~mm}$ were considered mature fruiting bodies (Figure 1 - figure supplement 2).

Three biological replicates of each sample type were stored at $-80^{\circ} \mathrm{C}$ until RNA extraction. Tissue samples were homogenized with micropestles using liquid $\mathrm{N}_{2}$, and RNA was extracted by using the Quick-RNA Miniprep Kit (Zymo Research) according to the manufacturer's instructions. Strand-specific cDNA libraries were constructed from poly(A)- 
captured RNA, using the Illumina TruSeq Stranded RNA-Seq library preparation kit, and sequenced on the Illumina HiSeq 4000/x platform in PE 2x150 format with 40 million reads per sample at OmegaBioservices (USA).

\section{Bioinformatic analyses of RNA-Seq data}

New data for P. ostreatus and Pt. gracilis was reanalysed together with previously published transcriptomes of seven Basidiomycota species (Supplementary File 4). To remove adaptors, ambiguous nucleotides and any low quality read end parts, reads were trimmed using bbduk.sh and overlapping read pairs were merged with bbmerge.sh tools (part of BBMap/BBTools; http://sourceforge.net/projects/bbmap/) with the following parameters: qtrim=rl trimq=25 minlen=40. A two-pass STAR alignment (Veeneman et al., 2015) was performed against reference genomes with the same parameters as in our previous study (Krizsán et al., 2019; FPKM_calc.R) except that the maximal intron length was reduced to 3000 nt. Read count data was normalized using EdgeR (Robinson et al., 2010) as in our previous study (Krizsán et al., 2019). Expression levels were calculated as fragments per kilobase of transcript per million mapped reads (FPKM). Samples, such as FBCL and FBS of Coprinopsis cinerea from Krizsán et al. (2019), and stage 2 primordia (P2) of $P$. ostreatus were excluded from our analysis to avoid the signs of fruiting body autolysis and for quality reasons, respectively. Raw RNA-Seq reads have been deposited to NCBI's GEO archive (GSE176181).

\section{Identification of developmentally expressed genes}

Developmentally expressed genes were defined as genes that show at least 2 or 4 -fold change in expression between any two fruiting body stages or tissue types and that show an expression level FPKM > 4, as detailed in Krizsán et al. (2019). The gene was excluded if the maximum expression was detected in the vegetative mycelium.

\section{Species tree and relative gene age estimation}

Protein sequences of 109 whole genomes (Supplementary File 4/a) across Basidiomycota and Ascomycota (as outgroup) were downloaded from the JGI genome portal (Sep. 2019;

Grigoriev et al., 2014; Nordberg et al., 2014). All-vs-all similarity search was carried out with MMseqs2 (Steinegger and Söding, 2017) using three iterations, and setting sensitivity to 5.7, max-seqs to 20,000, e-profile to 1e-4, a preliminary coverage cut-off to 0.2 and an e-value cut-off to 0.001 . Then, an asymmetrical coverage filtering was performed where we required $>=0.2$ pairwise alignment coverage from the longer protein and $>=0.8$ from the shorter one, with the aim to omit aspecific hits while retaining gene fragments (covercutter.R). Then, Markov Clustering with an inflation parameter 2.0 was performed using the ratio of "number of identical matches' (Nident) and 'query sequence length' (qlen) as weight in the matrix. After clustering we removed contaminating proteins from gene families following the logic of Richter et al. (2018).

For species tree reconstruction we used 115 single copy gene families, which were present in $>=50 \%$ of the 109 species. Multiple sequence alignments were inferred using PRANK v.170427 (Löytynoja, 2014) and trimmed with TrimAL v.1.2 (-strict) (CapellaGutierrez et al., 2009). Trimmed MSA-s shorter than 100 amino acid (AA) residues were discarded. Best partitioning schemes, substitution models and species tree reconstruction were performed under Maximum Likelihood (ML) in IQ-TREE v1.6.12 (Minh et al., 2020). 
For gene tree reconstructions, gene families which contained at least four proteins were aligned with the MAFFT LINSI v7.313 (Katoh and Standley, 2013) algorithm or with FAMSA v1.5.12 (Deorowicz et al., 2016) and trimmed with TrimAL (gt-0.4). We inferred gene trees for each of the alignments in RAxmlHPC-PTHREADS-AVX2 8.2.12 under the PROTGAMMAWAG model of sequence evolution and assessed branch robustness using the SH-like support (Stamatakis, 2014). Rooting and gene tree/species tree reconciliation were performed with NOTUNG v2.9. (Darby et al., 2016) using an edge-weight threshold of 90. Then, a modified version of COMPARE (Nagy et al., 2014) was used to delineate orthogroups within gene trees.

Orthogroups were used to assign relative gene ages (hereafter: gene age), following standard phylostratigraphic definitions (Domazet-Lošo et al., 2007): as the species tree node to which the Most Recent Common Ancestor (MRCA) of species represented in the orthogroup mapped. Enrichment of gene sets in gene age categories were analysed with Fisher's exact test ( $\mathrm{R}$ core team 2020).

\section{Transcriptome age index}

Transcriptome age index for each developmental stage of the nine investigated species was computed as described previously (Domazet-Lošo and Tautz, 2010) with slight modifications, using the following formula: $T A I=\frac{\sum_{i=1}^{n} R A_{i} e_{i}}{\sum_{i=1}^{n} e_{i}}$, where $\mathrm{RA}_{\mathrm{i}}$ represents the relative age of gene $i, e_{i}$ is the $\log 2$ FPKM value of gene $i$ at the given stage and $n$ is the total number of genes. If available, tissue specific expression values were averaged for each developmental stage. The TAI values of the investigated developmental stages were computed for each replicate, then averaged.

\section{Orthology based on reciprocal best hits}

To characterize the conservation of developmental genes, we defined single copy orthologs from the nine species based on reciprocal best hits between proteins. This strategy was stricter than the above-mentioned orthogroup definition, and was required to obtain functionally highly similar protein sets for comparing developmentally expressed genes. Proteins of each species were searched against the proteomes of other eight species using the RBH module of MMSeqs2 with an e-value cut-off of 1e-5. To remove spurious reciprocal best hits, we excluded a protein from the RBH group if its bit score was at least three times lower than the mean bit score of other hits of that query (self-hit excluded) and it shared $<50$ $\%$ of its hits with those of the query (RBH_MMSeq.R). The orthogroups ( 1 gene per species) obtained this way comprised considerably more focused gene sets than the approach used in Krizsán et al. (2019).

Orthogroups, which show developmentally dynamic expression with FC $>2$ in at least four species, and which proportion $>=0.5$, considered hereafter as conserved developmental orthogroups. These conserved developmental orthogroups were also separated by the expression of Cryptococcus genes. We considered an orthogroup as 'Shared orthogroup' if the Cryptococcus ortholog showed at least FC>2 developmental expression, while we considered it as 'CM-specific' if the Cryptococcus ortholog was missing or did not show developmental regulation.

\section{Annotation of genes, gene families}

We detected conserved domains in proteins using InterProScan-5.47-82.0 (Jones et al., 2014, IPRsimpcomp.R). Enrichment analysis on IPR domains was performed with Fisher's exact test (R Core Team, 2020), while enrichment analysis on gene ontology categories was carried out using the R package topGO 2.44.0 (Alexa and Rahnenfuhrer, 2020). Proteins were further 
characterized by the best bidirectional hits to proteins of the model organisms Saccharomyces cerevisiae (Engel et al., 2014), Schizosaccharomyces pombe (Wood et al., 2012), Neurospora crassa (Galagan et al., 2003) and Aspergillus nidulans (Cerqueira et al., 2014).

\section{RNA editing and allele specific expression}

To estimate the importance of RNA editing and Allele Specific Expression (ASE) during fruiting body formation of $P$. ostreatus we evaluated mismatches in Illumina reads according to their potential origin (RNA-editing, ASE, noise). A custom pipeline (Figure 10) was constructed to first classify mismatches either as candidates for "RNA editing" or "allelespecific". Then, these mismatches were analysed further in more specialized pipelines. First, we hard trimmed 10-10 nucleotides from both the 3' and 5' end of already quality trimmed reads to decrease the impact of sequencing errors during variant calling. A two-round STAR alignment was performed against both parental genomes (PC15 and PC9) as references, with the above mentioned parameters. Variants were identified with find_edit.awk script excluding bases with a Phred quality value below 30. Nucleotides differing the same way from both parental alleles were considered technical errors (caused by PCR amplification, sequencing or alignment), somatic mutations or RNA editing. Therefore, such mismatches were transferred to the RNA editing specific pipeline. In contrast, variants which differed only from one of the parental genomes were attributed to allele specific expression. The first part of the pipeline yielded lists of variants which were further analysed either in the RNA editing specific pipeline or in allele specific expression pipeline, as follows.

The RNA editing pipeline was detailed in Appendix 3 and in Figure 10.

In the allele specific expression pipeline (Figure 10), only previously assigned candidate allele specific SNPs were considered. All reads were assigned to the parental genome to which it exhibited a smaller Hamming distance (Hd=number of SNPs). We assigned a read as indecisive if i) $\mathrm{Hd}>1$ from both reference genomes ii) $\mathrm{Hd}>15$ from any of the reference genomes (too divergent read) or, iii) if the Hd was equal to both parental genomes. FPKM values were calculated as described above.

To describe the relative expression between the two parental nuclei (AS ratio) the number of PC15 reads was divided by the sum of parental specific reads (PC15 + PC9) for each gene $(\mathrm{g})$ in each sample $(\mathrm{s}): A S=\frac{P C 15_{g s}}{P C 15_{g s}+P C 9_{g s}}$. An AS ratio close to 1 means dominant expression from the PC15 nucleus, whereas an AS ratio close to 0 means dominant expression from the PC9 nucleus. An AS ratio 0.5 indicates equal expression from both nuclei. AS ratios were considered equal (set to 0.5 ) if i) the expression was too low $($ FPKM $<2)$, ii) the number of decisive reads was $<16$, iii) the proportion of indecisive reads was greater than $80 \%$. We calculated two further measures, Chromosome Read Ratio (CRR) and Nuclear Read Ratio (NRR) introduced by Gehrmann et al., (2018), which represent the FPKM values of PC15 nucleus divided by the FPKM values of PC9 summed over chromosomes, and over all genes, respectively.

We identified genes with two- (S2) and four-fold (S4) shifted expression between the two nuclei at AS cut-off values of AS $<0.31$ or AS $>0.68$ (corresponding to $5 \%$ quantile of all AS ratio values) and AS $<0.2$ or AS $>0.8$, respectively. For passing through these filters and geometric means of replicates had to reach the upper limits $(0.68$ or 0.8$)$ for PC15 specific ASE or less than lower limits $(0.31$ or 0.2$)$ for PC9 specific ASE. 
In order to understand how ASE may arise mechanistically, we compared putative promoters of ASE genes among parents, defined as the region from spanning $1000 \mathrm{nt}$ upstream to $200 \mathrm{nt}$ downstream of the transcription start site. Differences between the two

744 parental regions were expressed as percent identity. For this analysis the meanwhile released,

745 improved version of PC9 was used (Lee et al., 2021). Protein sequences of parents were

746 aligned with PRANK and a ML distance was calculated under WAG model (dist.ml function from phangorn R package Schliep, 2011). Gene pairs with putative promoters $<75 \%$ similar or where protein ML distances were $>0.5$ and alignment coverage $<0.7$ were removed to

749 avoid potential orthology assignment errors. To identify the strength of selection for these genes we inferred $\omega$ (dN/dS ratios) under two evolutionary models using CodeML, a program from PAML 4.4 (Yang, 2007). For this, CDSs from the genomes of species in the Pleurotinae clade (Supplementary File 4/a) were extracted using GenomicFeatures packages (Lawrence et al., 2013). 1:1 orthologs were detected with MMSeqs RBH function and codon aligned using -code option of PRANK. Reference tree for CodeML was extracted from the species tree, and $\omega$ values were calculated under one-ratio (M0) model assuming that $\omega$ has been constant throughout the tree and free-ratio model (fb) allowing an independent $\omega$ for each branch in

757 the tree. For statistical comparisons the Kruskal-Wallis rank-sum test with Nemenyi post hoc 758 test or paired Wilcoxon signed-rank test and Fisher's exact test were implemented in R (R 759 Core Team, 2020). 


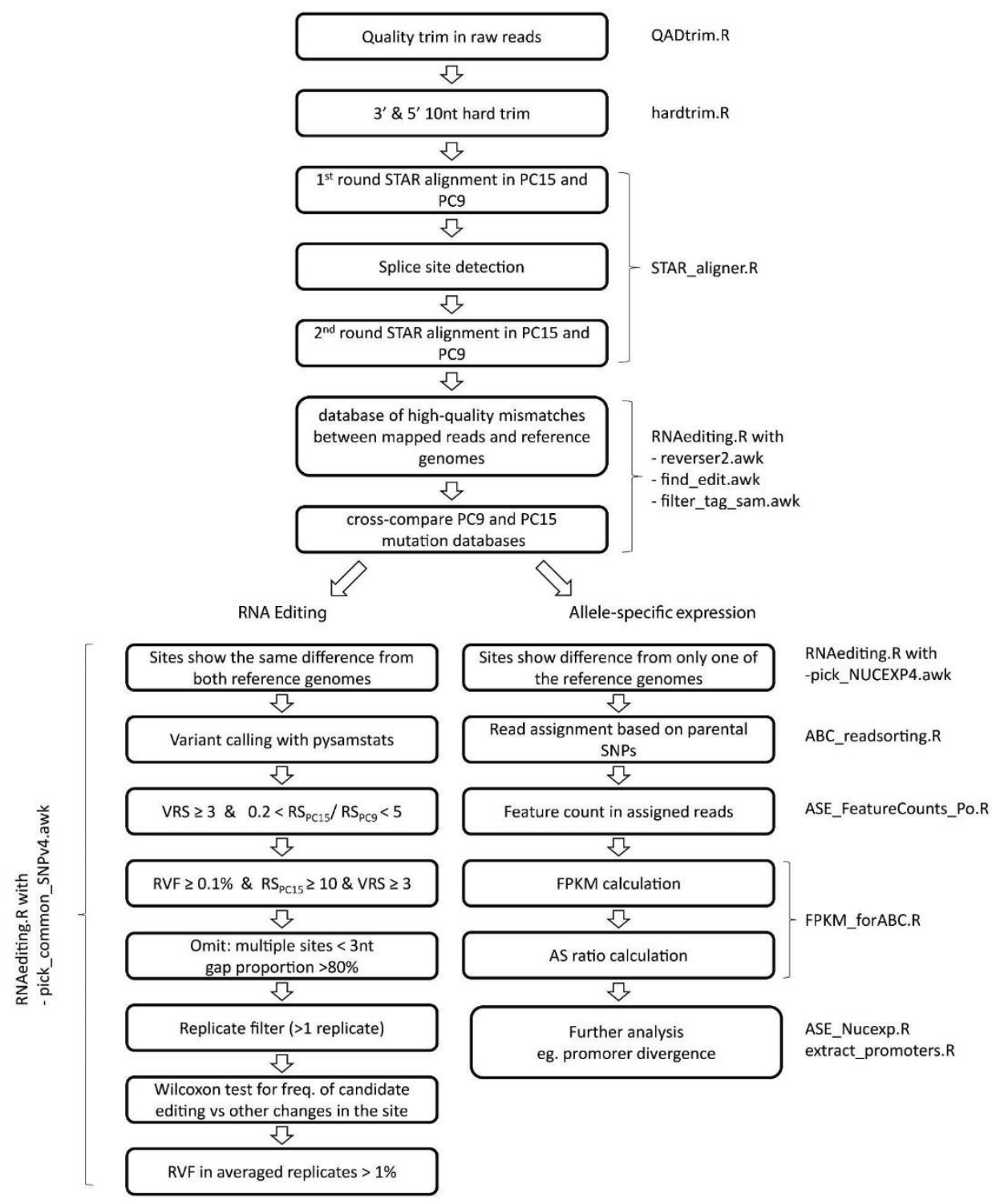

761 Figure 10: Pipeline of RNA editing and Allele Specific Expression annotation. Names of scripts 762 available in Dryad (doi:10.5061/dryad.5qfttdz5m) were displayed next to process-boxes.

763 Abbreviations: VRS Variant Read Support; RS Read Support; RVF Relative Variant Frequency.

\section{Data Availability}

766 The RNA-Seq data was deposited in the NCBI's Gene Expression Omnibus (GEO) Archive 767 at www.ncbi.nlm.nih.gov/geo (accession no. GSE176181). Other data used in this study are 768 available on Dryad (https://doi.org/10.5061/dryad.5qfttdz5m). 


\section{References}

Abedin M, King N. 2008. The premetazoan ancestry of cadherins. Science (80- ) 319:946-948. doi:10.1126/science.1151084

Alexa A, Rahnenfuhrer J. 2016. Gene set enrichment analysis with topGO https://bioconductor.org/packages/release/bioc/vignettes/topGO/inst/doc/topGO.pdf.

Alfaro M, Castanera R, Lavín JL, Grigoriev I V, Oguiza JA, Ramírez L, Pisabarro AG. 2016. Comparative and transcriptional analysis of the predicted secretome in the lignocellulosedegrading basidiomycete fungus Pleurotus ostreatus. Environ Microbiol 18:4710-4726. doi:10.1111/1462-2920.13360

Almási É, Sahu N, Krizsán K, Bálint B, Kovács GM, Kiss B, Cseklye J, Drula E, Henrissat B, Nagy I, Chovatia M, Adam C, LaButti K, Lipzen A, Riley R, Grigoriev I V., Nagy LG. 2019. Comparative genomics reveals unique wood-decay strategies and fruiting body development in the Schizophyllaceae. New Phytol 224:902-915. doi:10.1111/nph.16032

Altschul SF, Gish W, Miller W, Myers EW, Lipman DJ. 1990. Basic local alignment search tool. $J$ Mol Biol 215:403-410. doi:10.1016/S0022-2836(05)80360-2

Bayry J, Aimanianda V, Guijarro JI, Sunde M, Latgé J-P. 2012. Hydrophobins-Unique Fungal Proteins. PLOS Pathog 8:e1002700. doi:10.1371/JOURNAL.PPAT.1002700

Bembom O, Ivanek R. 2020. seqLogo: Sequence logos for DNA sequence alignments. https://bioconductor.org/packages/devel/bioc/vignettes/seqLogo/inst/doc/seqLogo.html

Bian Z, Ni Y, Xu JR, Liu H. 2019. A-to-I mRNA editing in fungi: occurrence, function, and evolution. Cell Mol Life Sci 76:329-340. doi:10.1007/s00018-018-2936-3

Borgognone A, Sanseverino W, Cigliano RA, Castanera R. 2019. Distribution, characteristics, and regulatory potential of long noncoding RNAs in brown-rot fungi. Int J Genomics 2019. doi:10.1155/2019/9702342

Buser R, Lazar Z, Käser S, Künzler M, Aebi M. 2010. Identification, characterization, and biosynthesis of a novel $\mathrm{N}$-glycan modification in the fruiting body of the basidiomycete Coprinopsis cinerea. J Biol Chem 285:10715-10723. doi:10.1074/jbc.M109.076075

Capella-Gutierrez S, Silla-Martinez JM, Gabaldon T. 2009. trimAl: a tool for automated alignment trimming in large-scale phylogenetic analyses. Bioinformatics 25:1972-1973. doi:10.1093/bioinformatics/btp348

Cerqueira GC, Arnaud MB, Inglis DO, Skrzypek MS, Binkley G, Simison M, Miyasato SR, Binkley J, Orvis J, Shah P, Wymore F, Sherlock G, Wortman JR. 2014. The Aspergillus Genome Database: multispecies curation and incorporation of RNA-Seq data to improve structural gene annotations. Nucleic Acids Res 42:D705-D710. doi:10.1093/nar/gkt1029

Chen J, Rozowsky J, Galeev TR, Harmanci A, Kitchen R, Bedford J, Abyzov A, Kong Y, Regan L, Gerstein M. 2016. A uniform survey of allele-specific binding and expression over 1000Genomes-Project individuals. Nat Commun 7:1-13. doi:10.1038/ncomms11101

Cheng J, Maier KC, Avsec Ž, Petra RUS, Gagneur J. 2017. Cis-regulatory elements explain most of the mRNA stability variation across genes in yeast. RNA 23:1648-1659. doi:10.1261/rna.062224.117

Cheng X, Hui JHL, Lee YY, Wan Law PT, Kwan HS. 2015. A “developmental hourglass" in fungi. Mol Biol Evol 32:1556-1566. doi:10.1093/molbev/msv047

Cowles CR, Hirschhorn JN, Altshuler D, Lander ES. 2002. Detection of regulatory variation in mouse genes. Nat Genet 32:432-437. doi:10.1038/ng992 
Dahary D, Elroy-Stein O, Sorek R. 2005. Naturally occurring antisense: Transcriptional leakage or real overlap? Genome Res 15:364-368. doi:10.1101/gr.3308405

Darby CA, Stolzer M, Ropp PJ, Barker D, Durand D. 2016. Xenolog classification. Bioinformatics 33:btw686. doi:10.1093/bioinformatics/btw686

Deorowicz S, Debudaj-Grabysz A, Gudys A. 2016. FAMSA: Fast and accurate multiple sequence alignment of huge protein families. Sci Rep 6:1-13. doi:10.1038/srep33964

Domazet-Lošo T, Brajković J, Tautz D. 2007. A phylostratigraphy approach to uncover the genomic history of major adaptations in metazoan lineages. Trends Genet 23:533-539. doi:10.1016/J.TIG.2007.08.014

Domazet-Lošo T, Tautz D. 2010. A phylogenetically based transcriptome age index mirrors ontogenetic divergence patterns. Nature 468:815-819. doi:10.1038/nature09632

Domazet-Lošo T, Carvunis A-R, Albà MM, Šestak MS, Bakarić R, Neme R, Tautz D. 2017. No Evidence for Phylostratigraphic Bias Impacting Inferences on Patterns of Gene Emergence and Evolution. Mol Biol Evol 34:843-856. doi:10.1093/MOLBEV/MSW284

Donaldson ME, Ostrowski LA, Goulet KM, Saville BJ. 2017. Transcriptome analysis of smut fungi reveals widespread intergenic transcription and conserved antisense transcript expression. BMC Genomics 18:1-14. doi:10.1186/s12864-017-3720-8

Donaldson ME, Saville BJ. 2013. Ustilago maydis natural antisense transcript expression alters mRNA stability and pathogenesis. Mol Microbiol 89:29-51. doi:10.1111/mmi.12254

Donaldson ME, Saville BJ. 2012. Natural antisense transcripts in fungi. Mol Microbiol 85:405-417. doi:10.1111/j.1365-2958.2012.08125.x

Dong D, Yuan Z, Zhang Z. 2011. Evidences for increased expression variation of duplicate genes in budding yeast: From cis- to trans-regulation effects. Nucleic Acids Res 39:837-847. doi:10.1093/nar/gkq874

Drost HG, Janitza P, Grosse I, Quint M. 2017. Cross-kingdom comparison of the developmental hourglass. Curr Opin Genet Dev. doi:10.1016/j.gde.2017.03.003

Engel SR, Dietrich FS, Fisk DG, Binkley G, Balakrishnan R, Costanzo MC, Dwight SS, Hitz BC, Karra K, Nash RS, Weng S, Wong ED, Lloyd P, Skrzypek MS, Miyasato SR, Simison M, Cherry JM. 2014. The Reference Genome Sequence of Saccharomyces cerevisiae: Then and Now. G3 Genes, Genomes, Genet 4:389-398. doi:10.1534/g3.113.008995

Faghihi MA, Wahlestedt C. 2009. Regulatory roles of natural antisense transcripts. Nat Rev Mol Cell Biol. doi:10.1038/nrm2738

Fay JC, Wittkopp PJ. 2008. Evaluating the role of natural selection in the evolution of gene regulation. Heredity (Edinb). doi:10.1038/sj.hdy.6801000

Flynn JM, Hubley R, Goubert C, Rosen J, Clark AG, Feschotte C, Smit AF. 2020. RepeatModeler2 for automated genomic discovery of transposable element families. Proc Natl Acad Sci U S A 117:9451-9457. doi:10.1073/pnas.1921046117

Gaitán-Hernández R, Salmones D. 2008. Obtaining and characterizing Pleurotus ostreatus strains for commercial cultivation under warm environmental conditions. Sci Hortic (Amsterdam) 118:106-110. doi:10.1016/J.SCIENTA.2008.05.029

Galagan JE, Calvo SE, Borkovich KA, Selker EU, Read ND, Jaffe D, FitzHugh W, Ma L-J, Smirnov 
S, Purcell S, Rehman B, Elkins T, Engels R, Wang S, Nielsen CB, Butler J, Endrizzi M, Qui D, Ianakiev P, Bell-Pedersen D, Nelson MA, Werner-Washburne M, Selitrennikoff CP, Kinsey JA, Braun EL, Zelter A, Schulte U, Kothe GO, Jedd G, Mewes W, Staben C, Marcotte E, Greenberg D, Roy A, Foley K, Naylor J, Stange-Thomann N, Barrett R, Gnerre S, Kamal M, Kamvysselis M, Mauceli E, Bielke C, Rudd S, Frishman D, Krystofova S, Rasmussen C, Metzenberg RL, Perkins DD, Kroken S, Cogoni C, Macino G, Catcheside D, Li W, Pratt RJ, Osmani SA, DeSouza CPC, Glass L, Orbach MJ, Berglund JA, Voelker R, Yarden O, Plamann M, Seiler S, Dunlap J, Radford A, Aramayo R, Natvig DO, Alex LA, Mannhaupt G, Ebbole DJ, Freitag M, Paulsen I, Sachs MS, Lander ES, Nusbaum C, Birren B. 2003. The genome sequence of the filamentous fungus Neurospora crassa. Nature 422:859-868. doi:10.1038/nature01554

Gaur U, Li K, Mei S, Liu G. 2013. Research progress in allele-specific expression and its regulatory mechanisms. J Appl Genet 54:271-283. doi:10.1007/s13353-013-0148-y

Gehrmann T, Pelkmans JF, Ohm RA, Vos AM, Sonnenberg ASM, Baars JJP, Wösten HAB, Reinders MJT, Abeel T. 2018. Nucleus-specific expression in the multinuclear mushroom-forming fungus Agaricus bisporus reveals different nuclear regulatory programs. Proc Natl Acad Sci U S A 115:4429-4434. doi:10.1073/pnas.1721381115

Grigoriev I V., Nikitin R, Haridas S, Kuo A, Ohm R, Otillar R, Riley R, Salamov A, Zhao X, Korzeniewski F, Smirnova T, Nordberg H, Dubchak I, Shabalov I. 2014. MycoCosm portal: Gearing up for 1000 fungal genomes. Nucleic Acids Res 42. doi:10.1093/nar/gkt1183

Grimm D, Wösten HAB. 2018. Mushroom cultivation in the circular economy. Appl Microbiol Biotechnol. doi:10.1007/s00253-018-9226-8

Gu X, Zhang Z, Huang W. 2005. Rapid evolution of expression and regulatory divergences after yeast gene duplication. Proc Natl Acad Sci U S A 102:707-712. doi:10.1073/pnas.0409186102

Gyawali R, Upadhyay S, Way J, Lin X. 2017. A family of secretory proteins is associated with different morphotypes in Cryptococcus neoformans. Appl Environ Microbiol 83. doi:10.1128/AEM.02967-16

Hou Z, Chen Q, Zhao M, Huang C, Wu X. 2020. Genome-wide characterization of the Zn(II)2Cys6 zinc cluster-encoding gene family in Pleurotus ostreatus and expression analyses of this family during developmental stages and under heat stress. PeerJ 2020:e9336. doi:10.7717/peerj.9336

Jones P, Binns D, Chang H-Y, Fraser M, Li W, McAnulla C, McWilliam H, Maslen J, Mitchell A, Nuka G, Pesseat S, Quinn AF, Sangrador-Vegas A, Scheremetjew M, Yong S-Y, Lopez R, Hunter S. 2014. InterProScan 5: genome-scale protein function classification. Bioinformatics 30:1236-40. doi:10.1093/bioinformatics/btu031

Jorgensen P, Nishikawa JL, Breitkreutz BJ, Tyers M. 2002. Systematic identification of pathways that couple cell growth and division in yeast. Science (80- ) 297:395-400. doi:10.1126/science. 1070850

Kalinka AT, Varga KM, Gerrard DT, Preibisch S, Corcoran DL, Jarrells J, Ohler U, Bergman CM, Tomancak P. 2010. Gene expression divergence recapitulates the developmental hourglass model. Nat 20104687325 468:811-814. doi:10.1038/nature09634

Kalvari I, Nawrocki EP, Ontiveros-Palacios N, Argasinska J, Lamkiewicz K, Marz M, Griffiths-Jones S, Toffano-Nioche C, Gautheret D, Weinberg Z, Rivas E, Eddy SR, Finn RD, Bateman A, Petrov AI. 2021. Rfam 14: Expanded coverage of metagenomic, viral and microRNA families. Nucleic Acids Res 49:D192-D200. doi:10.1093/nar/gkaa1047

Kamada T, Sano H, Nakazawa T, Nakahori K. 2010. Regulation of fruiting body photomorphogenesis in Coprinopsis cinerea. Fungal Genet Biol. doi:10.1016/j.fgb.2010.05.003 
Kang YJ, Yang DC, Kong L, Hou M, Meng YQ, Wei L, Gao G. 2017a. CPC2: A fast and accurate coding potential calculator based on sequence intrinsic features. Nucleic Acids Res 45:W12W16. doi:10.1093/nar/gkx428

Kang YJ, Yang DC, Kong L, Hou M, Meng YQ, Wei L, Gao G. 2017b. CPC2: A fast and accurate coding potential calculator based on sequence intrinsic features. Nucleic Acids Res 45:W12W16. doi:10.1093/nar/gkx428

Kapusta A, Feschotte C. 2014. Volatile evolution of long noncoding RNA repertoires: Mechanisms and biological implications. Trends Genet. doi:10.1016/j.tig.2014.08.004

Katoh K, Standley DM. 2013. MAFFT Multiple Sequence Alignment Software Version 7: Improvements in Performance and Usability. Mol Biol Evol 30:772-780. doi:10.1093/molbev/mst010

Ke HM, Lee HH, Chan-Yi Ivy Lin, Liu YC, Lu MR, Hsieh JWA, Chang CC, Wu PH, Lu MJ, Li JY, Shang G, Lu RJH, Nagy LG, Chen PY, Kao HW, Tsai IJ. 2020. Mycena genomes resolve the evolution of fungal bioluminescence. Proc Natl Acad Sci U S A 117:31267-31277. doi:10.1073/pnas.2010761117

Keller NP. 2018. Fungal secondary metabolism: regulation, function and drug discovery. Nat Rev Microbiol 2018173 17:167-180. doi:10.1038/s41579-018-0121-1

Khan Z, Bloom JS, Amini S, Singh M, Perlman DH, Caudy AA, Kruglyak L. 2012. Quantitative measurement of allele-specific protein expression in a diploid yeast hybrid by LC-MS. Mol Syst Biol 8:602. doi:10.1038/msb.2012.34

Kim W, Miguel-Rojas C, Wang J, Townsend JP, Trail F. 2018a. Developmental dynamics of long noncoding RNA expression during sexual fruiting body formation in Fusarium graminearum. MBio 9. doi:10.1128/mBio.01292-18

Kim W, Miguel-Rojas C, Wang J, Townsend JP, Trail F. 2018b. Developmental dynamics of long noncoding RNA expression during sexual fruiting body formation in Fusarium graminearum. MBio 9:1-17. doi:10.1128/mBio.01292-18

King N, Hittinger CT, Carroll SB. 2003. Evolution of key cell signaling and adhesion protein families predates animal origins. Science (80- ) 301:361-363. doi:10.1126/science.1083853

Kiss E, Hegedüs B, Virágh M, Varga T, Merényi Z, Kószó T, Bálint B, Prasanna AN, Krizsán K, Kocsubé S, Riquelme M, Takeshita N, Nagy LG. 2019. Comparative genomics reveals the origin of fungal hyphae and multicellularity. Nat Commun 10. doi:10.1038/s41467-019-12085-w

Knoll AH. 2011. The Multiple Origins of Complex Multicellularity. Annu Rev Earth Planet Sci 39:217-239. doi:10.1146/annurev.earth.031208.100209

Kondrashov FA, Rogozin IB, Wolf YI, Koonin E V. 2002. Selection in the evolution of gene duplications. Genome Biol 3:1-9. doi:10.1186/gb-2002-3-2-research0008

Kraakman LS, Griffioen G, Zerp S, Groeneveld P, Thevelein JM, Mager WH, Planta RJ. 1993. Growth-related expression of ribosomal protein genes in Saccharomyces cerevisiae. MGG Mol Gen Genet 239:196-204. doi:10.1007/BF00281618

Krizsán K, Almási É, Merényi Z, Sahu N, Virágh M, Kószó T, Mondo S, Kiss B, Bálint B, Kües U, Barry K, Cseklye J, Hegedüs B, Henrissat B, Johnson J, Lipzen A, Ohm RA, Nagy I, Pangilinan J, Yan J, Xiong Y, Grigoriev I V., Hibbett DS, Nagy LG. 2019. Transcriptomic atlas of mushroom development reveals conserved genes behind complex multicellularity in fungi. Proc Natl Acad Sci U S A 116:7409-7418. doi:10.1073/pnas.1817822116

Kües U, Navarro-González M. 2015. How do Agaricomycetes shape their fruiting bodies? 1. 
Morphological aspects of development. Fungal Biol Rev 29:63-97. doi:10.1016/j.fbr.2015.05.001

Künzler M. 2018. How fungi defend themselves against microbial competitors and animal predators. PLoS Pathog. doi:10.1371/journal.ppat.1007184

Lau AYT, Cheng X, Cheng CK, Nong W, Cheung MK, Chan RH-F, Hui JHL, Kwan HS. 2018. Discovery of microRNA-like RNAs during early fruiting body development in the model mushroom Coprinopsis cinerea. PLoS One 13:e198234. doi:10.1371/journal.pone.0198234

Lau AYT, Xie Y, Cheung MK, Cheung PCK, Kwan HS. 2020. Genome-wide mRNA and miRNA analysis in the early stages of germ tube outgrowth in Coprinopsis cinerea. Fungal Genet Biol 142:103416. doi:10.1016/j.fgb.2020.103416

Lawrence M, Gentleman R, Carey V. 2009. rtracklayer: An R package for interfacing with genome browsers. Bioinformatics 25:1841-1842. doi:10.1093/bioinformatics/btp328

Lawrence M, Huber W, Pagès H, Aboyoun P, Carlson M, Gentleman R, Morgan MT, Carey VJ. 2013. Software for Computing and Annotating Genomic Ranges. PLoS Comput Biol 9:1003118. doi:10.1371/journal.pcbi.1003118

Lee YY, de Ulzurrun GVD, Schwarz EM, Stajich JE, Hsueh YP. 2021. Genome sequence of the oyster mushroom Pleurotus ostreatus strain PC9. G3 Genes, Genomes, Genet 11. doi:10.1093/G3JOURNAL/JKAA008

Li H. 2018. Minimap2: Pairwise alignment for nucleotide sequences. Bioinformatics 34:3094-3100. doi:10.1093/bioinformatics/bty191

Li J, Liu X Bin, Zhao ZW, Yang ZL. 2019. Genetic diversity, core collection and breeding history of Pleurotus ostreatus in China. Mycoscience 60:14-24. doi:10.1016/j.myc.2018.07.002

Liao Y, Smyth GK, Shi W. 2014. FeatureCounts: An efficient general purpose program for assigning sequence reads to genomic features. Bioinformatics 30:923-930. doi:10.1093/bioinformatics/btt656

Liu C, Bi J, Kang L, Zhou J, Liu X, Liu Z, Yuan S. 2021. The molecular mechanism of stipe cell wall extension for mushroom stipe elongation growth. Fungal Biol Rev. doi:10.1016/j.fbr.2020.11.001

Liu H, Wang Q, He Y, Chen L, Hao C, Jiang C, Li Y, Dai Y, Kang Z, Xu JR. 2016. Genome-wide Ato-I RNA editing in fungi independent of ADAR enzymes. Genome Res 26:499-509. doi:10.1101/gr.199877.115

Liu H, Li Y, Chen D, Qi Z, Wang Q, Wang J, Jiang C, Xu JR. 2017. A-to-I RNA editing is developmentally regulated and generally adaptive for sexual reproduction in Neurospora crassa. Proc Natl Acad Sci U S A 114:E7756--E7765. doi:10.1073/pnas.1702591114

Liu L, He GJ, Chen L, Zheng J, Chen Y, Shen L, Tian X, Li E, Yang E, Liao G, Wang L. 2018. Genetic basis for coordination of meiosis and sexual structure maturation in cryptococcus neoformans. Elife 7. doi:10.7554/eLife.38683

Lloréns-Rico V, Cano J, Kamminga T, Gil R, Latorre A, Chen WH, Bork P, Glass JI, Serrano L, Lluch-Senar M. 2016. Bacterial antisense RNAs are mainly the product of transcriptional noise. Sci Adv 2:e1501363. doi:10.1126/sciadv.1501363

Löytynoja A. 2014. Phylogeny-aware alignment with PRANKMethods in Molecular Biology (Clifton, N.J.). pp. 155-170. doi:10.1007/978-1-62703-646-7_10

Marisol S-G, Martin R, Faheema K, Torda V, László G. N, David S. H. 2020. Macroevolutionary 
dynamics of fruiting body forms and nutritional modes in mushroom-forming fungi based on an 8400 species phylogeny.

McManus CJ, Coolon JD, Duff MO, Eipper-Mains J, Graveley BR, Wittkopp PJ. 2010. Regulatory divergence in Drosophila revealed by mRNA-seq. Genome Res 20:816-825. doi:10.1101/gr.102491.109

Medema MH, Blin K, Cimermancic P, De Jager V, Zakrzewski P, Fischbach MA, Weber T, Takano E, Breitling R. 2011. AntiSMASH: Rapid identification, annotation and analysis of secondary metabolite biosynthesis gene clusters in bacterial and fungal genome sequences. Nucleic Acids Res 39:W339--W346. doi:10.1093/nar/gkr466

Merényi Z, Prasanna AN, Wang Z, Kovács K, Hegedüs B, Bálint B, Papp B, Townsend JP, Nagy LG. 2020. Unmatched Level of Molecular Convergence among Deeply Divergent Complex Multicellular Fungi. Mol Biol Evol 37:2228-2240. doi:10.1093/molbev/msaa077

Meyerowitz EM. 2002. Comparative genomics. Plants compared to animals: The broadest comparative study of development. Science (80- ) 295:1482-1485. doi:10.1126/SCIENCE.1066609

Minh BQ, Schmidt HA, Chernomor O, Schrempf D, Woodhams MD, Von Haeseler A, Lanfear R, Teeling E. 2020. IQ-TREE 2: New Models and Efficient Methods for Phylogenetic Inference in the Genomic Era. Mol Biol Evol 37:1530-1534. doi:10.1093/molbev/msaa015

Montanini B, Chen PY, Morselli M, Jaroszewicz A, Lopez D, Martin F, Ottonello S, Pellegrini M. 2014. Non-exhaustive DNA methylation-mediated transposon silencing in the black truffle genome, a complex fungal genome with massive repeat element content. Genome Biol 15:1-16. doi:10.1186/s13059-014-0411-5

Muraguchi H, Umezawa K, Niikura M, Yoshida M, Kozaki T, Ishii K, Sakai K, Shimizu M, Nakahori K, Sakamoto Y, Choi C, Ngan CY, Lindquist E, Lipzen A, Tritt A, Haridas S, Barry K, Grigoriev I V., Pukkila PJ. 2015. Strand-specific RNA-seq analyses of fruiting body development in Coprinopsis cinerea. PLoS One 10:1-23. doi:10.1371/journal.pone.0141586

Nakazawa T, Kaneko S, Miyazaki Y, Jojima T, Yamazaki T, Katsukawa S, Shishido K. 2008. Basidiomycete Lentinula edodes CDC5 and a novel interacting protein CIPB bind to a newly isolated target gene in an unusual manner. Fungal Genet Biol 45:818-828. doi:10.1016/J.FGB.2008.02.007

Nagy LG. 2018. Many roads to convergence. Science (80- ) 361:125-126. doi:10.1126/science.aau3144

Nagy LG, Kovács GM, Krizsán K. 2018. Complex multicellularity in fungi: evolutionary convergence, single origin, or both? Biol Rev 93:1778-1794. doi:10.1111/brv.12418

Nagy LG, Ohm RA, Kovács GM, Floudas D, Riley R, Gácser A, Sipiczki M, Davis JM, Doty SL, de Hoog GS, Lang BF, Spatafora JW, Martin FM, Grigoriev I V, Hibbett DS. 2014. Latent homology and convergent regulatory evolution underlies the repeated emergence of yeasts. Nat Commun 5:4471. doi:10.1038/ncomms5471

Nawrocki EP, Eddy SR. 2013. Infernal 1.1: 100-fold faster RNA homology searches. Bioinformatics 29:2933-2935. doi:10.1093/bioinformatics/btt509

Nguyen TA, Cissé OH, Yun Wong J, Zheng P, Hewitt D, Nowrousian M, Stajich JE, Jedd G. 2017. Innovation and constraint leading to complex multicellularity in the Ascomycota. Nat Commun 8:14444. doi:10.1038/ncomms14444

Nordberg H, Cantor M, Dusheyko S, Hua S, Poliakov A, Shabalov I, Smirnova T, Grigoriev I V., Dubchak I. 2014. The genome portal of the Department of Energy Joint Genome Institute: 2014 
updates. Nucleic Acids Res 42. doi:10.1093/nar/gkt1069

Ohga S. 2000. Transcriptional regulation of laccase and cellulase in relation to fruit body formation in the mycelium of Lentinula edodes on a sawdust-based substrate. Mycoscience 41:149-153. doi:10.1007/BF02464324

Ohm RA, de Jong JF, de Bekker C, Wösten HAB, Lugones LG. 2011. Transcription factor genes of Schizophyllum commune involved in regulation of mushroom formation. Mol Microbiol 81:1433-1445. doi:10.1111/j.1365-2958.2011.07776.x

Ohm RA, De Jong JF, Lugones LG, Aerts A, Kothe E, Stajich JE, De Vries RP, Record E, Levasseur A, Baker SE, Bartholomew KA, Coutinho PM, Erdmann S, Fowler TJ, Gathman AC, Lombard V, Henrissat B, Knabe N, Kües U, Lilly WW, Lindquist E, Lucas S, Magnuson JK, Piumi F, Raudaskoski M, Salamov A, Schmutz J, Schwarze FWMR, Vankuyk PA, Horton JS, Grigoriev I V., Wösten HAB. 2010. Genome sequence of the model mushroom Schizophyllum commune. Nat Biotechnol 28:957-963. doi:10.1038/nbt.1643

Orban A, Weber A, Herzog R, Hennicke F, Rühl M. 2021. Transcriptome of different fruiting stages in the cultivated mushroom Cyclocybe aegerita suggests a complex regulation of fruiting and reveals enzymes putatively involved in fungal oxylipin biosynthesis. BMC Genomics 2021221 22:1-23. doi:10.1186/S12864-021-07648-5

van Peer AF, Wang F, van Driel KGA, de Jong JF, van Donselaar EG, Müller WH, Boekhout T, Lugones LG, Wösten HAB. 2010. The septal pore cap is an organelle that functions in vegetative growth and mushroom formation of the wood-rot fungus Schizophyllum commune. Environ Microbiol 12:833-844. doi:10.1111/j.1462-2920.2009.02122.x

Pertea G, Pertea M. 2020. GFF Utilities: GffRead and GffCompare. F1000Research 9:304. doi:10.12688/f1000research.23297.2

Pertea M, Pertea GM, Antonescu CM, Chang TC, Mendell JT, Salzberg SL. 2015. StringTie enables improved reconstruction of a transcriptome from RNA-seq reads. Nat Biotechnol 33:290-295. doi:10.1038/nbt.3122

Pezzella C, Lettera V, Piscitelli A, Giardina P, Sannia G. 2013. Transcriptional analysis of Pleurotus ostreatus laccase genes. Appl Microbiol Biotechnol 97:705-717. doi:10.1007/s00253-012-39809

Piasecka B, Lichocki P, Moretti S, Bergmann S, Robinson-Rechavi M. 2013. The Hourglass and the Early Conservation Models - Co-Existing Patterns of Developmental Constraints in Vertebrates. PLOS Genet 9:e1003476. doi:10.1371/JOURNAL.PGEN.1003476

R Core Team. 2020. R: A language and environment for statistical computing. R Foundation for Statistical Computing. Vienna, Austria. https://www.r-project.org/.

Rhind N, Chen Z, Yassour M, Thompson DA, Haas BJ, Habib N, Wapinski I, Roy S, Lin MF, Heiman DI, Young SK, Furuya K, Guo Y, Pidoux A, Chen HM, Robbertse B, Goldberg JM, Aoki K, Bayne EH, Berlin AM, Desjardins CA, Dobbs E, Dukaj L, Fan L, FitzGerald MG, French C, Gujja S, Hansen K, Keifenheim D, Levin JZ, Mosher RA, Müller CA, Pfiffner J, Priest M, Russ C, Smialowska A, Swoboda P, Sykes SM, Vaughn M, Vengrova S, Yoder R, Zeng Q, Allshire R, Baulcombe D, Birren BW, Brown W, Ekwall K, Kellis M, Leatherwood J, Levin H, Margalit H, Martienssen R, Nieduszynski CA, Spatafora JW, Friedman N, Dalgaard JZ, Baumann P, Niki H, Regev A, Nusbaum C. 2011. Comparative functional genomics of the fission yeasts. Science (80- ) 332:930-936. doi:10.1126/science.1203357 
Riley R, Salamov AA, Brown DW, Nagy LG, Floudas D, Held BW, Levasseur A, Lombard V, Morin E, Otillar R, Lindquist EA, Sun H, LaButti KM, Schmutz J, Jabbour D, Luo H, Baker SE, Pisabarro AG, Walton JD, Blanchette RA, Henrissat B, Martin F, Cullen D, Hibbett DS, Grigoriev I V. 2014. Extensive sampling of basidiomycete genomes demonstrates inadequacy of the white-rot/brown-rot paradigm for wood decay fungi. Proc Natl Acad Sci U S A 111:99239928. doi:10.1073/pnas.1400592111

Robinson MD, McCarthy DJ, Smyth GK. 2010. edgeR: a Bioconductor package for differential expression analysis of digital gene expression data. Bioinformatics 26:139-140. doi:10.1093/bioinformatics/btp616

Royse DJ, Baars J, Tan Q. 2017. Current Overview of Mushroom Production in the WorldEdible and Medicinal Mushrooms. John Wiley \& Sons, Ltd. pp. 5-13. doi:10.1002/9781119149446.ch2

Sakai H, Kajiwara S. 2003. A Stearoyl-CoA-specific $\Delta 9$ Fatty Acid Desaturase from the Basidiomycete Lentinula edodes. Biosci Biotechnol Biochem 67:2431-2437. doi:10.1271/bbb.67.2431

Schliep KP. 2011. phangorn: Phylogenetic analysis in R. Bioinformatics 27:592-593. doi:10.1093/bioinformatics/btq706

Sebé-Pedrós A, Degnan BM, Ruiz-Trillo I. 2017. The origin of Metazoa: a unicellular perspective. Nat Rev Genet 18:498-512. doi:10.1038/nrg.2017.21

Sebé-Pedrós A, Saudemont B, Chomsky E, Plessier F, Mailhé MP, Renno J, Loe-Mie Y, Lifshitz A, Mukamel Z, Schmutz S, Novault S, Steinmetz PRH, Spitz F, Tanay A, Marlow H. 2018. Cnidarian Cell Type Diversity and Regulation Revealed by Whole-Organism Single-Cell RNASeq. Cell 173:1520-1534.e20. doi:10.1016/j.cell.2018.05.019

Shao J, Chen H, Yang D, Jiang M, Zhang H, Wu B, Li J, Yuan L, Liu C. 2017. Genome-wide Identification and Characterization of Natural Antisense Transcripts by Strand-specific RNA Sequencing in Ganoderma lucidum. Sci Rep 7:1-15. doi:10.1038/s41598-017-04303-6

Shih C-H, Fay JC. 2021. Cis-regulatory variants affect gene expression dynamics in yeast. bioRxiv 2021.03.16.435665. doi:10.1101/2021.03.16.435665

Sipos G, Prasanna AN, Walter MC, O’Connor E, Bálint B, Krizsán K, Kiss B, Hess J, Varga T, Slot J, Riley R, Bóka B, Rigling D, Barry K, Lee J, Mihaltcheva S, LaButti K, Lipzen A, Waldron R, Moloney NM, Sperisen C, Kredics L, Vágvölgyi C, Patrignani A, Fitzpatrick D, Nagy I, Doyle S, Anderson JB, Grigoriev I V., Güldener U, Münsterkötter M, Nagy LG. 2017. Genome expansion and lineage-specific genetic innovations in the forest pathogenic fungi Armillaria. Nat Ecol Evol 1:1931-1941. doi:10.1038/s41559-017-0347-8

Smith JM, Szathmary E. 1995. The Major Transitions in Evolution. New York:W. H. Freeman and Company.

Song CH, Cho KY, Nair NG, Vine J. 2018. Growth Stimulation and Lipid Synthesis in Lentinus Edodes. https://doi.org/101080/00275514198912025782 81:514-522. doi:10.1080/00275514.1989.12025782

Stamatakis A. 2014. RAxML version 8: a tool for phylogenetic analysis and post-analysis of large phylogenies. Bioinformatics 30:1312-3. doi:10.1093/bioinformatics/btu033

Steinegger M, Söding J. 2017. MMseqs2 enables sensitive protein sequence searching for the analysis of massive data sets. Nat Biotechnol. doi:10.1038/nbt.3988 
Teichert I. 2020. Fungal RNA editing: who, when, and why? Appl Microbiol Biotechnol. doi:10.1007/s00253-020-10631-x

Teichert I, Dahlmann TA, Kück U, Nowrousian M. 2017. RNA editing during sexual development occurs in distantly related filamentous ascomycetes. Genome Biol Evol 9:855-868. doi:10.1093/gbe/evx052

Van Oss SB, Carvunis AR. 2019. De novo gene birth. PLoS Genet 15:e1008160. doi:10.1371/journal.pgen.1008160

Varga T, Krizsán K, Földi C, Dima B, Sánchez-García M, Sánchez-Ramírez S, Szöllősi GJ, Szarkándi JG, Papp V, Albert L, Andreopoulos W, Angelini C, Antonín V, Barry KW, Bougher NL, Buchanan P, Buyck B, Bense V, Catcheside P, Chovatia M, Cooper J, Dämon W, Desjardin D, Finy P, Geml J, Haridas S, Hughes K, Justo A, Karasiński D, Kautmanova I, Kiss B, Kocsubé S, Kotiranta H, LaButti KM, Lechner BE, Liimatainen K, Lipzen A, Lukács Z, Mihaltcheva S, Morgado LN, Niskanen T, Noordeloos ME, Ohm RA, Ortiz-Santana B, Ovrebo C, Rácz N, Riley R, Savchenko A, Shiryaev A, Soop K, Spirin V, Szebenyi C, Tomšovský M, Tulloss RE, Uehling J, Grigoriev I V., Vágvölgyi C, Papp T, Martin FM, Miettinen O, Hibbett DS, Nagy LG. 2019. Megaphylogeny resolves global patterns of mushroom evolution. Nat Ecol Evol 3:668-678. doi:10.1038/s41559-019-0834-1

Veeneman BA, Shukla S, Dhanasekaran SM, Chinnaiyan AM, Nesvizhskii AI. 2015. Two-pass alignment improves novel splice junction quantification. Bioinformatics 32:btv642. doi:10.1093/bioinformatics/btv642

Mate Viragh, Zsolt Merényi, Arpad Csernetics, Csenge Foldi, Neha Sahu, Liu Xiao-Bin, David S Hibbett, Laszlo G Nagy (2021) Evolutionary morphogenesis of sexual fruiting bodies in Basidiomycota: toward a new evo-devo synthesis. Microbiology and Molecular Biology Reviews 86(1), e00019-21.

Vogt E, Künzler M. 2019. Discovery of novel fungal RiPP biosynthetic pathways and their application for the development of peptide therapeutics. Appl. Microbiol. Biotechnol. 2019 10314. 103:5567-5581.

Vonk PJ, Ohm RA. 2021. H3K4me2 ChIP-Seq reveals the epigenetic landscape during mushroom formation and novel developmental regulators of Schizophyllum commune. Sci Rep 11:8178. doi:10.1038/s41598-021-87635-8

Wainer-Katsir K, Linial M. 2019. Allele specific expression in human - Genomic makeup and phenotypic implications. bioRxiv. doi:10.1101/757997

Wang M, Uebbing S, Ellegren H. 2017. Bayesian inference of allele-specific gene expression indicates abundant Cis-regulatory variation in natural flycatcher populations. Genome Biol Evol 9:1266-1279. doi:10.1093/gbe/evx080

Wang Z, Jiang Y, Wu H, Xie X, Huang B. 2019. Genome-Wide Identification and Functional Prediction of Long Non-coding RNAs Involved in the Heat Stress Response in Metarhizium robertsii. Front Microbiol 10:1-11. doi:10.3389/fmicb.2019.02336

Wood V, Harris MA, McDowall MD, Rutherford K, Vaughan BW, Staines DM, Aslett M, Lock A, Bähler J, Kersey PJ, Oliver SG. 2012. PomBase: A comprehensive online resource for fission yeast. Nucleic Acids Res 40:D695-D699. doi:10.1093/nar/gkr853

Xie C, Gong W, Zhu Z, Yan L, Hu Z, Peng Y. 2018. Comparative transcriptomics of Pleurotus eryngii reveals blue-light regulation of carbohydrate-active enzymes (CAZymes) expression at primordium differentiated into fruiting body stage. Genomics 110:201-209. doi:10.1016/j.ygeno.2017.09.012

Yang Z. 2007. PAML 4: Phylogenetic analysis by maximum likelihood. Mol Biol Evol 24:1586-1591. doi:10.1093/molbev/msm088 
Ye Y, Minami A, Igarashi Y, Izumikawa M, Umemura M, Nagano N, Machida M, Kawahara T, Shin-ya K, Gomi K, Oikawa H. 2016. Unveiling the Biosynthetic Pathway of the Ribosomally Synthesized and Post-translationally Modified Peptide Ustiloxin B in Filamentous Fungi. Angew Chemie Int Ed 55:8072-8075. doi:10.1002/anie.201602611

Zhu W, Hu J, Li Y, Yang B, Guan Y, Xu C, Chen F, Chi J, Bao Y. 2019. Comparative proteomic analysis of pleurotus ostreatus reveals great metabolic differences in the cap and stipe development and the potential role of ca2+ in the primordium differentiation. Int J Mol Sci 20:6317. doi:10.3390/ijms20246317

Zhu Y, Luo H, Zhang X, Song J, Sun C, Ji A, Xu J, Chen S. 2014. Abundant and selective RNAediting events in the medicinal mushroom ganoderma lucidum. Genetics 196:1047-1057. doi:10.1534/genetics.114.161414

\section{Acknowledgements}

We are thankful to Otto Miettinen for permission to utilize unpublished genomic data of Aphanobasidium pseudotsugae. The authors acknowledge support by the Hungarian National Research, Development, and Innovation Office (contract No. GINOP-2.3.2-15-2016-00052), the "Momentum" program of the Hungarian Academy of Sciences (contract No. LP201913/2019 to L.G.N.) and the European Research Council (grant no. 758161 to L.G.N.).

\section{Supplementary Materials:}

\section{Captions for Supplementary Files 1 to 5}

Supplementary File 1. (separate file). Literature collected developmental genes in Coprinopsis cinerea and Pleurotus sp.

Supplementary File 2. (separate file). InterPro domain enrichment analysis for genes with Allele Specific Expression (S2 and S4) among all IPR annotated genes.

Supplementary File 3. (separate file). Conserved 1:1 ortholog groups.

Supplementary File 4. (separate file). Species which were used for transcriptomic analysis and for species tree.

Supplementary File 5. (separate file). Gene Ontology enrichment for CM-specific and Shared orthologs

\section{Legends for Figures}

Figure 1 Phylogenetic relationships among nine species analysed in this study. Numbers in circles next to nodes represent gene ages used in phylostratigraphic analyses of $P$. ostreatus. Nodes are numbered from 1-20 from the root of the tree to the tip harbouring $P$. ostreatus. The first emergence of complex multicellularity in this lineage is shown with red, according to Merényi et al (2020). The scale bar represents 0.2 expected change per site. Fruiting bodies of Pleurotus ostreatus (upper) and Pterula gracilis (lower) are shown in the box. Abbreviations as follows: 'Hym' Hymenochetales 
Figure 2 Proportion of Developmentally expressed (DR > 4 FC) genes in different gene ages. Asterisk (*) represents significant differences p-value $<0.05$ (Fisher's exact test with BenjaminiHochberg correction). Gene age was calculated based on orthogroup membership (the presence of clear orthologs across species). For each species, nodes along the node path were numbered in ascending order on the species tree from root to tip starting with the value 1. (See Figure 1 for an example); node numbers were then used as the gene age values.

Figure 3 Transcriptome conservation in the nine species based on transcriptome age index (TAI). Abbreviations as follows: 'VM' vegetative mycelium; 'P1' stage 1 primordium; 'P3' stage3 primordium; 'YFB' young fruiting body, 'FB' fruiting body.

Figure 4 Contribution of two haploid nuclei of P.ostreatus to total gene expression. Expression of PC15 relative to the sum of PC15 and PC9 (AS ratio) was visualised in a heatmap for genes that showed at least two-fold ASE in at least one stage. Thresholds that we used to define S2 and S4 gene sets are marked in the colour key. Abbreviations are as follows: 'VM' vegetative mycelium; 'P1' stage 1 primordium; 'P3' stage3 primordium; 'YFB' young fruiting body, 'FB' fruiting body; ' $\mathrm{H}$ ' cap (entire); 'C' cap trama; 'L' lamellae; 'S' stipe; 'V' cuticle; 'D' dedifferentiated tissue of cap.

Figure 5 Examples for allele specific expression (ASE) during fruiting body formation of Pleurotus ostreatus. Expression level $\left(\log _{2}\right.$ transformed FPKM) from the two nuclei are coloured with blue (PC9) and red (PC15). P. ostreatus gene- and protein-IDs (PleosPC15_2_) are displayed in each plot as a title. a) Hydrophobin, b) UstYa-like mycotoxin biosynthesis protein genes. Differences in the upstream gene regions are shown under the plots. Abbreviations are as follows: 'VM' vegetative mycelium; 'P1' stage 1 primordium; 'P3' stage3 primordium; 'YFB' young fruiting body, 'FB' fruiting body; 'H' cap (entire); 'C' cap trama; 'L' lamellae; 'S' stipe; 'V' cuticle; 'D' dedifferentiated tissue of cap.

Figure 6 Allele-specific expression may arise from cis-regulatory divergence. a) percent sequence identity between the $1 \mathrm{~kb}$ upstream regions of PC15 and PC9 genes b) dN/dS distribution for ASE (S2 and S4) and equally expressed genes under the free model in CODEML. Abbreviations are as follows: 'EE' equally expressed; 'S2' Allele Specific Expression with 2 fold change; 'S4' Allele Specific 1229 Expression with 4 fold change.

1230 Figure 7 ASE genes are enriched among young genes. The proportion of ASE shows a significantly tendency towards higher values (Mann-Kendall statistics) across gene ages, in the case of a) all genes b) developmentally expressed genes $(\mathrm{FC}>4)$. Horizontal red line represents the ratio of all ASE/EE genes, while significant differences from the background (Fisher's exact test $p$-value $<0.001$ ) are shown with green (overrepresentation) and blue (underrepresentation). Size of circles represents the number of proteins ( $\log 10$ transformed). Abbreviations are as follows: 'EE' equally expressed; 'ASE' Allele Specific Expression with at least two-fold change.

1237 Figure 8 Conserved developmental expression in CM fungi. a) Schematic representation of sexual development in the Basidiomycota. $\mathbf{b})$ distribution of genes and their developmental expression across the nine species. Dark and light green refers to genes with developmental regulation at fold change $>4$ and 2, respectively, whereas white and black denote non-developmentally expressed and missing genes, respectively. Dendrogram was inferred in a hierarchical clustering based on expression categories. Gene Ontology (GO) enrichment for c) CM-specific and d) Shared orthogroups. KS means the p-value of Kolmogorov-Smirnov test implemented in the R package 'topGO'. On panels c and d, cutoff lines (dashed line) are drawn at enrichment scores corresponding to $\mathrm{p}=0.05, \mathrm{p}=0.01$ and $\mathrm{p}=0.001$ (from left to right). GO terms are ordered by Kolmogorov-Smirnov p-values. See also Supplementary File 5/a-b for GO enrichment details. 

ancestors of lineages in which the first complex structures emerged (see also Figure 1). Y-axis represents relative gene age (for definition of gene ages see Dryad: Figure D1). X-axis displays the odds ratio of the enrichment of developmentally expressed orthogroups relative to all orthogroups in a given age category based on Fisher's exact test. If the odds ratio exceeds 1 (red dotted line) developmentally expressed orthogroups are overrepresented in that gene age. Significant (FDR p< 0.05 ) overrepresentation is indicated by blue. The size of circles corresponds to the FDR corrected pvalue of Fisher's exact test.

Figure 10: Pipeline of RNA editing and Allele Specific Expression annotation. Names of scripts available in Dryad (doi:10.5061/dryad.5qfttdz5m) were displayed next to process-boxes. Abbreviations: VRS Variant Read Support; RS Read Support; RVF Relative Variant Frequency.

\section{Legends for Figure Supplements}

Figure 1-figure supplement 1 Sampled developmental stages and tissue types during fruiting body formation of Pleurotus ostreatus. a) 'VM' vegetative mycelium b) 'P1' stage 1 primordium; c) 'P3' stage 3 primordium; d) 'YFB' young fruiting body; e) 'FB' fruiting body; f) dashed areas and black arrows show different tissue types ' $S$ ' stipe, 'C' cap trama, ' $D$ ' dedifferentiated tissue of cap trama, 'L' lamellae, 'V' cuticle. Bars represent $1 \mathrm{~mm}$ in a and b, $5 \mathrm{~mm}$ in $\mathrm{c}$ and $\mathrm{d}$ while $1 \mathrm{~cm}$ in e-g.

1267 Figure 1-figure supplement 2 Sampled developmental stages during fruiting body formation of 1268 Pterula gracilis. a) 'VM' vegetative mycelium; b) 'P' primordium; c) 'YFB' young fruiting body; e) 'FB' fruiting body; Bars represent $1 \mathrm{~mm}$ in b-c $5 \mathrm{~mm}$ in $\mathrm{d}$ while $1 \mathrm{~cm}$ in a.

Figure 1-figure supplement 3 Multidimensional scaling (MDS) plot based on the expression of genes in a) Pleurotus ostreatus and b) Pterula gracilis. Normalized transcriptome data accurately identified sample groups with biological replicates being tightly positioned together. Abbreviations as follows: 'VM' vegetative mycelium; 'P1' stage 1 primordium; 'P3' stage3 primordium; 'YFB' young fruiting body, 'FB' fruiting body; 'H' cap (entire); 'C' cap trama (only the inner part, without Lamellae, or skin); 'L' lamellae; 'S' stipe; 'V' cuticle; 'D' dedifferentiated tissue of cap.

Figure 1-figure supplement 4 The distribution of developmentally expressed genes in each species. Abbreviations: NDR not developmentally expressed; >DR2 Developmentally expressed with at least 2 Fold Change; >DR4 Developmentally expressed with at least 4 Fold Change.

Figure 4-figure supplement 1 Principal Component Analysis based on AS ratio. Replicates of stages clustered together and therefore Allele Specific Expression showed a development- and tissuespecific pattern. Abbreviations as follows: 'VM' vegetative mycelium; 'P1' stage 1 primordium; 'P3' stage3 primordium; 'YFB' young fruiting body, 'FB' fruiting body; ' $\mathrm{H}$ ' cap (entire); 'C' cap trama (only the inner part, without Lamellae, or skin); 'L' lamellae; 'S' stipe; 'V' cuticle; 'D' dedifferentiated tissue of cap.

Figure 4-figure supplement 2 Allele specific expression was not biased toward one nucleus or chromosome(s). a) The Nuclear Read Ratio (NRR, the contribution of nuclei to the total expression) across stages and tissues. b) Chromosomal Read Ratio (CRR, the contribution of nuclei to the expression of scaffolds) across stages and tissues. Red dots represent the biological replicates separately. A slight dominance of PC9 was observable (mean NRR across samples 0.97; max difference $12.5 \%$ Values smaller than 1 mean the dominance of the PC9 nucleus over PC15 while the opposite marks the dominance of PC15. Abbreviations as follows: 'VM' vegetative mycelium; 'P1' stage 1 primordium; 'P3' stage3 primordium; 'YFB' young fruiting body, 'FB' fruiting body; ' $\mathrm{H}$ ' cap 
(entire); 'C' cap trama (only the inner part, without Lamellae, or skin); 'L' lamellae; 'S' stipe; 'V' cuticle; ' $\mathrm{D}$ ' dedifferentiated tissue of cap.

Figure 6-figure supplement 1 Comparison of genes with ASE or EE. a) Maximum likelihood amino acid distances between PC15 and PC9 proteins (model=WAG). b) dN/dS distribution for the three gene groups under the M0 model in CodeML. Abbreviations: equally expressed genes EE, genes with allele specific expression at least in one stage with two- (S2) or four-fold change (S4). Lines and p-values $(<1 \mathrm{e}-3)$ represent the pairwise comparison of Nemenyi post-hoc test of the Kruskalof Kruskal Wallis test.

Figure 7-figure supplement 1 Distribution of genes across gene ages ( 1 representing oldest and 20 the youngest), broken down by ASE, developmental regulation, and duplication in Pleurotus ostreatus. Bars represent proportions of gene numbers relative to the total gene number of a group (equal, S2 or S4). Abbreviations: equal - equally expressed genes; S2 - ASE with two-fold change; S4 -ASE with four-fold change; NDR - non-developmentally expressed gene DR - developmentally expressed gene.

Figure 8-figure supplement 1 Proportion of Developmentally expressed (DR > 4 FC) genes in different gene ages. P-values and odds ratio above bars comes from Fisher's exact test, added only when significant $(\mathrm{p}<0.05)$. Gene age was calculated based on orthogroup membership (the presence of clear orthologs across species), and e.g. nodes numbered from 1-20 from the root of the tree to the tip harboring P. ostreatus. (see Figure 1)

\section{Figure 8-figure supplement 1 Functional categories across the conserved developmental} orthogroups. Number of conserved orthogroups in different functional categories

Figure 8-figure supplement 2 Expression of meiotic genes in the nine species. Abbreviations as follows: 'VM' vegetative mycelium; 'P1' stage 1 primordium; 'P3' stage3 primordium; 'YFB' young fruiting body, 'FB' fruiting body; ' $\mathrm{H}$ ' cap (entire); 'C' cap trama (only the inner part, without Lamellae, or skin); 'L' lamellae; 'S' stipe; 'V' cuticle; ' $D$ ' dedifferentiated tissue of cap 'A' annulus. For stage details see Supplementary File 4/c.

\section{Figure 8-figure supplement 3 Expression of ribosomal proteins in the nine species.}

Abbreviations as follows: 'VM' vegetative mycelium; 'P1' stage 1 primordium; 'P3' stage3 primordium; 'YFB' young fruiting body, 'FB' fruiting body; ' $\mathrm{H}$ ' cap (entire); ' $\mathrm{C}$ ' cap trama (only the inner part, without Lamellae, or skin); 'L' lamellae; 'S' stipe; ' $V$ ' cuticle; ' $D$ ' dedifferentiated tissue of cap 'A' annulus. For stage details see Supplementary File 4/c. 


\title{
$1 \quad$ Appendix 1
}

\section{Gene age predicts the transcriptional landscape of sexual 3 morphogenesis in multicellular fungi}

\author{
Zsolt Merényi ${ }^{1}$, Máté Virágh ${ }^{1}$, Emile Gluck-Thaler ${ }^{2}$, Jason C. Slot ${ }^{3}$, Brigitta Kiss ${ }^{1}$, Torda \\ Varga $^{1}$, András Geösel ${ }^{4}$, Botond Hegedüs ${ }^{1}$, Balázs Bálint ${ }^{1}$, László G. Nagy ${ }^{1,5, *}$
}

\section{Identification of gene clusters}

Genes contributing to the same phenotype can occasionally be found clustered together in fungal genomes. Because such clustering is predicted to both facilitate gene coexpression and maintain linkage over long periods of evolutionary time, we tested whether any developmentally expressed genes were physically clustered together more often than expected by chance, and whether any of these clusters were conserved across species. Furthermore, since many secondary metabolites encoded by gene clusters play a role in development, we tested if any of these developmentally expressed gene clusters might overlap with predicted biosynthetic gene clusters in eight Basidiomycota species, including $P$. ostreatus and Pt. gracilis (Dryad: Table D2). We first designated all developmentally expressed genes separated by six or less intervening genes as candidate clusters. We then calculated the probability of observing a cluster of that size using a binomial test, based on the expected number of developmentally expressed genes that would be found in the same sized genomic window were developmentally expressed genes randomly distributed across the genome. Clusters with a probability of observation $<0.01$ were designated clustering 'hotspots'. We checked hotspots for overlap with predicted biosynthetic gene clusters using de novo antiSMASH v5 annotations (Medema et al., 2011). Conservation of hotspots between different fungal species was assessed by BLASTp (Altschul et al., 1990) using two metrics: percent gene content similarity, which is the number of genes in the query hotspot that are also clustered together in the target genome; and percent FDBR similarity, which is the number of developmentally expressed genes in the query hotspot that are also developmentally expressed and clustered together in the target genome.

\section{Developmental gene clusters are not conserved}

Having established that the developmental hourglass may not apply to fungi, we next asked if we can find evidence in fungi for the physical clustering of developmental genes in the genome, a characteristic of several key genes involved in animal pattern formation. Certain fungal genes, such as those encoding secondary metabolite biosynthetic pathways are well known to cluster physically (Keller, 2018), whereas similar traits for developmental genes have not yet been investigated. We found evidence for the occasional grouping of developmentally expressed genes into hotspots in the genomes (see Methods) (Appendix 1figure 1, Dryad: Table D2). Altogether 153 hotspots were detected in eight genomes; however, most of these were species-specific and not conserved across species (e.g. the luciferase cluster in the bioluminescent $A$. ostoyae, Ke et al., 2020b). Surprisingly, most hotspots did not overlap with predicted biosynthetic gene clusters (Appendix 1-figure 2). 
The presence of hotspots but the lack of conservation suggests that these developmental gene clusters may be linked to species-specific developmental traits.

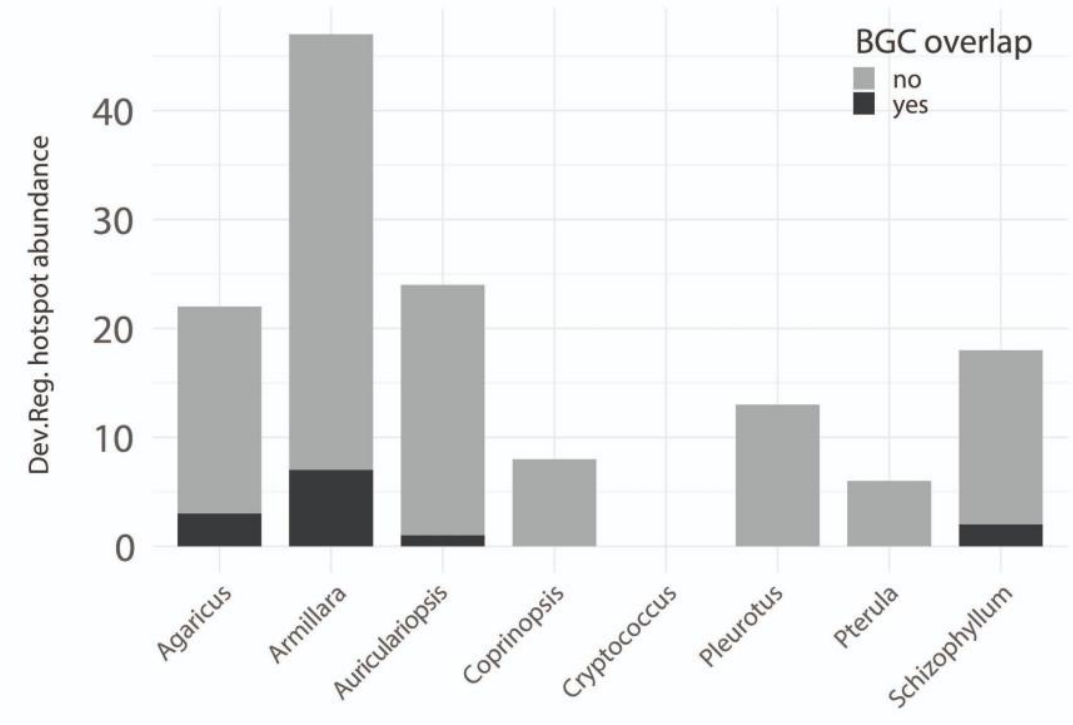

45 Appendix 1 -figure 1 Developmentally expressed genes occasionally cluster together in genomic 'hotspots'. A bar chart summarizing the number of hotspots detected per genome (total $=153$ ), and the degree of overlap between hotspots and predicted biosynthetic gene 48 clusters (BGCs).

a

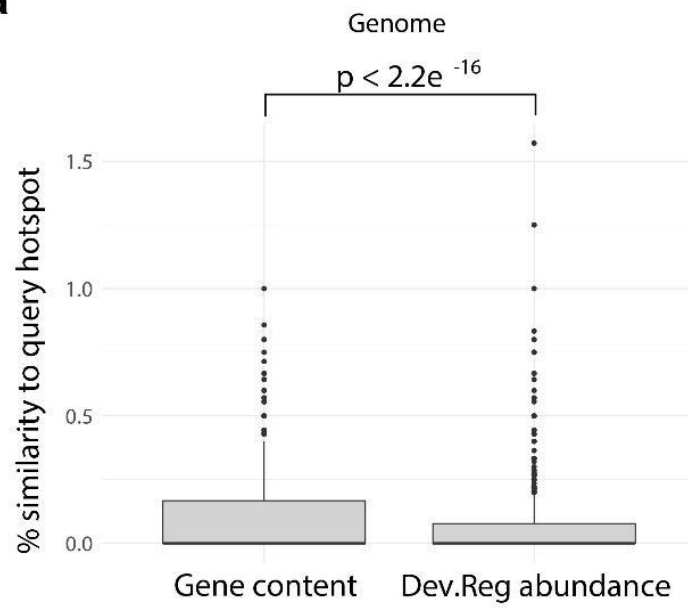

b

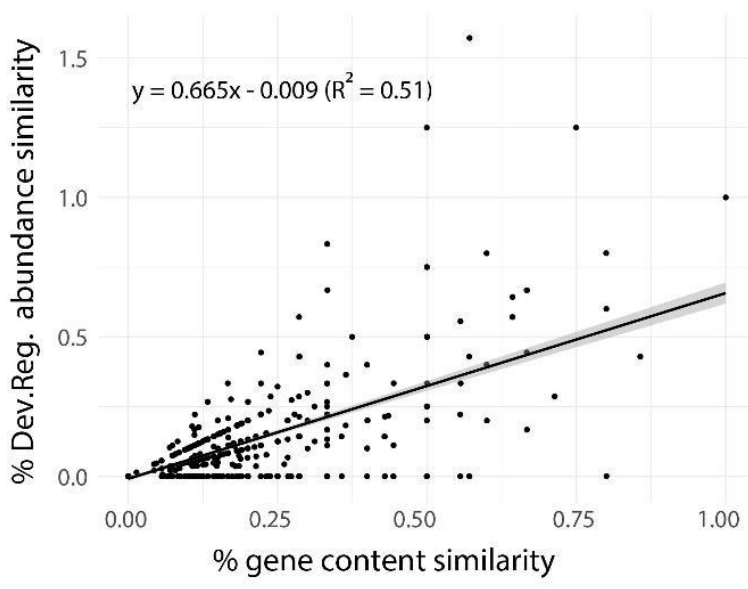

49

50

51

52

53

54

55

56

57

58

\section{Appendix 1-figure 2 Developmentally expressed genes occasionally cluster together in} genomic 'hotspots' b) A box-and-whisker plot summarizing the distribution of $\%$ gene content conservation and the distribution of \% Dev.Reg. abundance conservation of all 153 hotspots when searched for in genomes other than the one in which they are found.

Significance between distributions determined by the Wilcoxon Rank Sum test. c) Scatterplot and linear regression describing relationship between the $\%$ gene content conservation and \% Dev.Reg. abundance conservation of each of the 153 hotspots when searched for in genomes other than the one in which they are found (number of observations $=153$ hotspot queries $\times 8$ target genomes). \% Dev.Reg. abundance conservation may exceed 100\% if more Dev.Reg. 
59 genes are found in target regions as compared with query hotspot. Shaded region around the 60 fitted regression line represents that $95 \%$ confidence interval.

61

62

63

64

65

66

67 
1

2

3

4

5

6

7

8

9

10

11

12

13

14

15

16

17

18

19

20

21

22

23

24

25

26

27

28

29

30

31

32

33

\title{
Appendix 2
}

\section{Gene age predicts the transcriptional landscape of sexual morphogenesis in multicellular fungi}

\author{
Zsolt Merényi ${ }^{1}$, Máté Virágh ${ }^{1}$, Emile Gluck-Thaler ${ }^{2}$, Jason C. Slot ${ }^{3}$, Brigitta Kiss ${ }^{1}$, Torda \\ Varga ${ }^{1}$, András Geösel ${ }^{4}$, Botond Hegedüs ${ }^{1}$, Balázs Bálint ${ }^{1}$, László G. Nagy ${ }^{1,5, *}$
}

\section{Identification of Natural Antisense Transcripts}

Natural antisense transcripts (NAT) were defined as de novo assembled transcripts located antisense to a gene $>200$ nucleotide (nt) long, not showing similarity to structural RNA species, not overlapping with UTRs of neighbouring genes, and showing an expression above a given cut-off (Appendix 2-figure 1). For de novo transcript assembly, quality filtered reads were first mapped to the reference genome using STAR_2.6.1a_08-27 (Veeneman et al., 2015). After identifying splice sites, a second mapping was performed. StringTie version 2.0.3 (Pertea et al., 2015) was used to generate a genome-guided de novo transcriptome assembly and annotation (NATextractor.R). Transcripts shorter than $200 \mathrm{nt}$ or supported by $<5$ reads in a single sample were excluded. Output GTF files from each sample were merged, compared to the reference annotation with gffcompare v0.11.2 (Pertea and Pertea, 2020) and transcripts with exonic overlap on the opposite strand (i.e. antisense; class_code $\mathrm{x}$ ) were retained. To exclude transcripts mapped to repeats, RepeatModeler v2.0 (Flynn et al., 2020) was used to identify repeat regions of genomes. Conserved structural RNA transcripts (tRNAs, U2 spliceosome, ribosomal RNAs, Hammerhead ribozymes) were identified with Infernal 1.1.3 (Nawrocki and Eddy, 2013) based on the Rfam database (Kalvari et al., 2021) and were removed. Fungal genomes are densely packed with genes, raising the possibility that a detected transcript is actually the UTR region of the closest gene (Rhind et al., 2011). To avoid identifying UTR regions as NATs, candidate NATs showing a strongly correlated expression (Pearson's P-value < 0.05 ) and located <500 nt from the closest coding genes on the same strand were discarded from further analysis. Coding potential of NATs were characterized based on the default cut-off of the Coding Potential Calculator CPC2 (Kang et al., 2017a).

Expression level of NATs was quantified with the FeatureCounts R package (Liao et al., 2014; NAT_FeatureCounts.R) based on the union of the exons per transcript. FPKM calculations were carried out as mentioned above, only transcripts with at least five mapped reads in at least three samples were retained. Developmental regulation of potential NATs was calculated as for genes. To assess conservation of NATs we mapped the transcripts on the genomes of the 109 species with minimap2 v 2.17 (options: -k15 -w5 --splice -g2000 G200k -A1 -B1 -O1,20 -E1,0 -C9 -z500 -ub --junc-bonus=9 --splice-flank=yes) (Li, 2018).

Appendix 2-figure 1 Pipeline of Natural Antisense Transcripts. Numbers represent the retained transcripts in each filtering step. 


\begin{tabular}{|c|c|c|}
\hline P. ostreatus & & P. gracilis \\
\hline 7607 & In repeat masked region & 3011 \\
\hline \multicolumn{3}{|c|}{$\sqrt{3}$} \\
\hline 7556 & Non-structural RNA & 3008 \\
\hline \multicolumn{3}{|c|}{$\sqrt{3}$} \\
\hline 2228 & Minimal expression filter & 777 \\
\hline \multicolumn{3}{|c|}{$\sqrt{3}$} \\
\hline 2086 & UTR filter & 763 \\
\hline \multicolumn{3}{|c|}{$\sqrt{3}$} \\
\hline 2043 & $\begin{array}{c}\text { avg FPKM }>=2 \\
\text { of min one stage/tissue }\end{array}$ & 763 \\
\hline \multicolumn{3}{|c|}{$\sqrt{3}$} \\
\hline 939 & Non-coding & 312 \\
\hline
\end{tabular}

\section{Natural Antisense Transcripts show fast turnover}

42 Natural antisense transcripts (NATs) are abundantly transcribed from fungal genomes and 43 can include important regulatory RNAs that influence, among others, sexual development 44 (Donaldson et al., 2017; Donaldson and Saville, 2012; Faghihi and Wahlestedt, 2009; Kim et 45 al., 2018a). We analysed NATs in P. ostreatus and Pt. gracilis based on strand-specific 46 RNA-seq data, and we identified 2,043 and 763 de novo transcripts as NATs (Appendix 2 47 figure 1), corresponding to $17.6 \%$ and $6.3 \%$ of protein coding genes, respectively. Lengths, 48 exon structures and coding potentials of the assembled NATs were similar to those in earlier 49 reports (Borgognone et al., 2019; Kim et al., 2018a; Wang et al., 2019) (Appendix 2-figure 50 1-2).

Appendix 2-figure 2 Length (a/b) and exon number (c/d) distribution of natural antisense 53 transcripts in Pleurotus ostreatus $(\mathrm{a} / \mathrm{c})$ and Pterula gracilis $(\mathrm{b} / \mathrm{d})$. NATs were divided into 54 putatively coding and noncoding categories using the default settings of CPC2 (Kang et al., 55 2017b) 

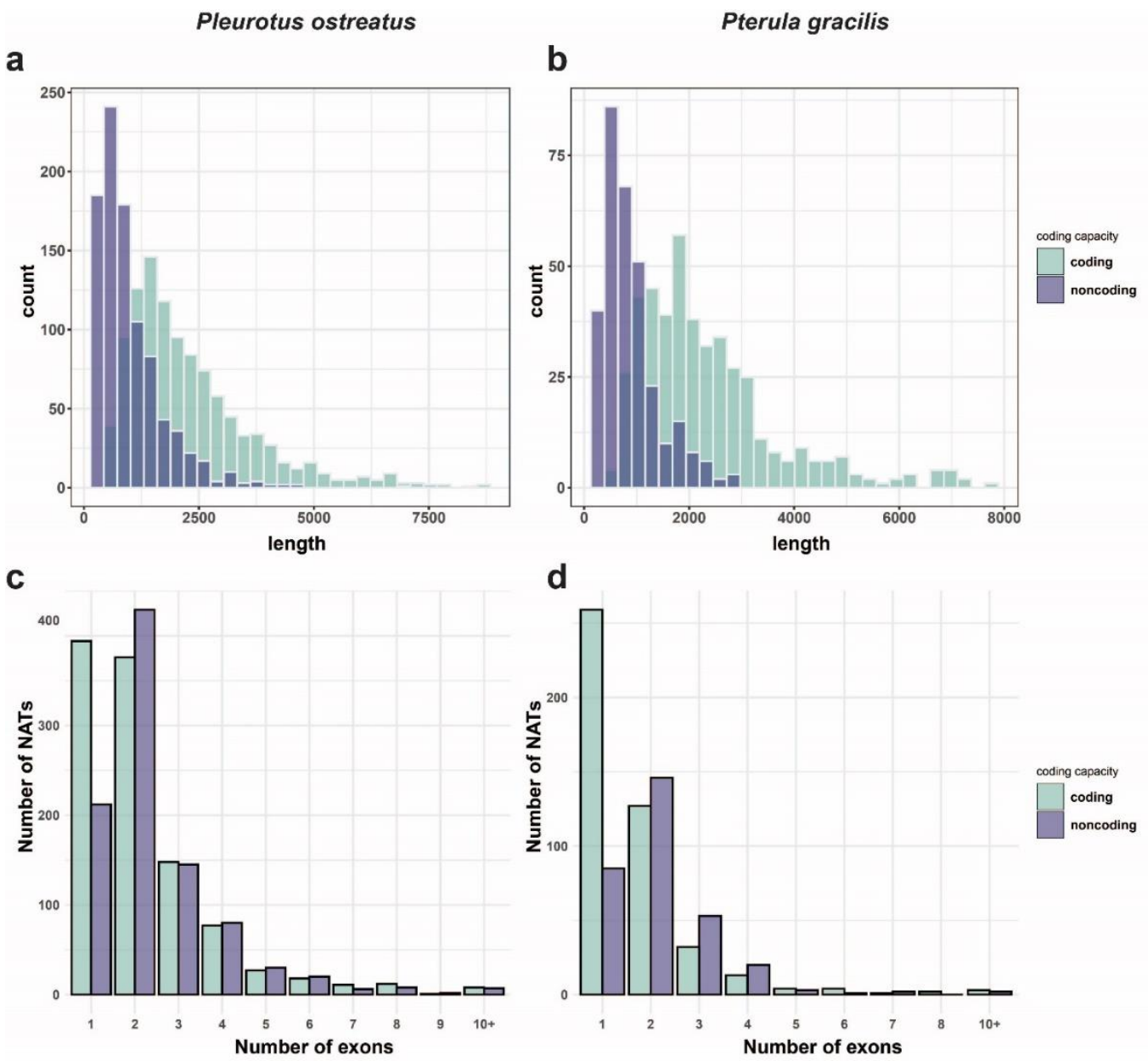

NATs showed developmentally dynamic expressions with NAT expression patterns reflecting stage and tissue identity, with tight grouping of biological replicates (Appendix 2-figure 3). Similarly to the pattern of MDS for total gene expression, FBC and FBS samples and the early stages (P1,P3 and YFB) were close to each other. As many as 1173 (57.4\%) and $126(16.5 \%)$ NATs of P. ostreatus and Pt. gracilis were developmentally expressed, respectively. These may expand the space of developmentally expressed transcripts in fruiting bodies, thus, irrespective of their exact mechanism of action, can contribute to CM. In P. ostreatus we identified 166 NATs $(8.1 \%)$ that showed at least 2-fold higher expression in all fruiting body stages than in vegetative mycelium, comparatively more than predicted coding genes $(4.8 \%)$. Such transcripts may regulate the transition from simple multicellularity in VM to complex multicellularity in FB, one of the most significant transcriptomic reprogramming events in the fungal life cycle (Krizsán et al., 2019). Kim et al. (2018) found a considerable proportion (21.3\%) of lncRNA (which overlap only partially with NATs) that might have a role in sexual development of Fusarium graminearum. Nevertheless, only $39.1 \%$ of $P$. ostreatus and $4.1 \%$ of Pt. gracilis of the NAT-possessing genes show developmental regulation with at least 4 fold change.

Appendix 2-figure 3 Principal Component Analysis (PCA) plot based on the expression of Natural Antisense Transcripts detected in a) Pleurotus ostreatus and b) Pterula gracilis. Abbreviations as follows: 'VM' vegetative mycelium; 'P1' stage 1 primordium; 'P3' stage3 primordium; 'YFB' young fruiting body, 'FB' fruiting body; ' $\mathrm{H}$ ' cap (entire); 'C' cap trama 
(only the inner part, without Lamellae, or skin); 'L' lamellae; 'S' stipe; 'V' cuticle; 'D' dedifferentiated tissue of cap.

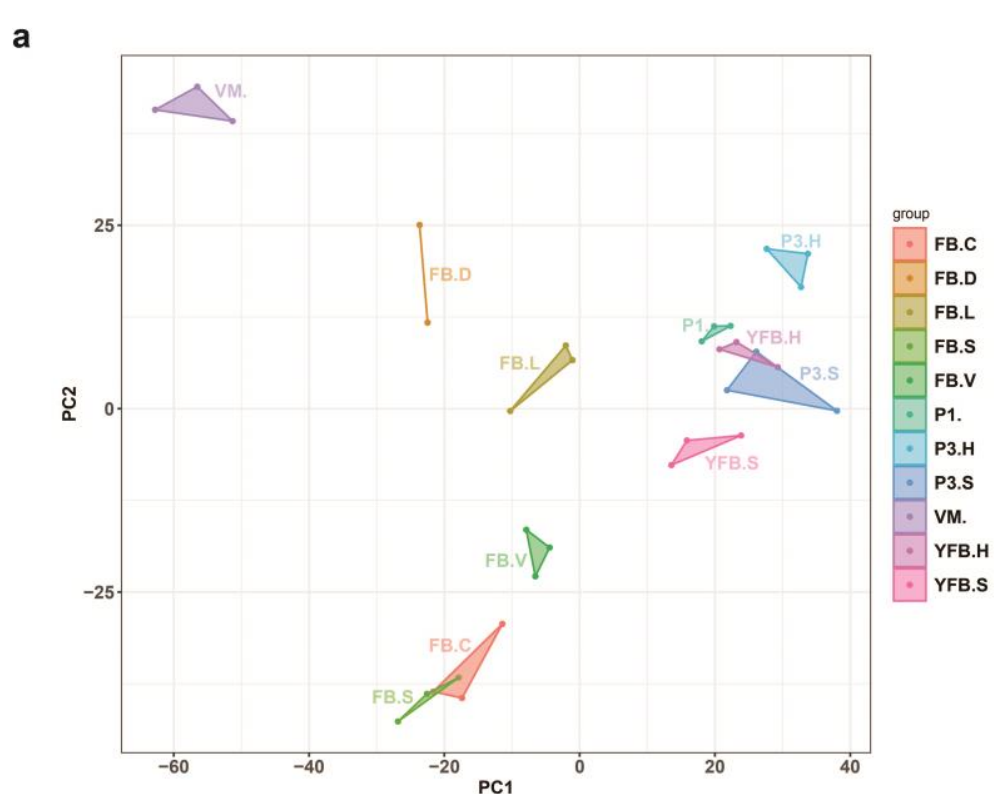

b

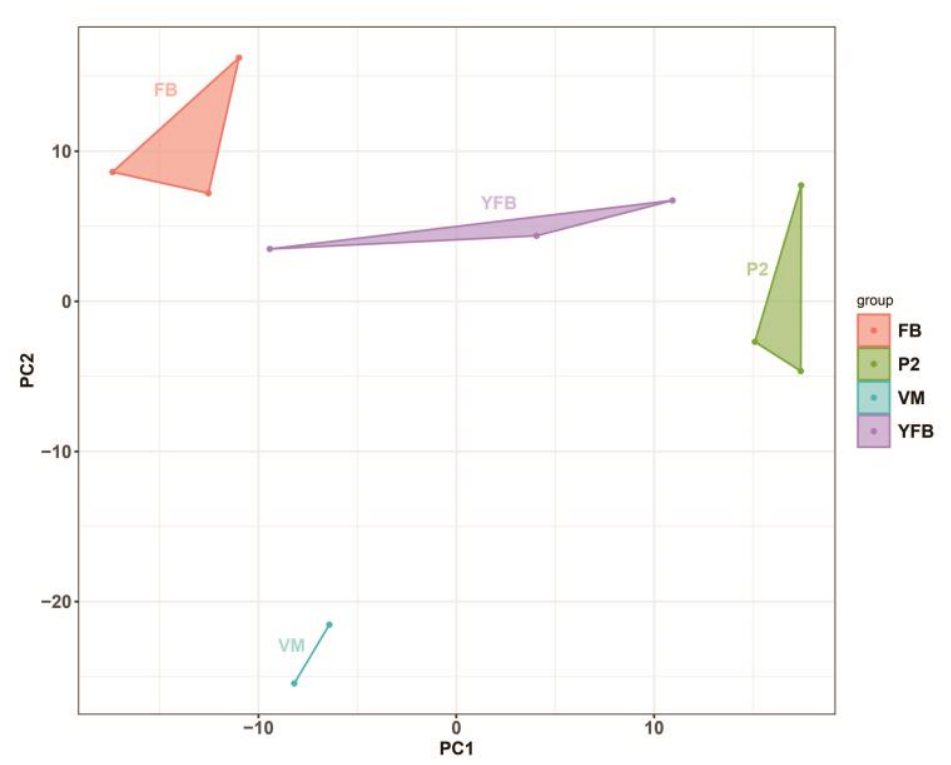

The detected NATs displayed low sequence conservation. Of the 2,043 NATs of $P$. ostreatus, 1,815 (89\%) showed homology in the closest sequenced species (P. eryngii) and only 177 (8.7\%) in other species (Appendix 2-figure 4). In Pt. gracilis only $15(2.0 \%)$ NATs showed homology in other species (Appendix 2-figure 5). We find that low overlap with gene exons can explain the lack of sequence conservation in NATs. In P. ostreatus, only 596 of the 2,043 NATs (29\%) showed at least $75 \%$ total exon-exon overlap. This suggests that, even if located in conserved genes, NATs mostly overlap with introns or intergenic regions, which may allow rapid sequence turnover, as reported in vertebrates (Kapusta and Feschotte, 2014). We also failed to detect conservation of sense gene identity: of the 6,232 co-orthologous genes between $P$. ostreatus and Pt. gracilis, only 70 showed evidence for NAT in both species. All of these observations imply low conservation of NATs at the sequence level, consistent with the view that NAT homology is detectable only among closely related species (Donaldson and Saville, 2013; Rhind et al., 2011). 
97 Appendix 2-figure 4 Conservation of sense genes and their antisense transcripts (NAT) of 98 Pleurotus ostreatus across 109 species. a) similarity of proteins of sense transcripts - having 99 antisense transcripts - measured with - $\log 10$ (e-value) from MMSeqs search against the 109 100 species dataset b) mapping score of antisense transcripts based on Minimap2. Warmer colour 101 represents a higher similarity according to the scales. Black square denotes $P$. ostreatus.

102 Rows represents the species while columns represent the antisense query transcripts (b) or 103 proteins from sense transcripts (a). For a larger species tree see Fig.1.
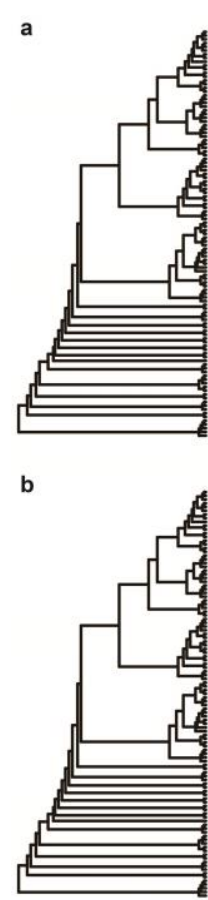
Appendix 2-figure 5 Conservation of sense genes and their antisense transcripts (NAT) of Pterula gracilis across 109 species. a) similarity of proteins of sense transcripts - having antisense transcripts - measured with - $\log 10$ (e-value) from MMSeqs search against the 109 species dataset b) mapping score of antisense transcripts based on Minimap2. Warmer colour represents a higher similarity according to the scales. Black square denotes $P$. gracilis. Rows represents the species while columns represent the antisense query transcripts (b) or proteins from sense transcripts (a). For a larger species tree see Fig.1.
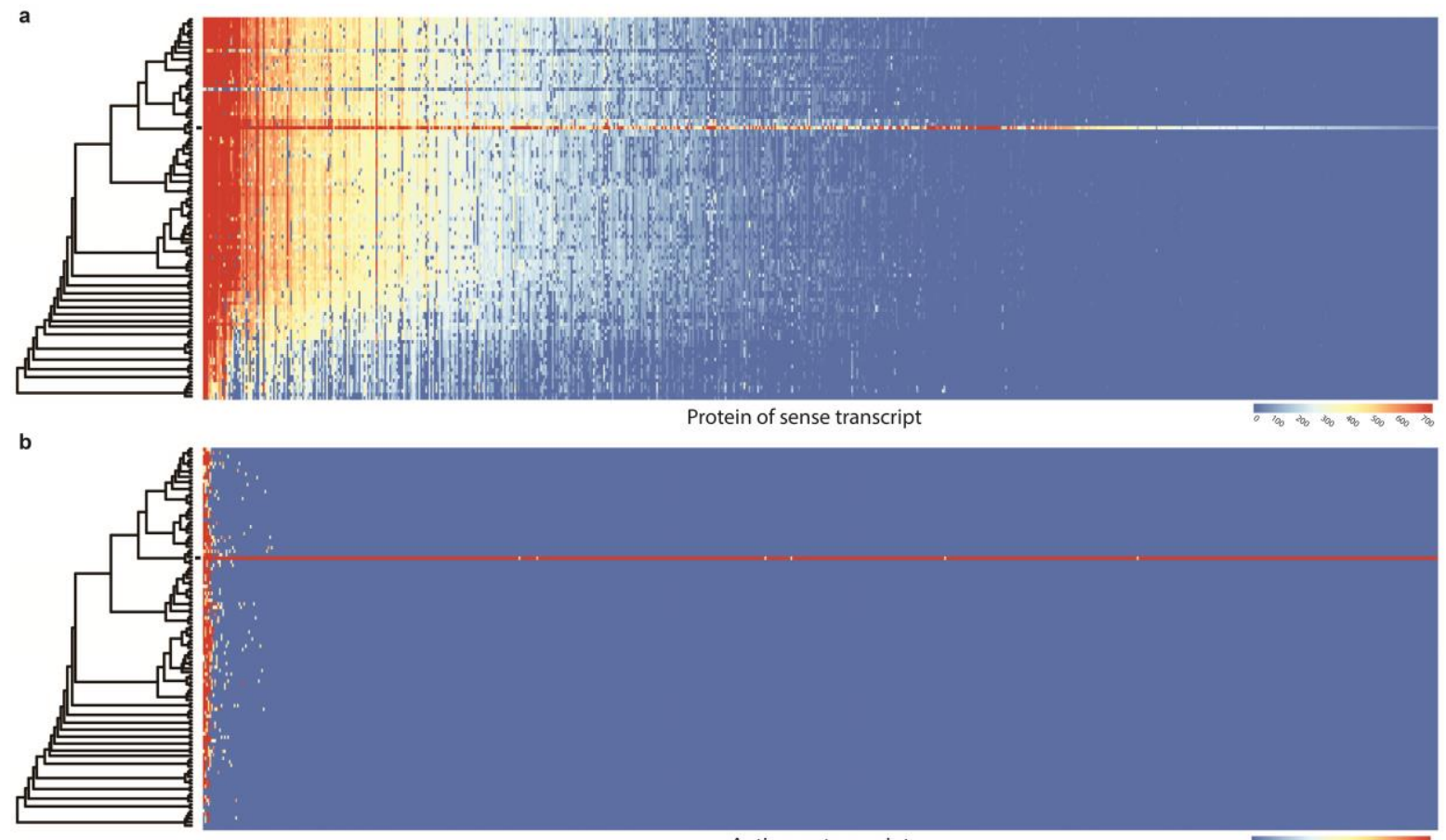

Protein of sense transcript

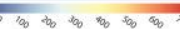

In $P$. ostreatus 263 NATs (12.8\%) showed significant positive (Pearson $\mathrm{r}>0.7, \mathrm{P}<$ 0.05 , Appendix 2 -figure 6-7 $\mathrm{P}<0.01$ ) while 33 showed significant negative expression correlation (Pearson $r<-0.7, \mathrm{P}<0.05$, Appendix 2-figure 8) with their sense genes. An enrichment of positive over negative correlation between sense and antisense transcript pairs was noted previously in Fusarium and in Ganoderma lucidum (Kim et al., 2018b; Shao et al., 2017). Positively correlating pairs may be co-regulated via chromatin accessibility, or be stabilized via dsRNA formation (Donaldson and Saville, 2013), whereas negative correlation can be explained by transcriptional interference, antisense mediated chromatin remodelling or RNA masking (reviewed in Donaldson \& Saville, 2012), all of which may be relevant to CM, but further research is needed to clarify their roles.

Together, the developmentally relevant expression, the lack of functional clues (Appendix 2-figure 9) and the low conservation of NATs suggests that antisense transcription is a fast-evolving component of CM transcriptomes with potential functions in modulating gene expression. Nevertheless, as above, non-adaptive explanations should not be ruled out, such as some NATs being transcriptional noise or leakage (Dahary et al., 2005; Lloréns-Rico et al., 2016). 
135 Appendix 2 -figure 6 Expression pattern of 263 sense transcripts and their antisense 136 transcripts which showed significant positive correlation (Pearson $r \geq 0.7, p<0.05$ ) in 137 Pleurotus ostreatus. Corresponding lines of the heatmaps contain sense and antisense 138 transcript pairs. Abbreviations as follows: 'VM' vegetative mycelium; 'P1' stage 1 139 primordium; 'P3' stage3 primordium; 'YFB' young fruiting body, 'FB' fruiting body; ' $\mathrm{H}$ ' 140 cap (entire); 'C' cap trama (only the inner part, without Lamellae, or skin); ' $L$ ' lamellae; 'S' 141 stipe; 'V' cuticle; 'D' dedifferentiated tissue of cap.

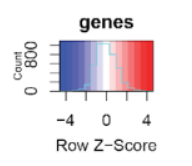

Sense transcript

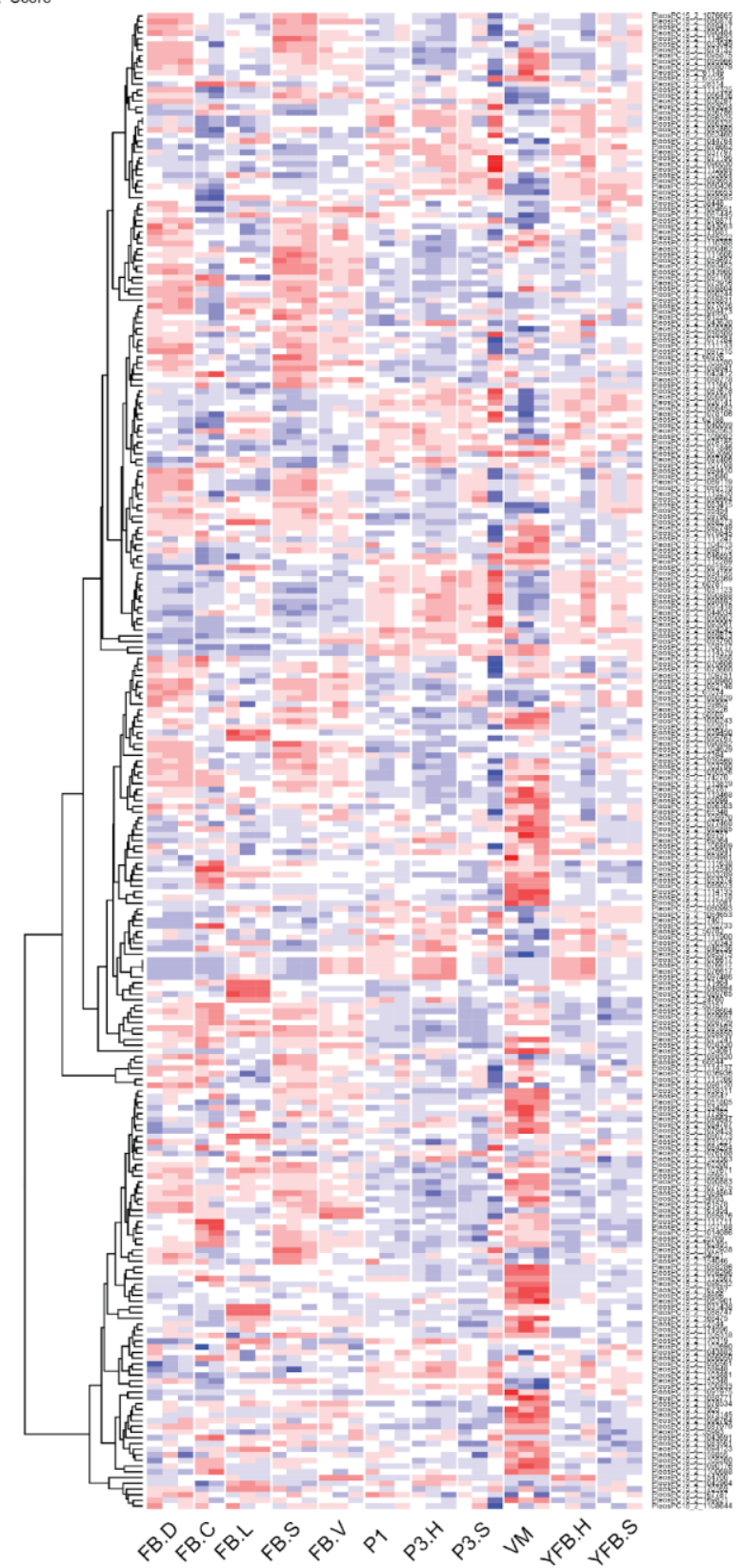

Antisense transcript

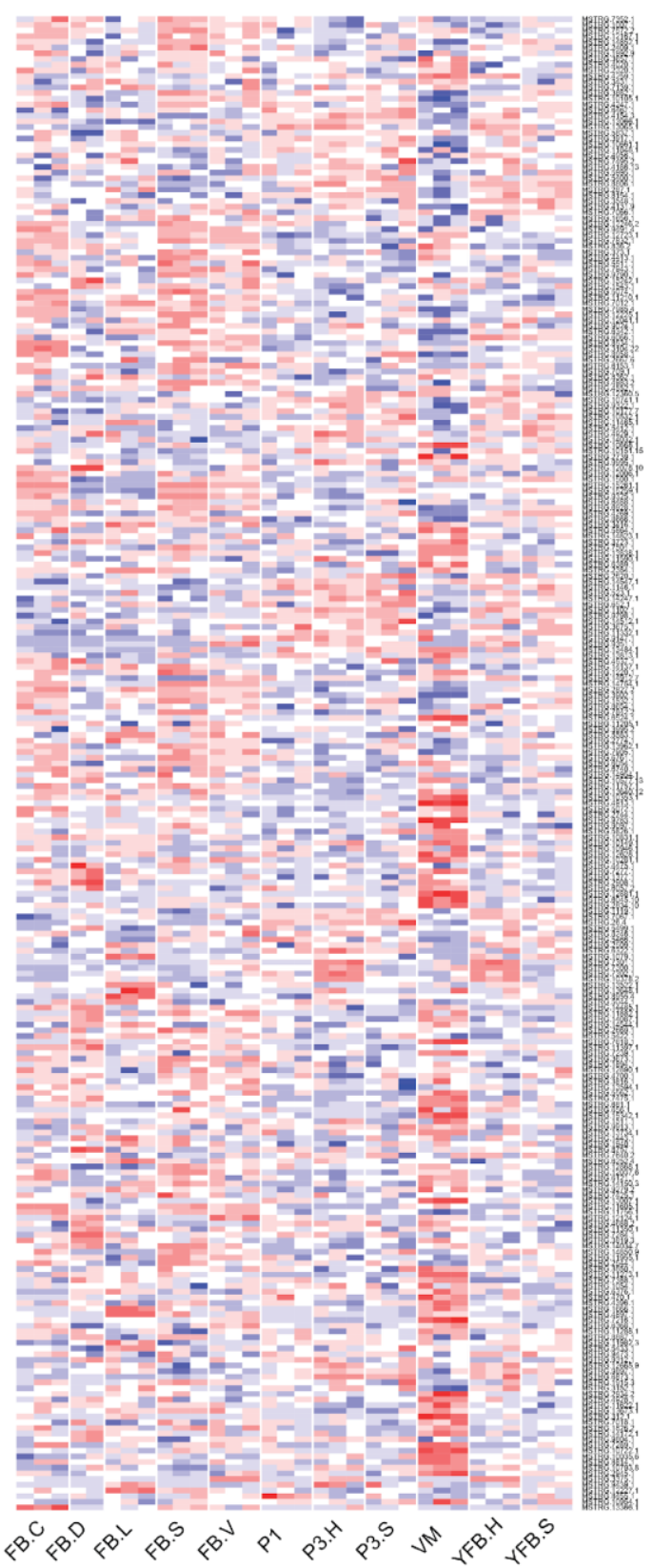


Appendix 2 -figure 7 Permutation test for the number of a) negative $(\mathrm{r}<-0.7, \mathrm{P}<0.05)$ and $\mathrm{b})$ positive $(r>0.7, \mathrm{P}<0.05)$ correlations among the expression of NATs and random genes. Red line represents the observed number of significant correlations.

a
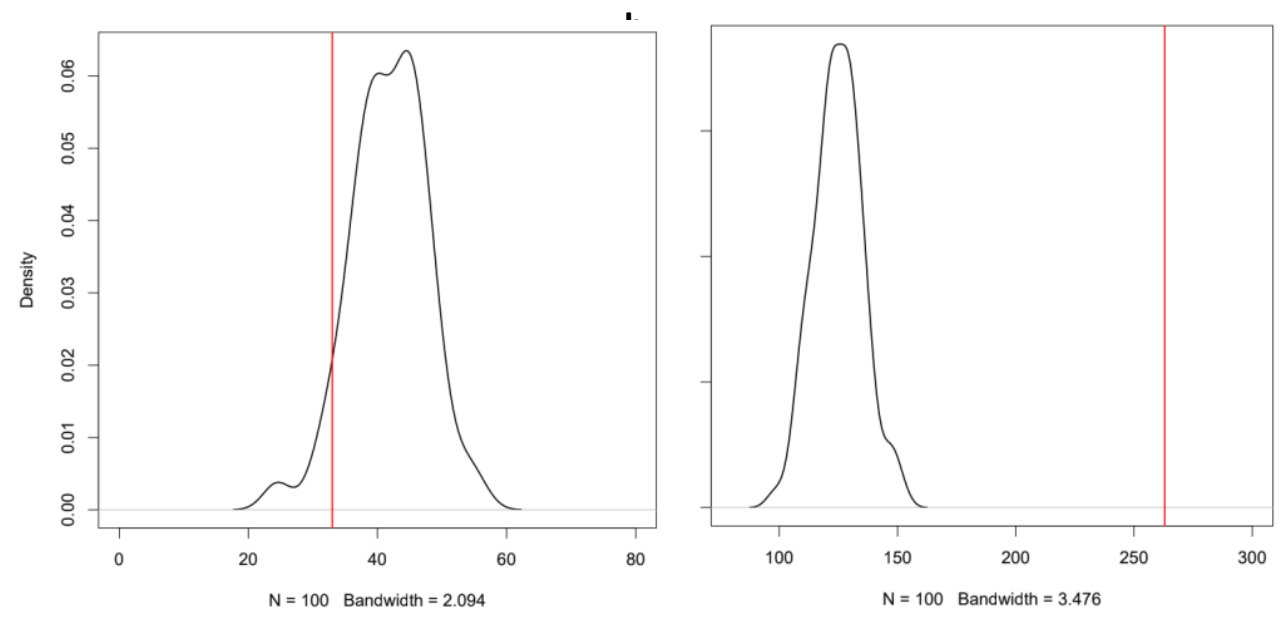

Appendix 2 -figure 8 Expression pattern of 33 sense transcripts and their antisense transcripts which showed significant negative correlation (Pearson $r \leq-0.7 p<0.05$ ) in Pleurotus ostreatus. Corresponding lines of the heatmaps contain sense and antisense transcript pairs. Abbreviations as follows: 'VM' vegetative mycelium; 'P1' stage 1 primordium; 'P3' stage3 primordium; 'YFB' young fruiting body, 'FB' fruiting body; ' $\mathrm{H}$ ' cap (entire); ' $\mathrm{C}$ ' cap trama (only the inner part, without Lamellae, or skin); 'L' lamellae; ' $\mathrm{S}$ ' stipe; ' $\mathrm{V}$ ' cuticle; 'D' dedifferentiated tissue of cap.
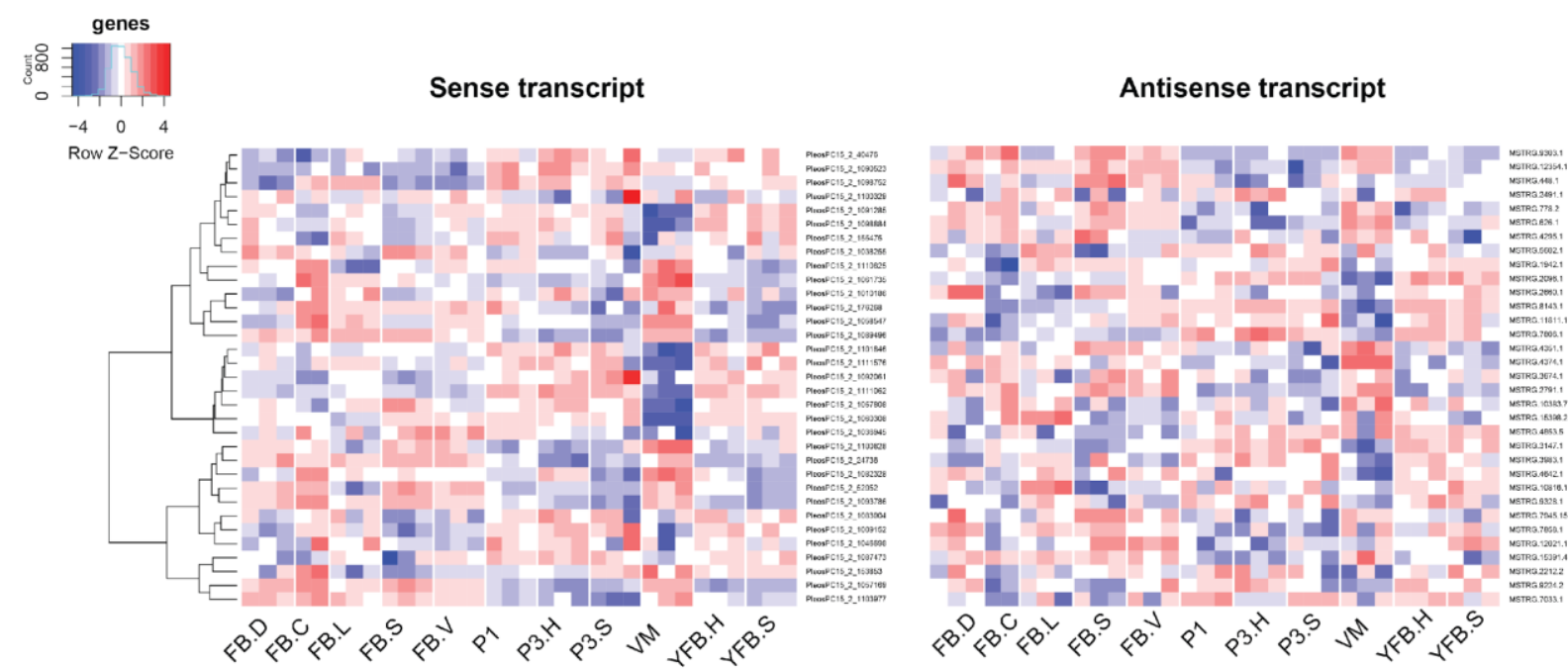
Appendix 2-figure 9: Gene Ontology (GO) enrichment for genes which have Natural Antisense Transcripts a) in Pleurotus ostreatus and b) in Pterula gracilis. KS means the pvalue of Kolmogorov-Smirnov test implemented in the R package 'topGO'. BP: Biological 168 Process; MF: Molecular Function; CC: Cellular component.

a

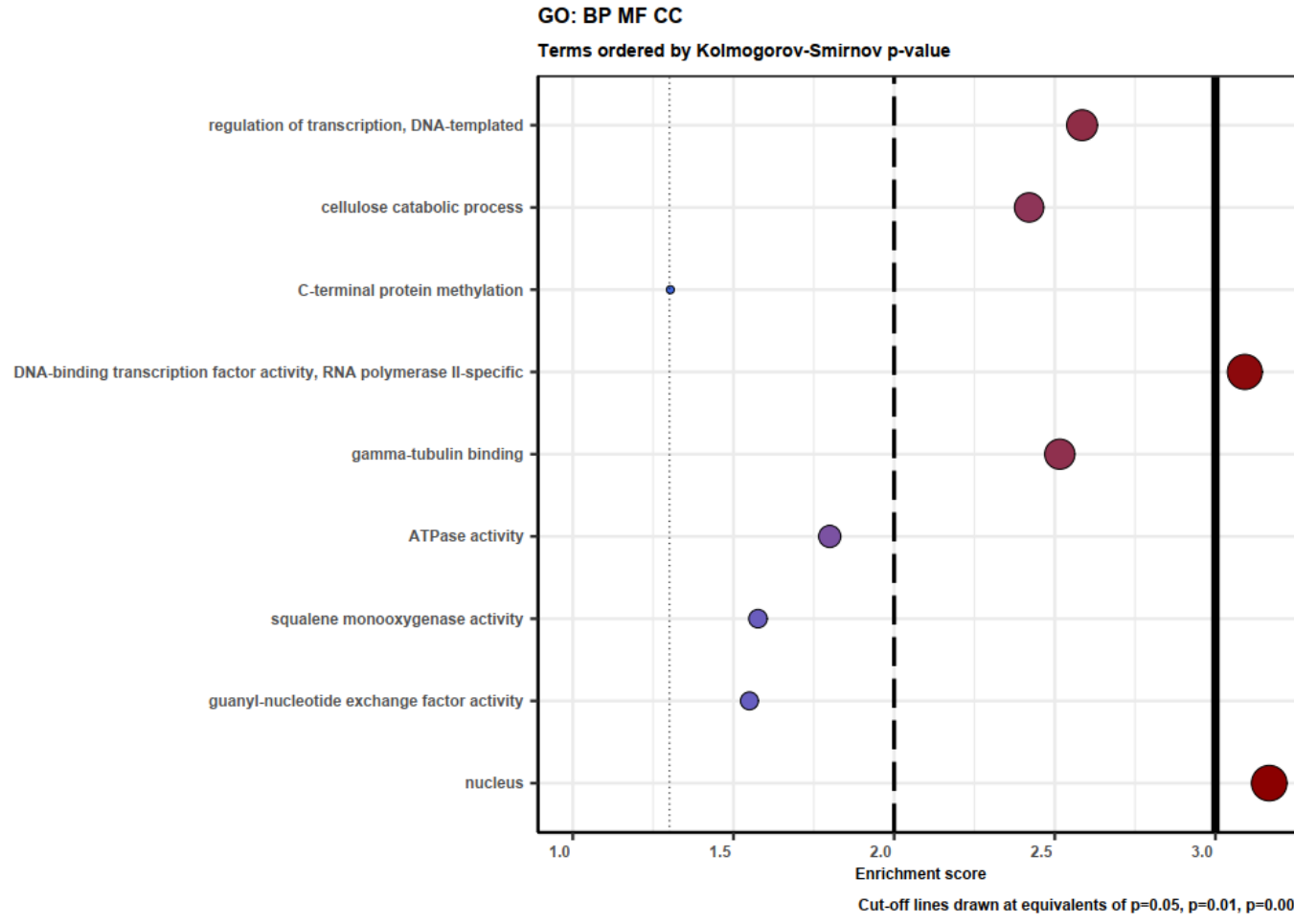

$-\log 10(\mathrm{KS})$

○ 1.5

2.0

2.5

3.0

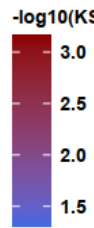

GO: BP MF CC

b

Terms ordered by Kolmogorov-Smirnov p-value

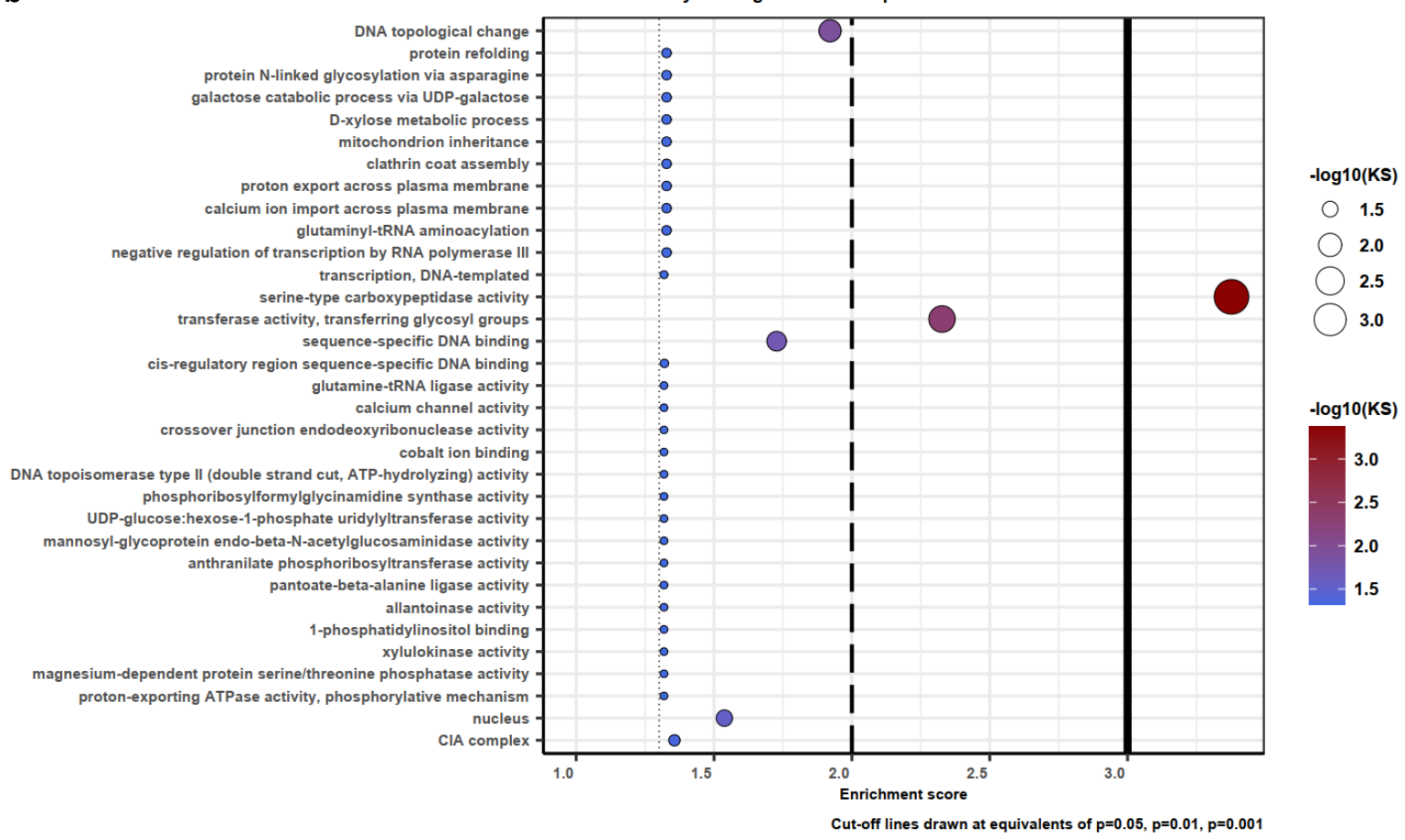


1

2

3

4

5

6

7

8

\title{
Appendix 3
}

\section{Gene age predicts the transcriptional landscape of sexual morphogenesis in multicellular fungi}

\author{
Zsolt Merényi ${ }^{1}$, Máté Virágh ${ }^{1}$, Emile Gluck-Thaler ${ }^{2}$, Jason C. Slot ${ }^{3}$, Brigitta Kiss ${ }^{1}$, Torda \\ Varga ${ }^{1}$, András Geösel ${ }^{4}$, Botond Hegedüs ${ }^{1}$, Balázs Bálint ${ }^{1}$, László G. Nagy ${ }^{1,5, *}$
}

\section{RNA editing pipeline}

In the RNA editing pipeline (main text: Figure 10) we re-called variants for sites with pysamstats 1.0.1 (https://github.com/alimanfoo/pysamstats; min-base quality 30 and max depth to 500,000) that were input to the RNA editing pipeline. We continued the analysis with only those variants which had $>=3$ supporting reads, mapped to both reference genomes and the total read support did not differ more than five times between the two parental mappings, in order to avoid signal coming purely from the differential mapping to the two reference genomes (e.g. erroneous alignment). Further, we removed variants where read coverage was $<10$, a single variant was supported by $<3$ reads, or the proportion of the variant was below $0.1 \%$ in order to reduce the effect of technical errors, but retain editing sites. Because erroneous alignment around splice sites can produce variants indistinguishable from editing events, we discarded variants in which multiple sites with mismatches grouped within $3 \mathrm{nt}$ distance of each other and in which the proportion of gaps exceeded $80 \%$ of the read coverage. After this step we kept only variants which were present in at least two biological replicates. In addition, for a variant to be considered an RNA editing site, it had to be significantly more frequent across all samples (Wilcoxon rank sum test with $p<0.01$ ) than any other nucleotide at that site (except reference). Finally, we considered a site an RNA editing site, if the geometric mean of its frequencies across the three replicates exceeded $1 \%$. Relative to the editing site, -3 upstream and +3 downstream surrounding sequences were extracted with rtracklayer package (Lawrence et al., 2009) and motifs were searched with the seqlogo package (Bembom and Ivanek, 2020).

\section{RNA editing is not abundant in fruiting body transcriptomes}

In the RNA-editing pipeline (main text: Figure 10), 627,093 of the 1,999,221 input variants remained after filtering for extreme low frequency $(<0.1 \%)$. We chose this permissive threshold (as opposed to 1/3/10\% in other protocols (Zhu et al., 2014), to avoid discarding any signal in the early steps. As many as 546,790 sites were located in gene regions, of which 346,105 possibly corresponded to erroneous mapping around splice sites (Appendix 3-figure 1), while 218,685 were retained for further analysis. Surprisingly, only $1.2 \%$ of these $(2,701$ sites $)$ were consistent between at least two of the three biological replicates. After eliminating potential sequencing errors (Wilcoxon signed-rank test, $\mathrm{p}$ value $<0.01$ ), we obtained 1,179 variants. Requiring at least $1 \%$ mean variant frequency in at least 1 stage left 332 potential RNA editing sites, with 6 to 62 in each variant type. (Dryad: 
Table D5). Among these A-to-I and C-to-U transitions were not enriched (Appendix 3-

41 figure 2/a), consistent with previous Basidiomycota studies (Bian et al., 2019; Teichert, 2020). To explore other explanations, we examined what, other than RNA-editing, our remaining variants could potentially correspond to. By examining motifs around the 332 sites, we detected solely an enrichment of adenines 1-2 nucleotides downstream of C-to-A sites (Appendix 3-figure 2/c). However, because 69\% (20 of 29) of these were within +/20 nt from the 3 ' end of the last exon of genes, we think that adenine enrichment corresponds to the polyadenylation sequence. Together, we interpret these results as limited or no evidence for RNA editing in P. ostreatus.

Appendix 3 - figure 1 Examples for variants of different types. In a) and b) erroneous read alignment around splice sites causing variants (red arrows) similar to RNA editing. In c) and d) green arrows represent potential RNA editing sites, while yellow arrows represent allele 53 specific SNPs.

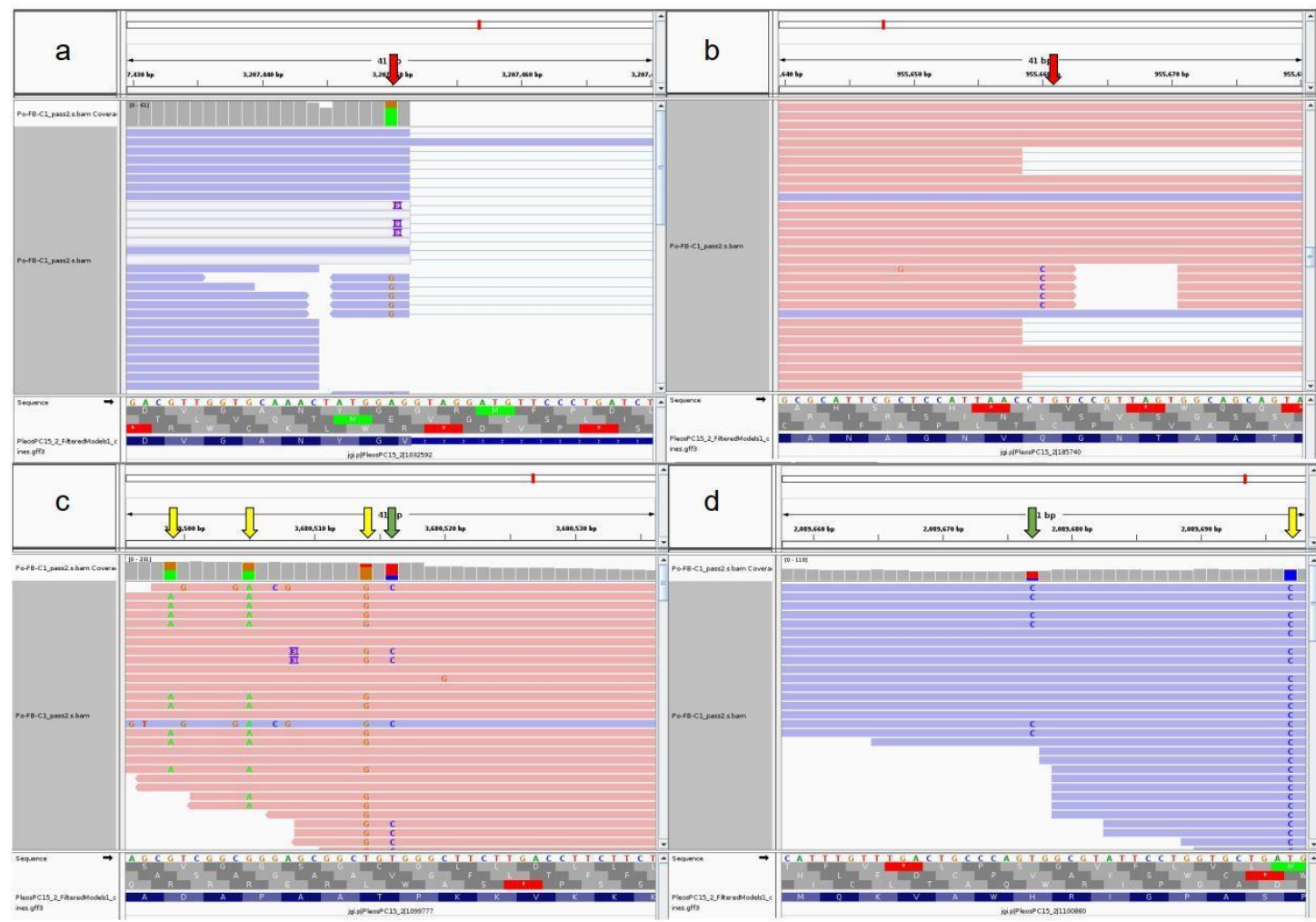


57 Appendix 3 - figure 2 Enrichment of variant types and motifs among potential RNA editing 58 sites. a) Distribution of variant types retained in the RNA editing specific pipeline with A-to-I 59 variants being marked with green. b-e) Sequence motifs surrounding the most frequent 60 candidate RNA editing changes displayed as sequence logos. $4^{\text {th }}$ position represents the 61 variants among reads. 1-3 is the upstream 3 positions, while 4-7 is the downstream 3 62 positions. b) A-to-G c) C-to-A d) C-to-T e) G-to-A changes.

a

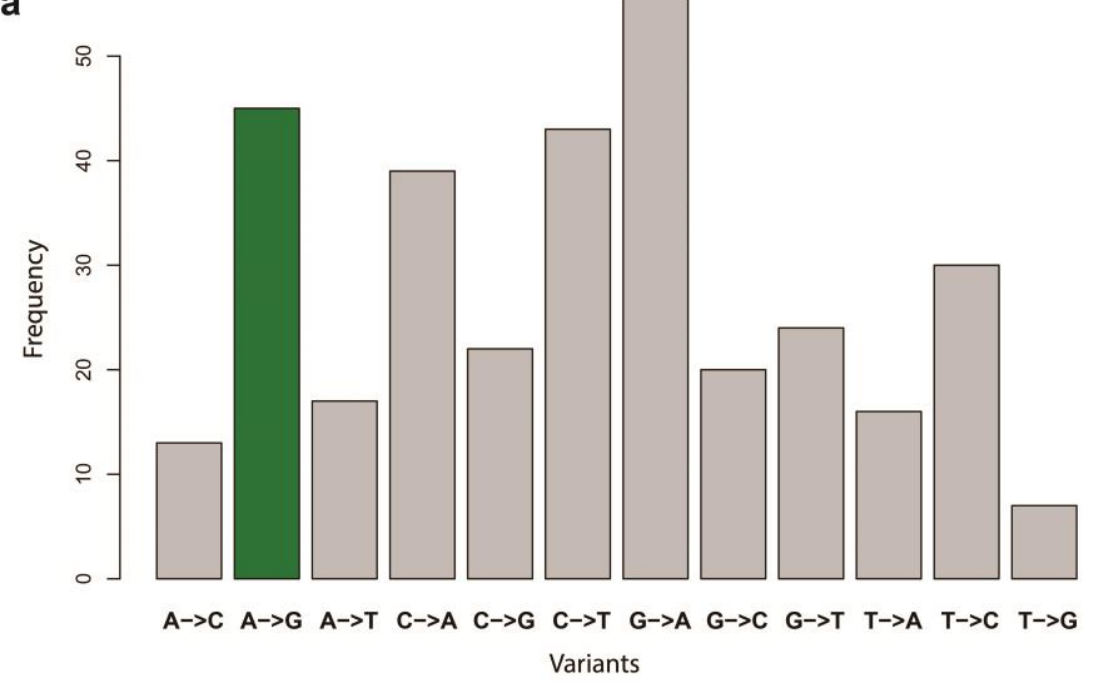

b

C
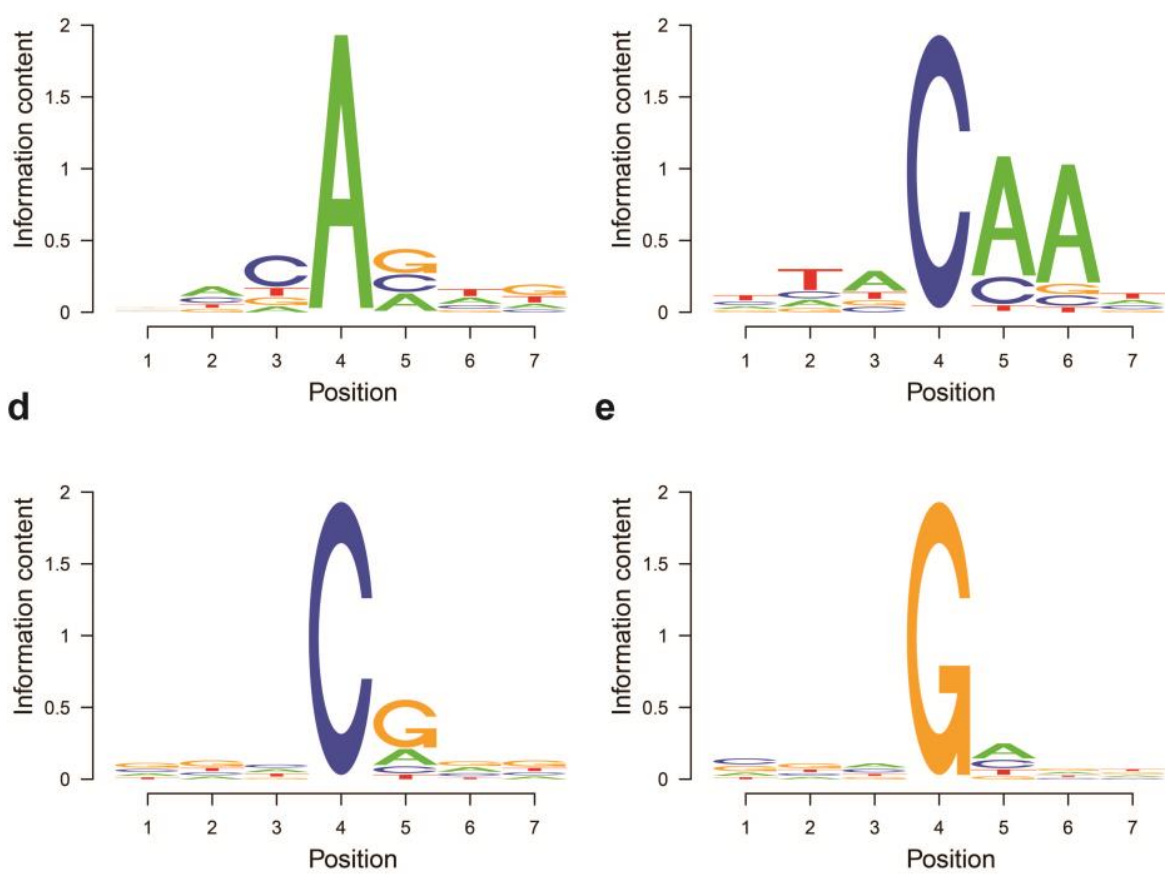
a

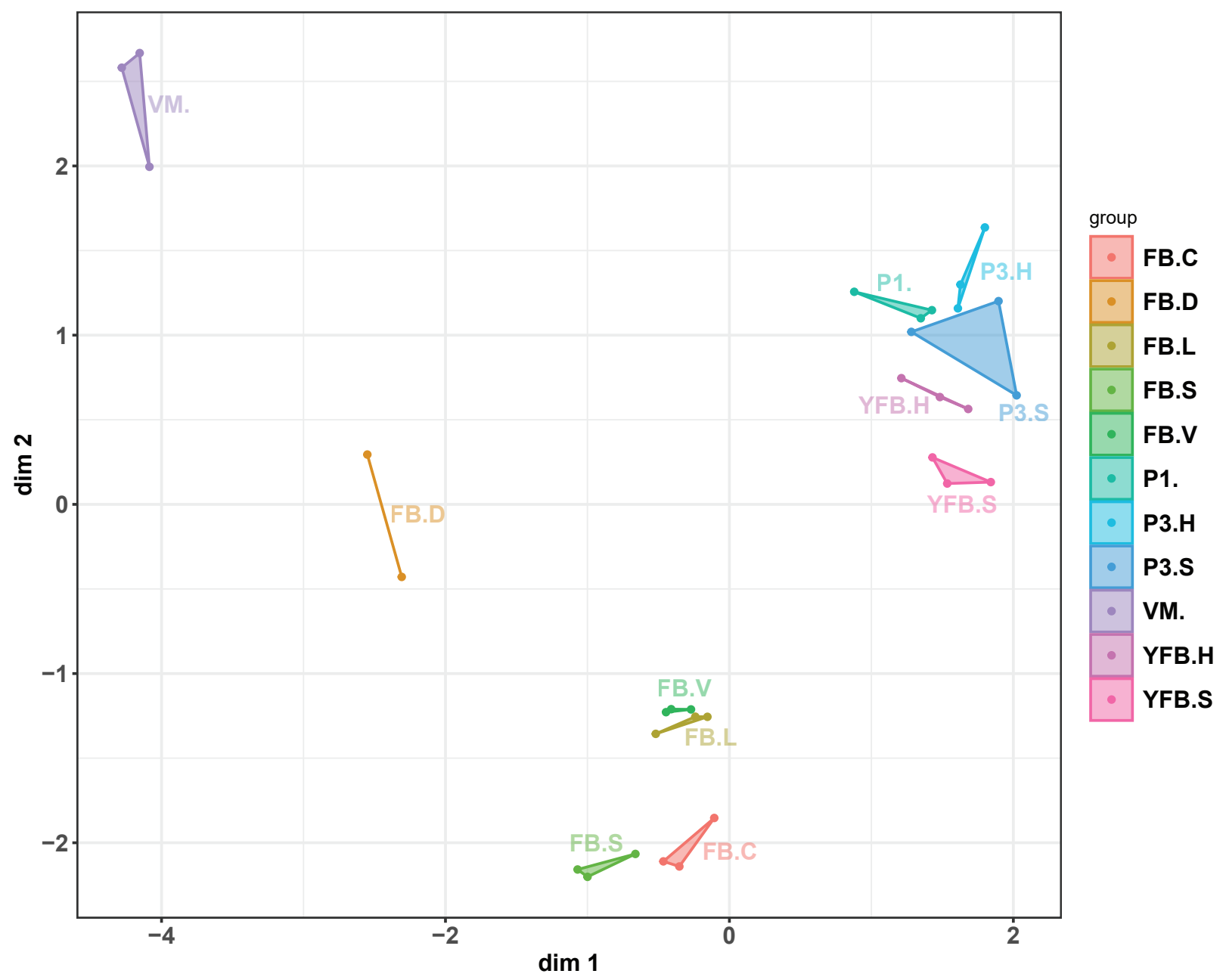

b

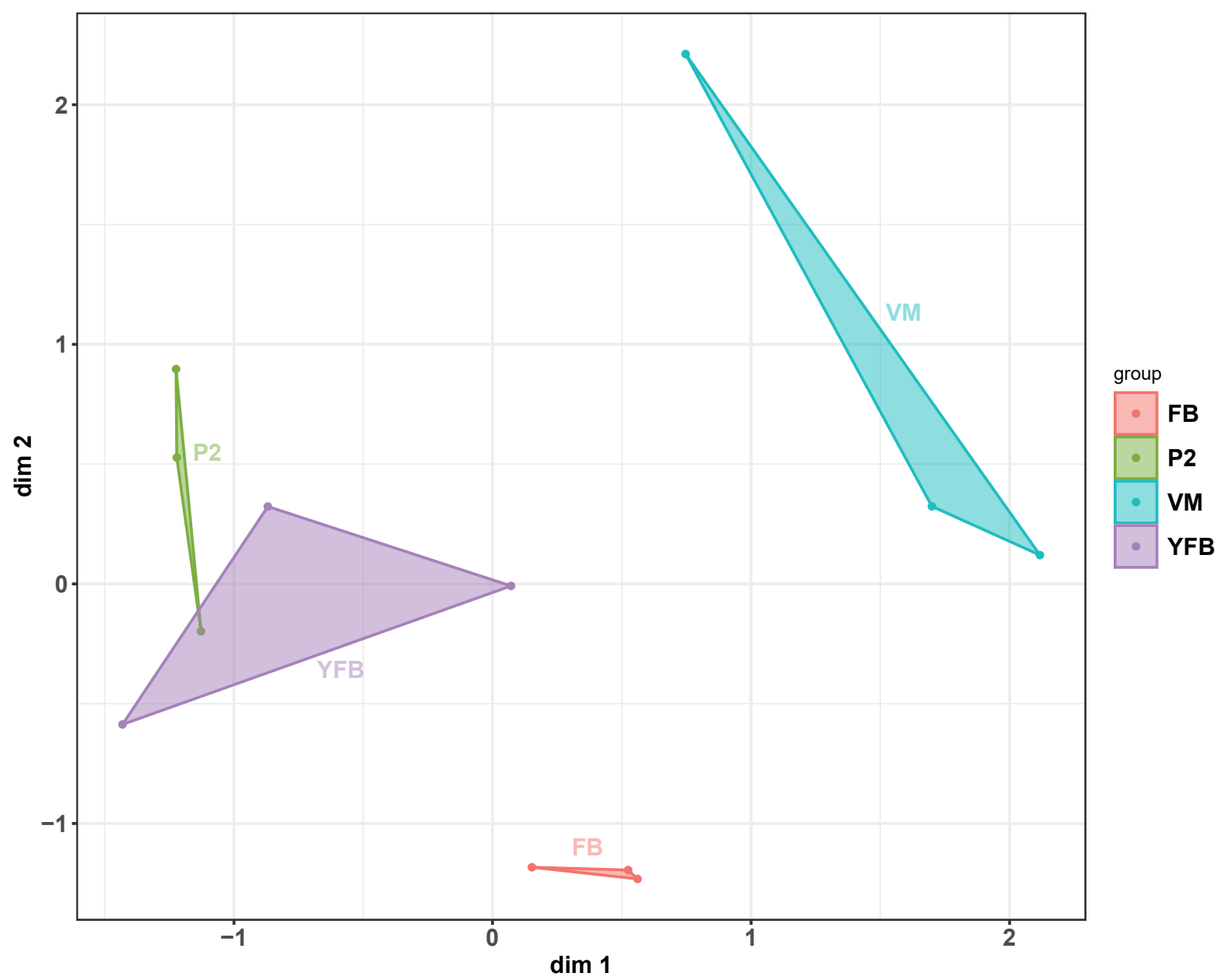




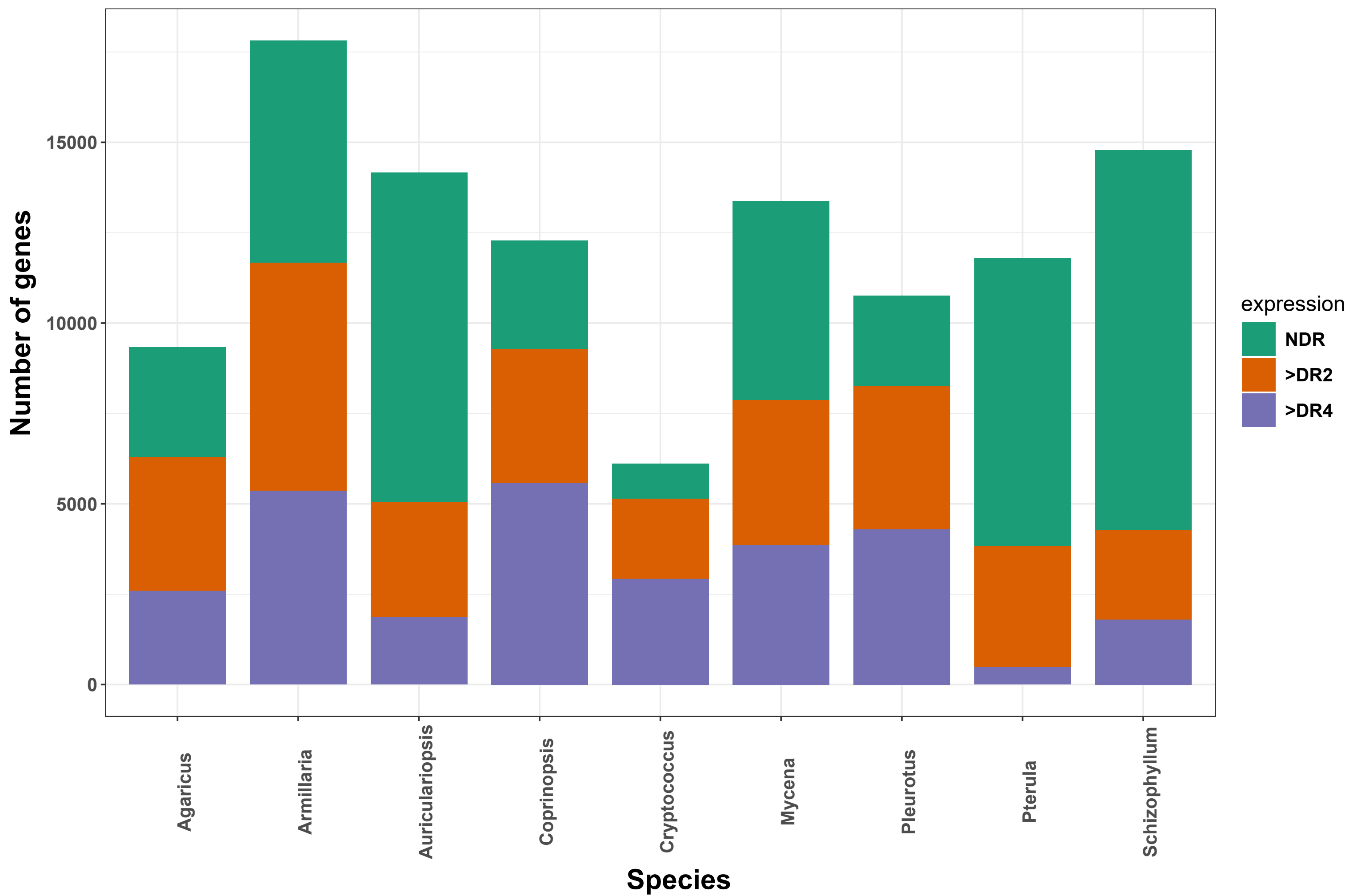


a

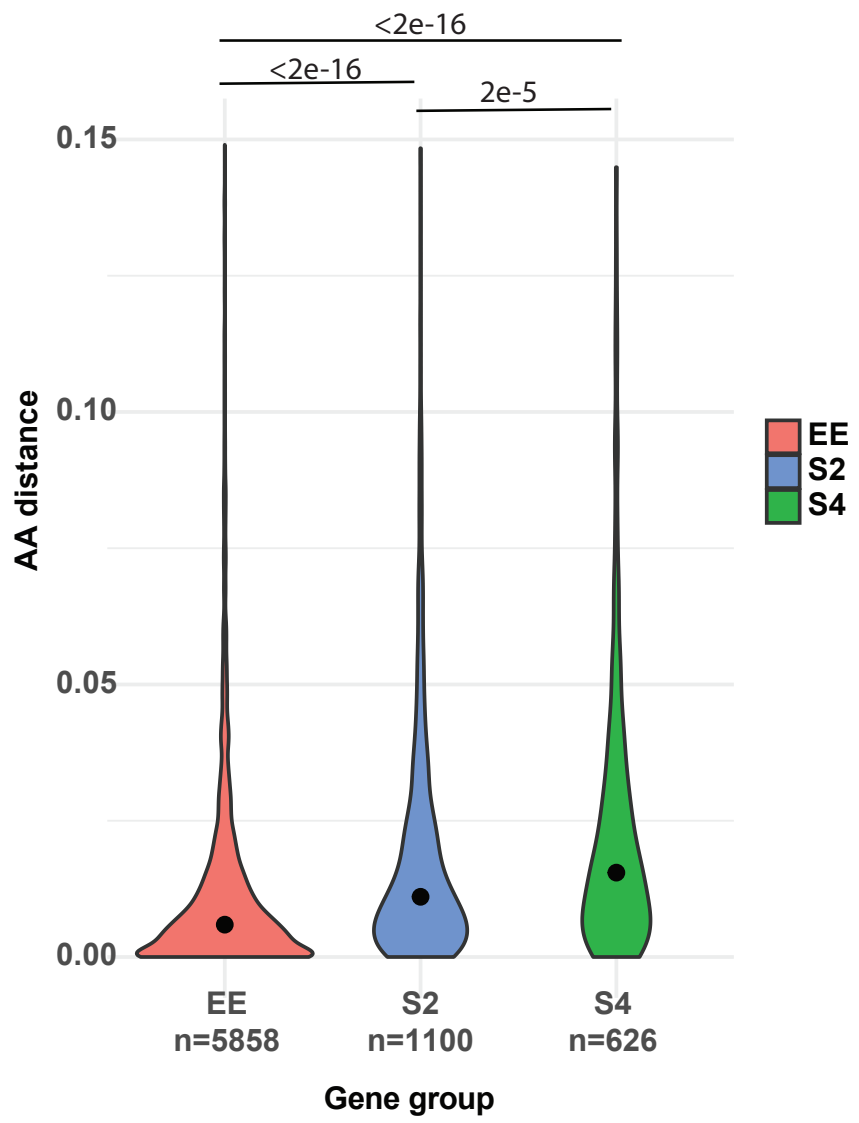

b

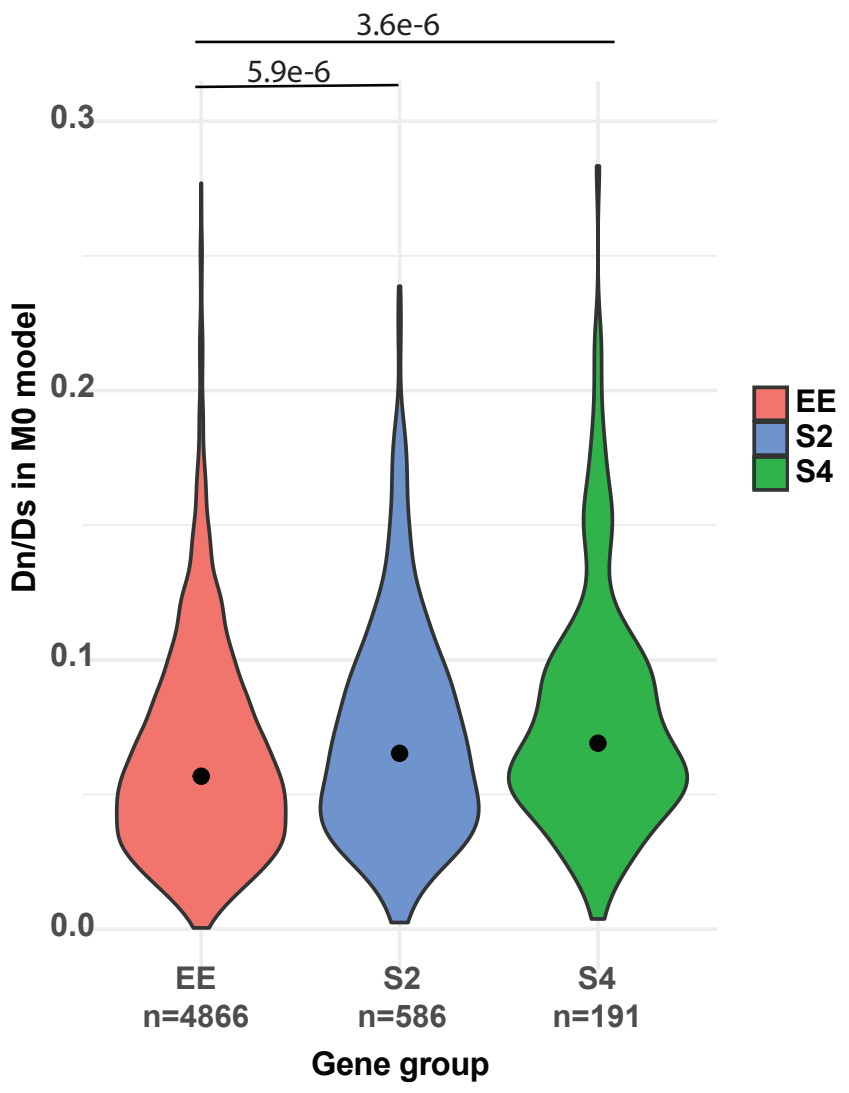




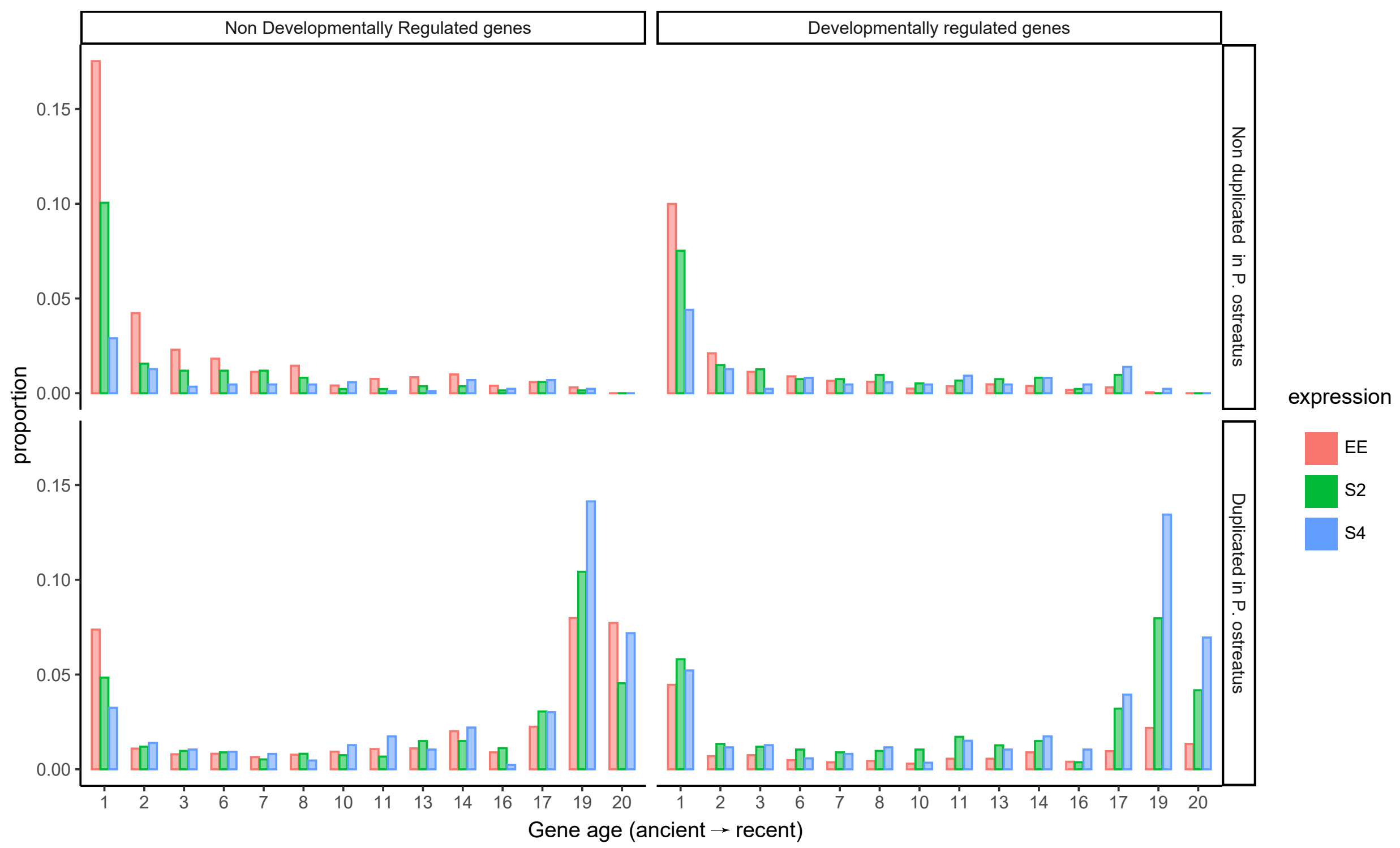




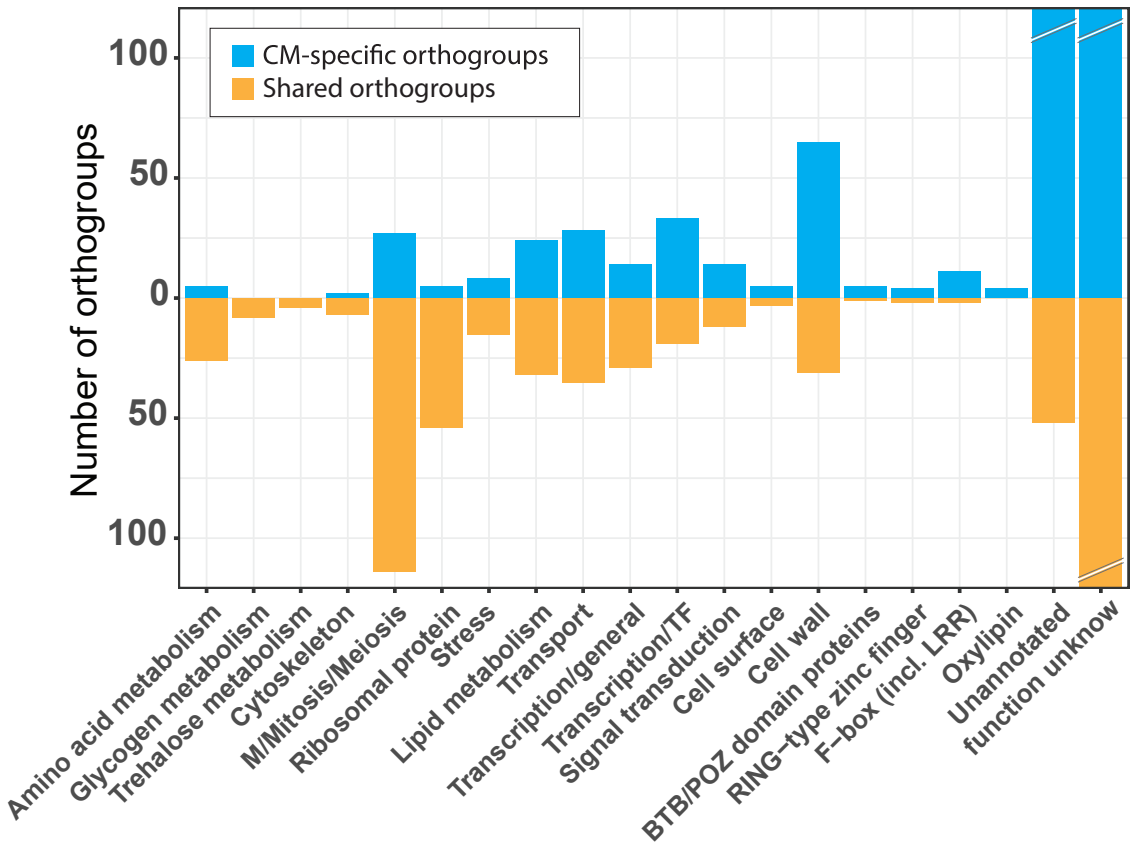




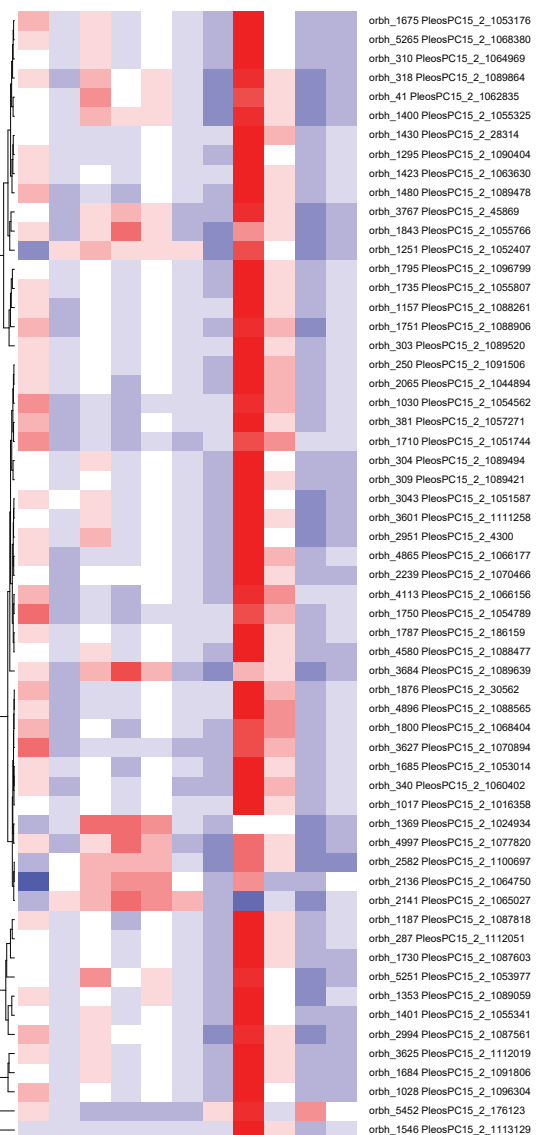

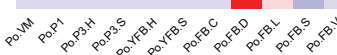

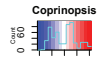

Coprinopsis

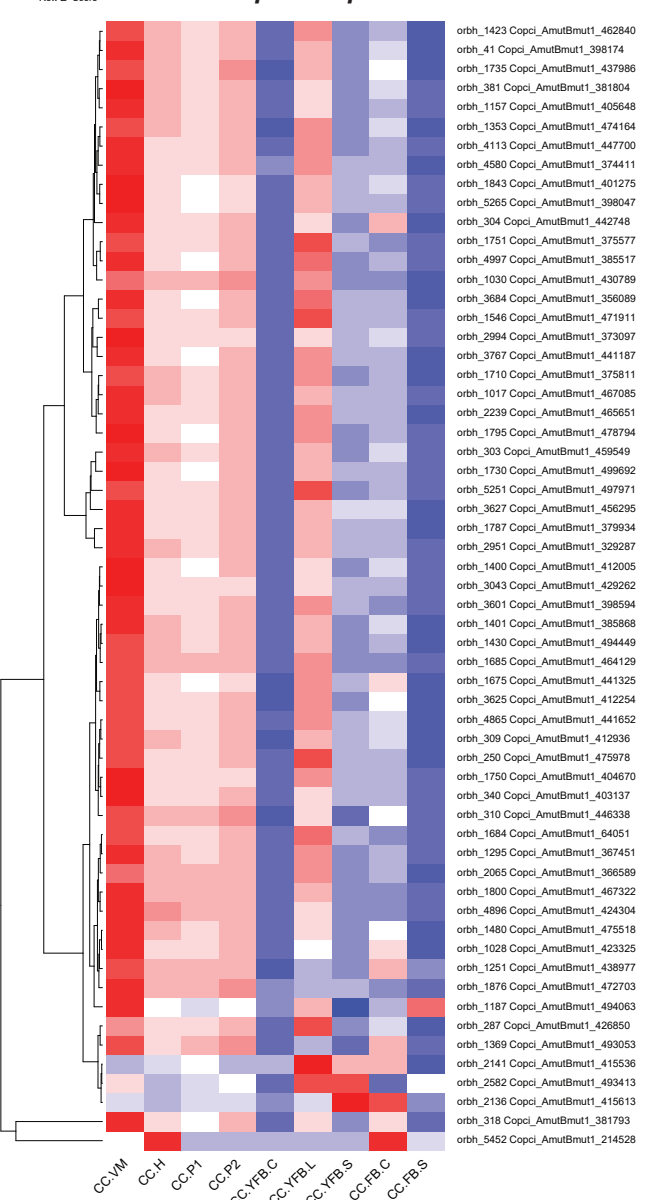

crypococous

Cryptococcus

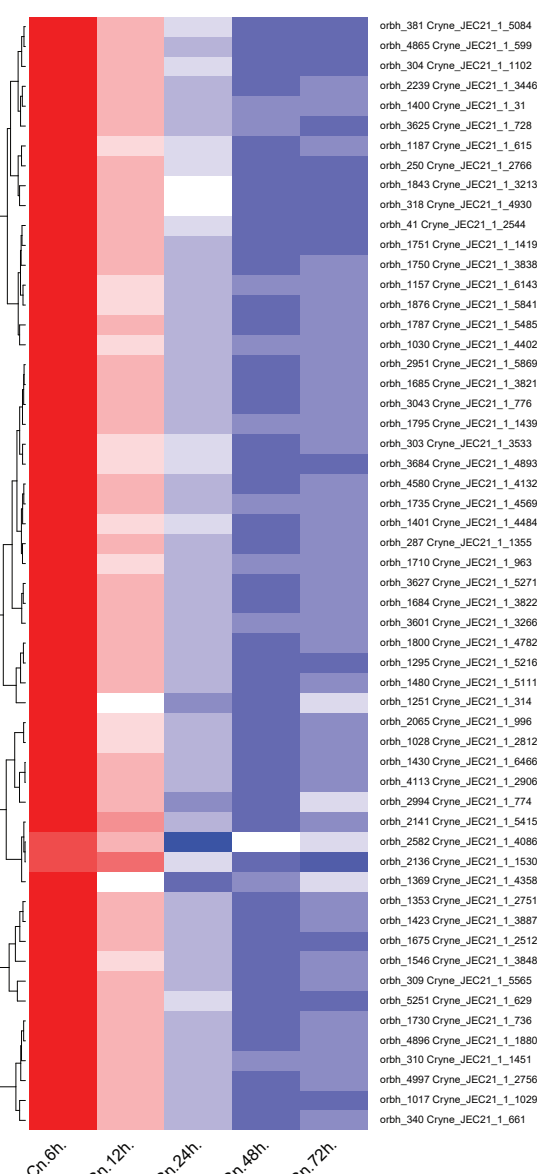

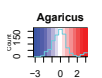

Agaricus

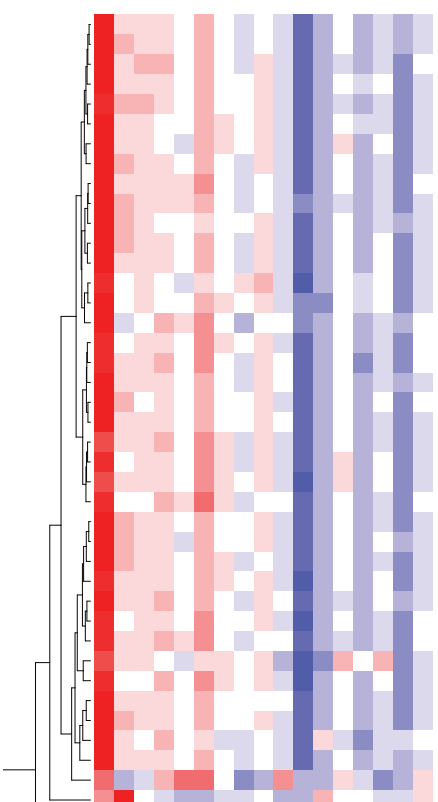

सt
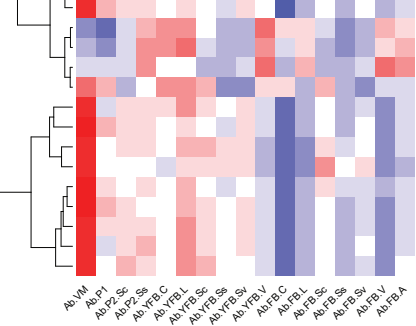

âmatara

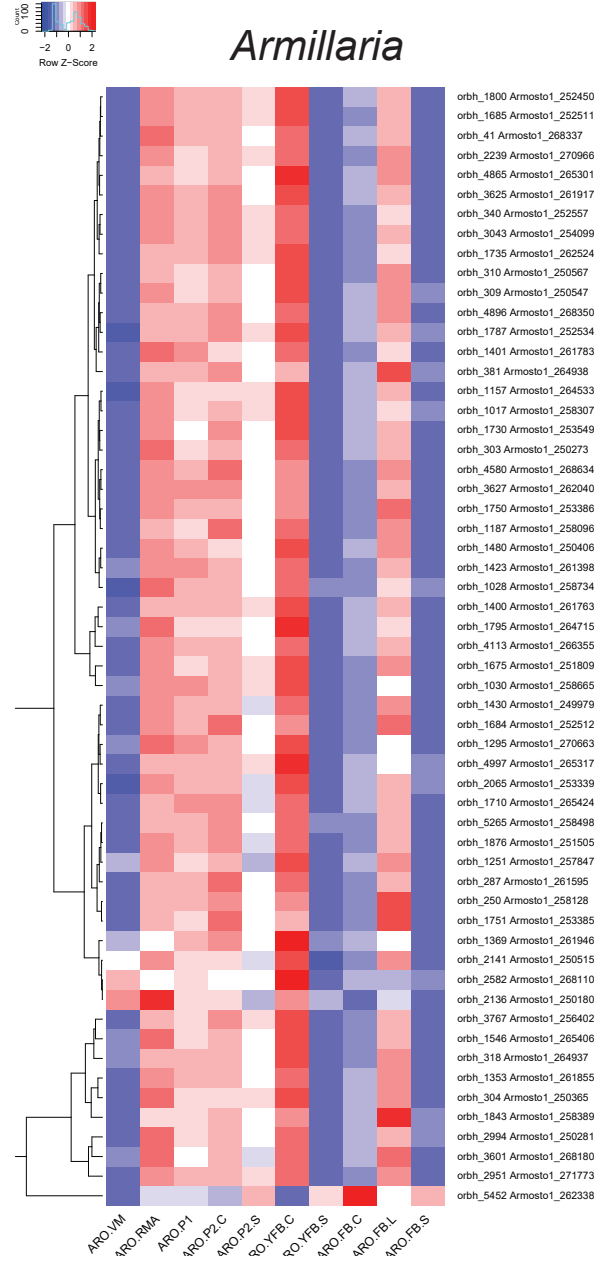

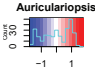

Auriculariopsis

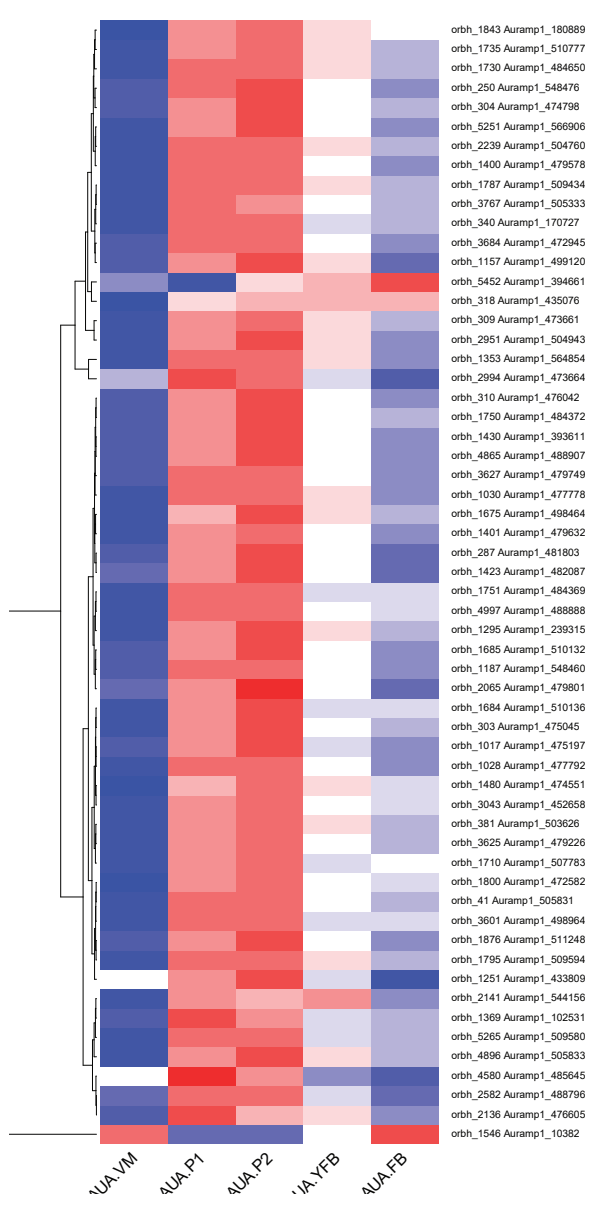

is: incona

Mycena

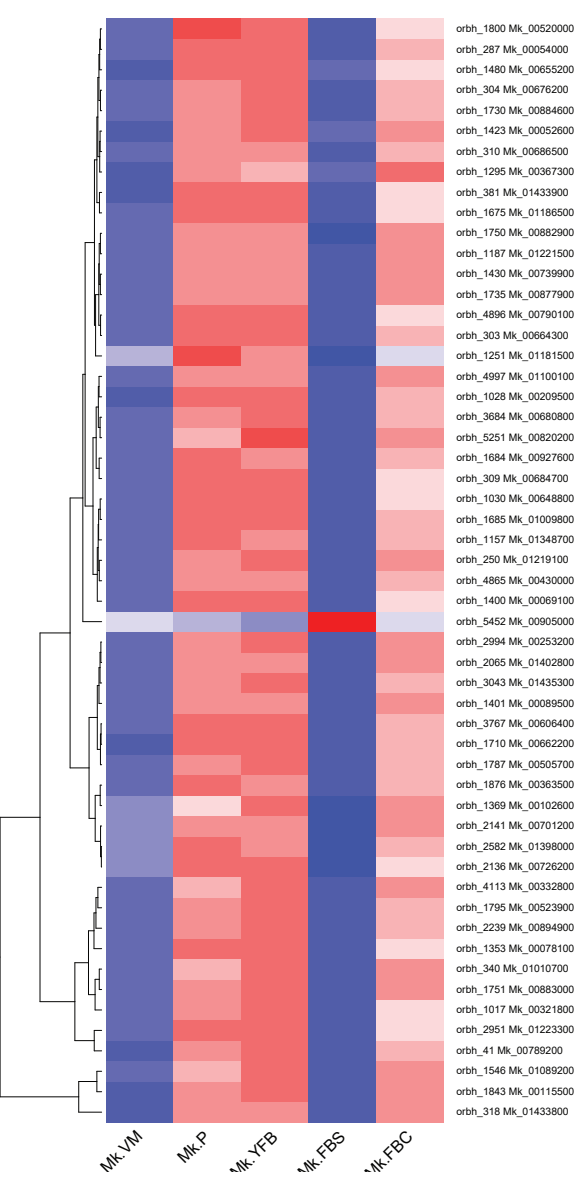

f. Plewar

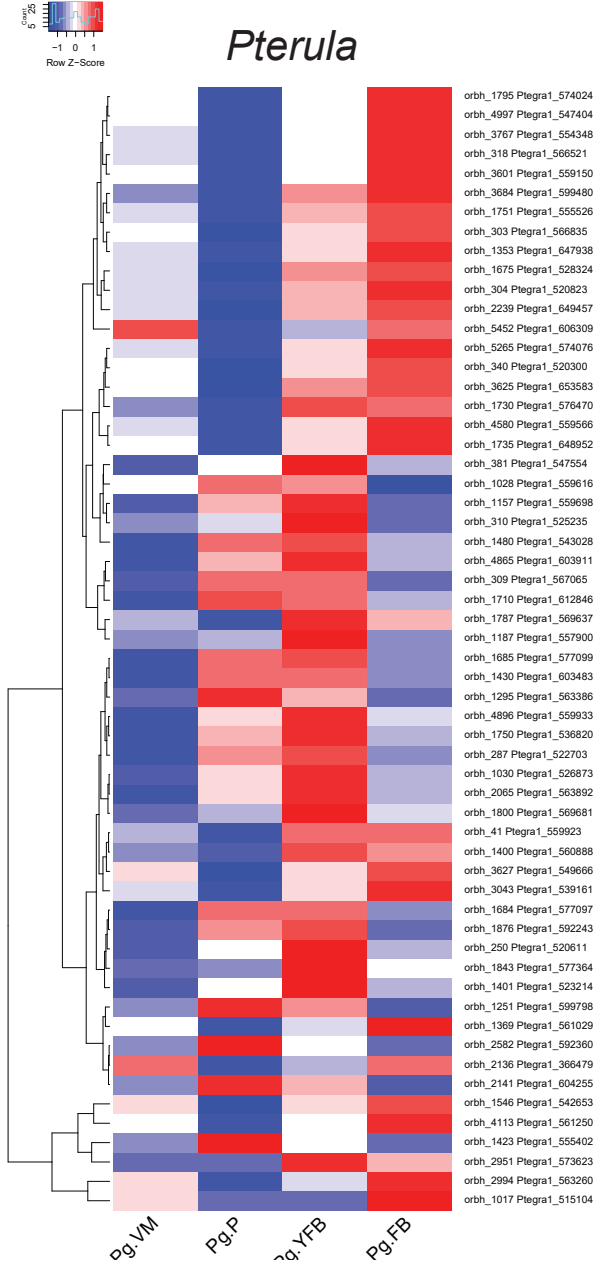

scchoophylum

Schizophyllum

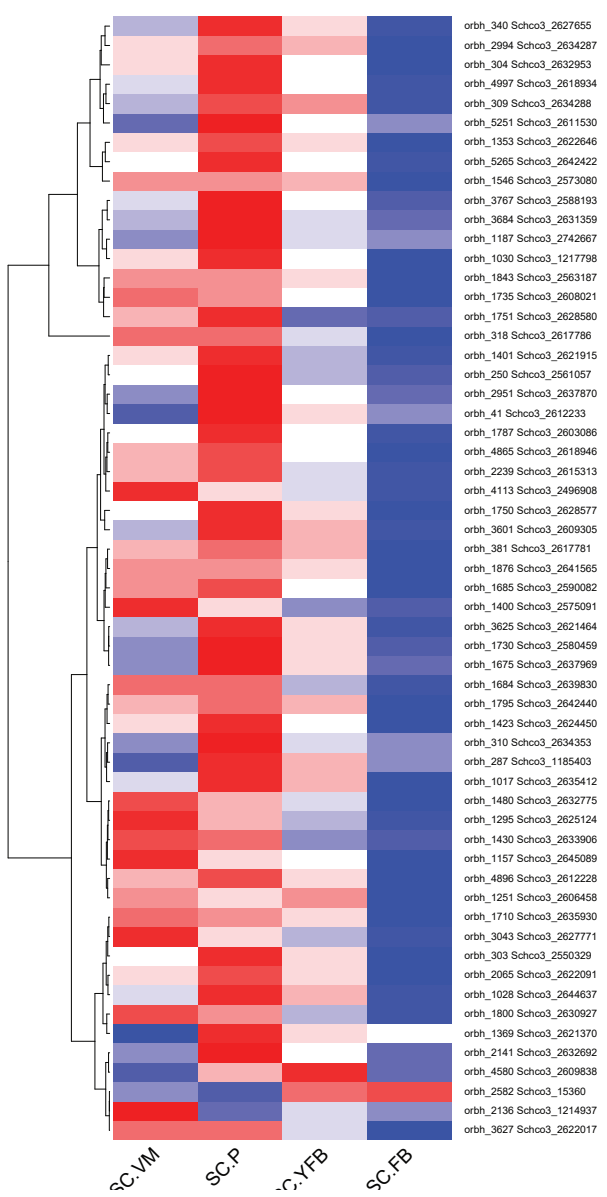

